
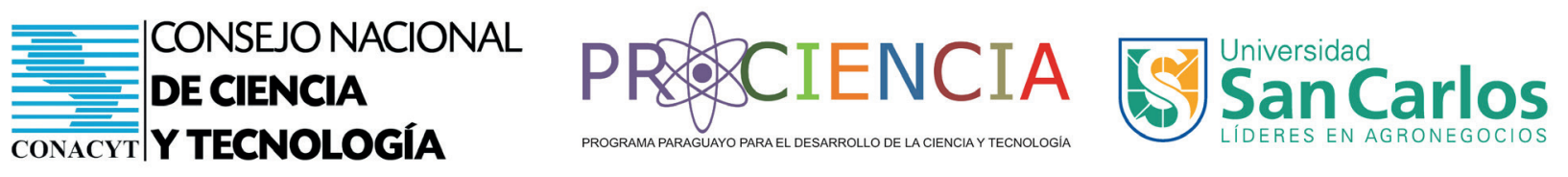

Feei

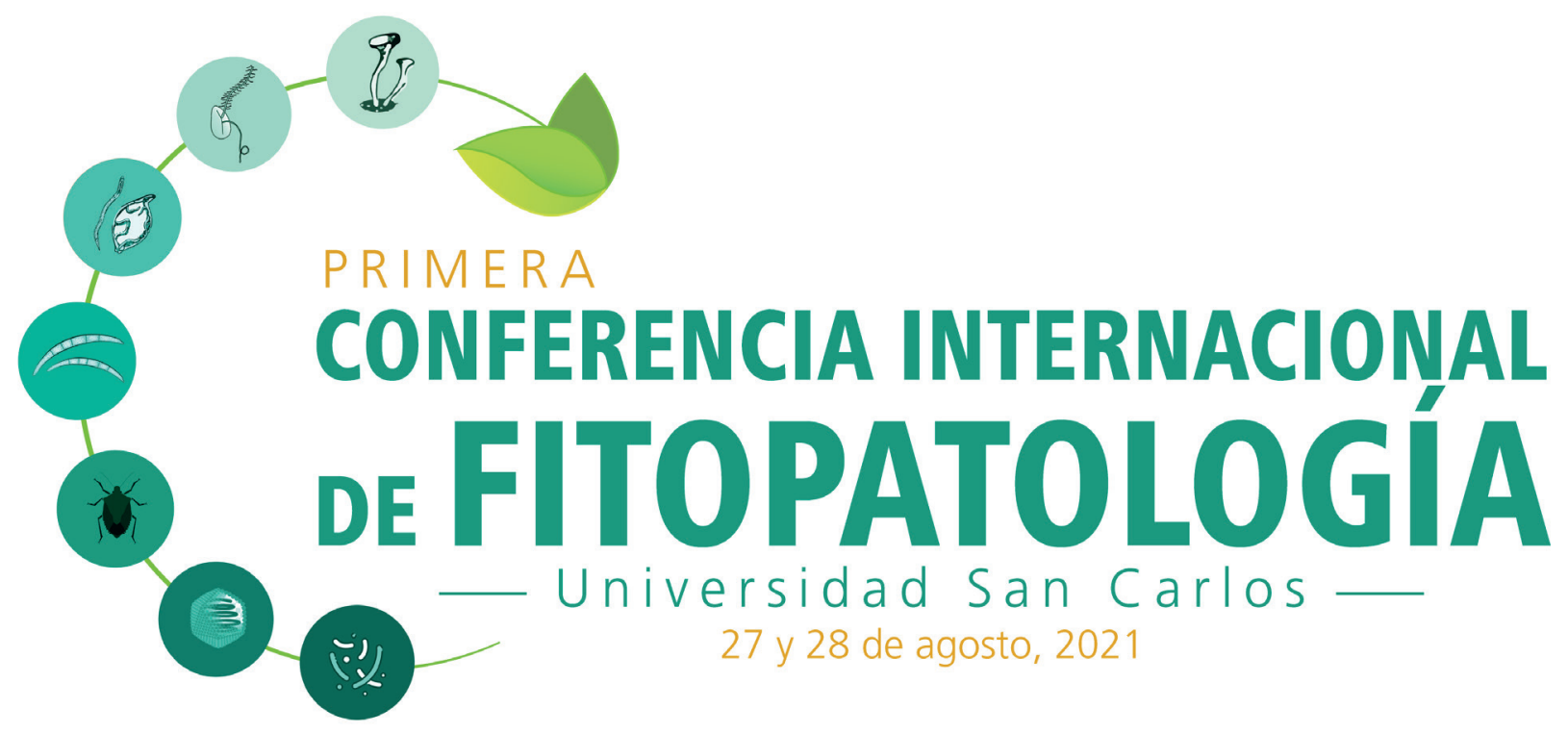

\title{
LIBRO DE RESÚMENES \\ DE LA PRIMERA CONFERENCIA INTERNACIONAL DE FITOPATOLOGÍA DE PARAGUAY
}

Charlas magistrales con investigadores de Argentina, Brasil, Estados Unidos, México, Paraguay y Uruguay.

Exposiciones virtuales de estudios científicos.

\section{Y 28 DE AGOSTO}

UNIVERSIDAD SAN CARLOS

Alfredo Seiferheld 4989 c/ Roque González

ASUNCIÓN, PARAGUAY 


\section{San Carlos}

\section{DIRECCION TECNICA}

ING. AGR. HORACIO LOPEZ-NICORA, Ph.D.

ING. AGR. MSC. GUILLERMO ENCISO MALDONADO

COORDINACIÓN OPERATIVA

ING. QUÍMICA MÓNICA CASANUEVA OJEDA

REVISIÓN CIENTÍFICA

COMITÉ CIENTÍFICO DE LA PRIMERA CONFERENCIA INTERNACIONAL DE FITOPATOLOGÍA

COORDINACIÓN DE LA REVISIÓN CIENTÍFICA

ING. AGR. GABRIELA CABALLERO MAIRESSE

ING. AGR. HERÓN VERÓNICA HERNÁNDEZ

\section{REVISIÓN LITERARIA}

\section{GRUPO EDITORIAL ATLAS}

DISEÑO Y DIAGRAMACIÓN

GUPO EDITORIAL ATLAS

\section{FOTOGRAFÍAS}

ING. AGR. MSC. GUILLERMO ENCISO MALDONADO

ING. AGR. MSC. ANDRÉS SANABRIA VELÁZQUEZ

ING. AGR. MSC. MARCO MAIDANA OJEDA

\section{CONTACTO}

Email: congresofitopatologia@usc.edu.py

Web: Www.eventos.usc.edu.py

Telefono: (59521) 615500

Asunción - Paraguay

Paraguay

ISBN: 978-99925-250-6-7

DOI: https://doi.org/10.53997/KFVP1131

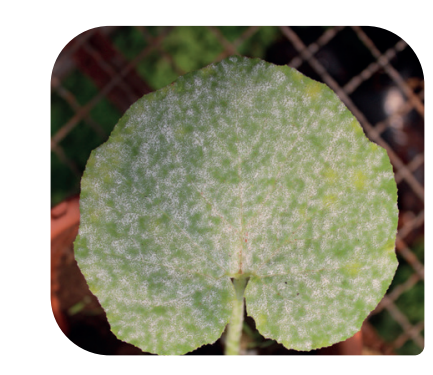

AGRADECIMIENTOS:

ESTE PROYECTO ES COFINANCIADO POR EL

CONSEJO NACIONAL DE CIENCIA Y TECNOLOGÍA (CONACYT) CON RECURSOS DEL FONDO PARA LA EXCELENCIA DE LA EDUCACIÓN Y LA INVESTIGACIÓN (FEEI) DEL PARAGUAY.

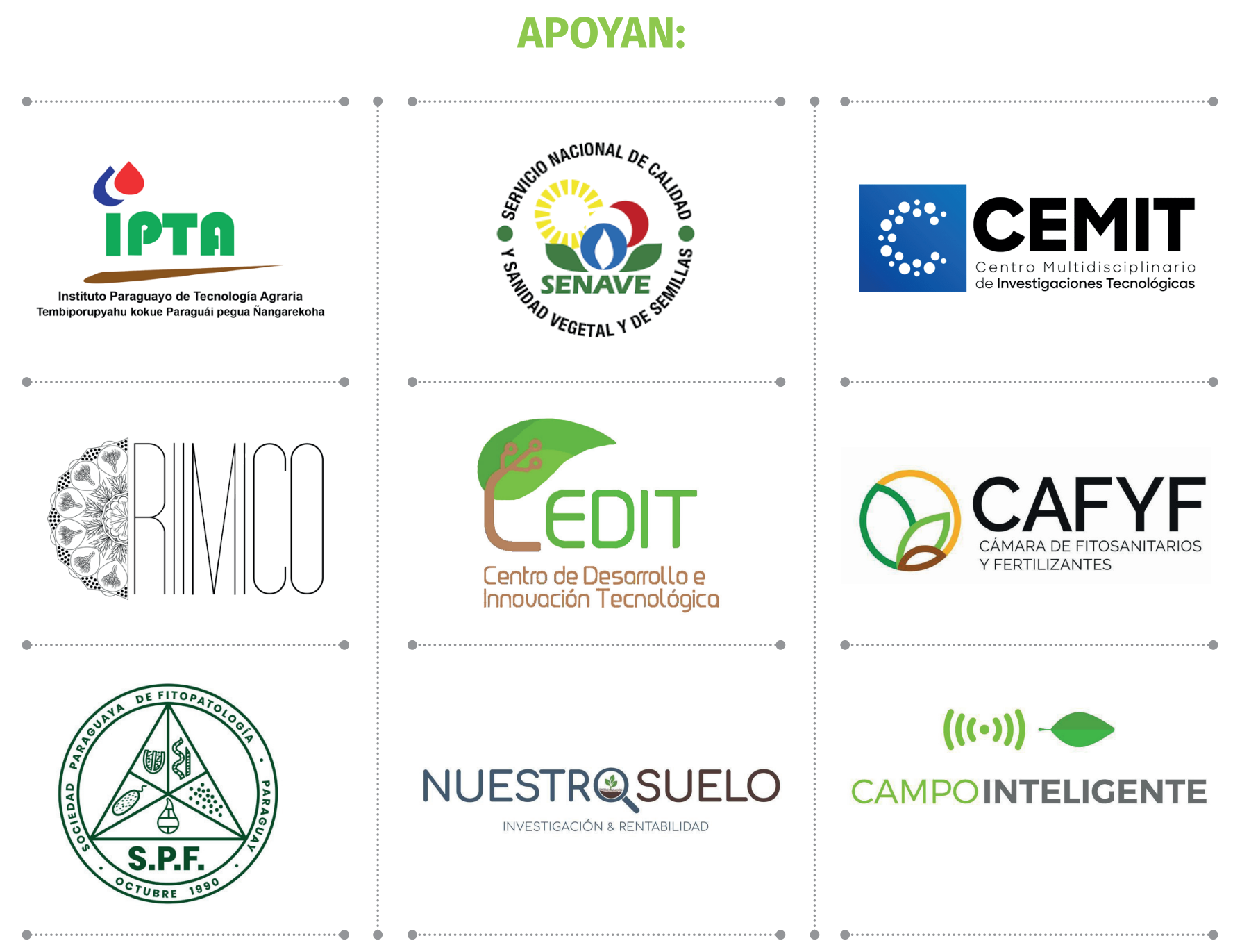




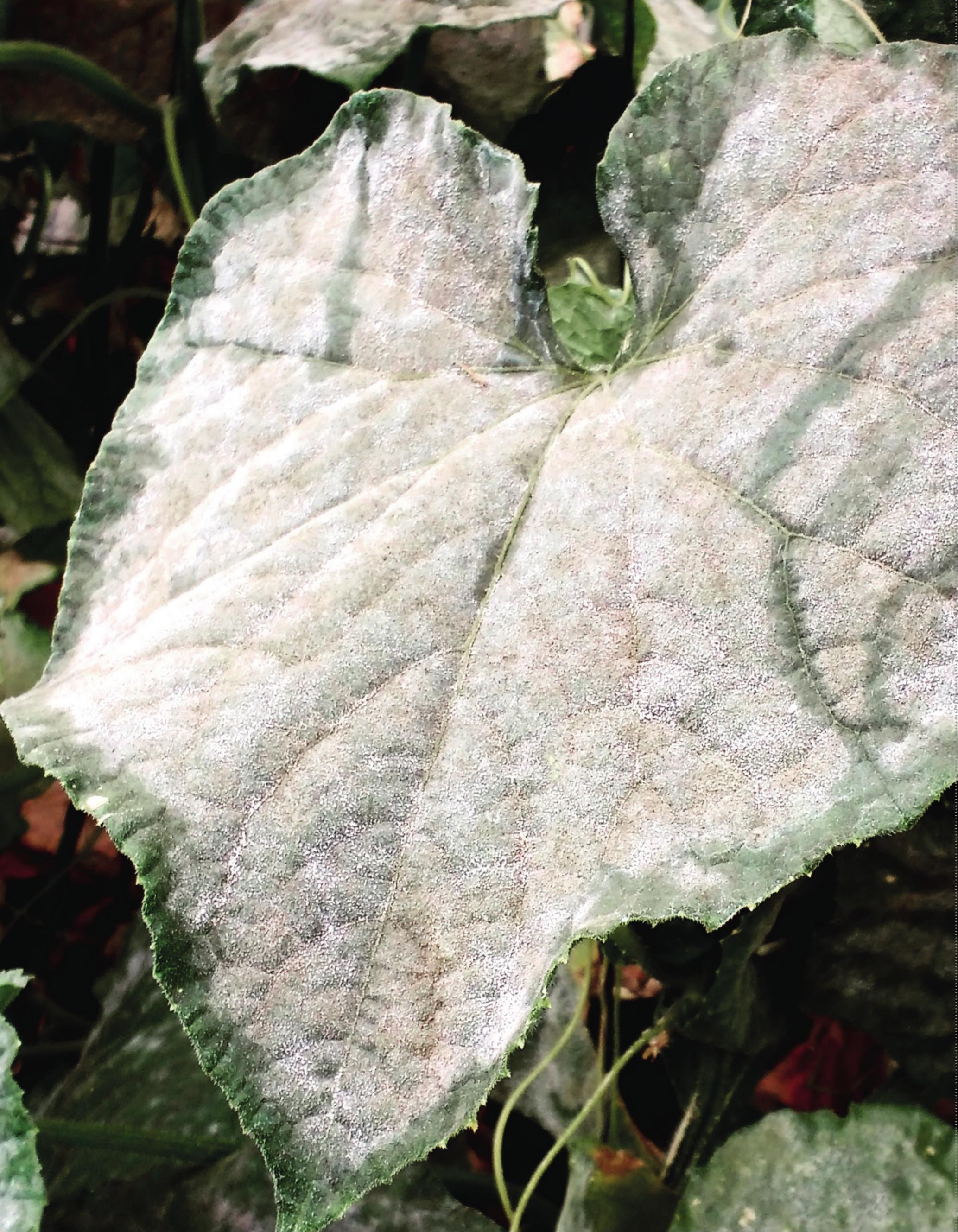

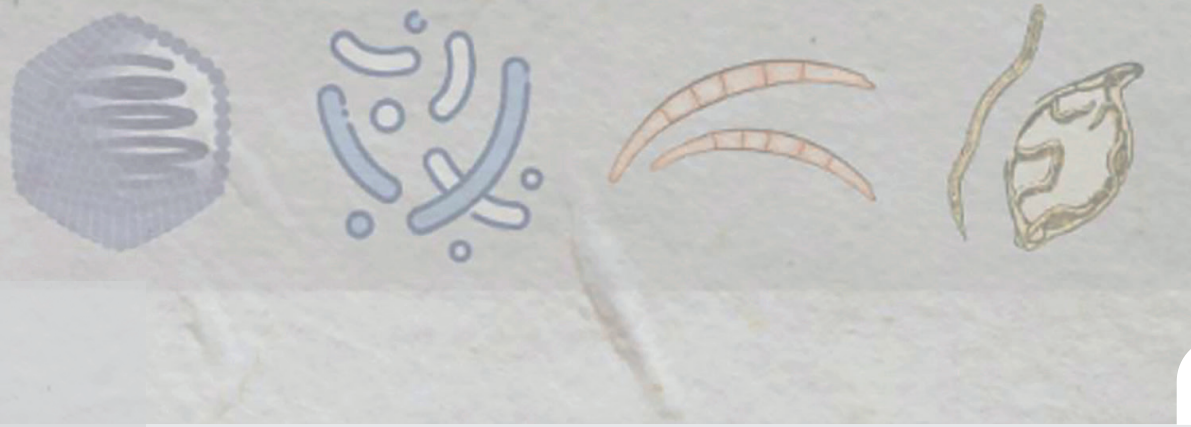

\section{COMITÉ CIENTÍFICO}

Ing. Agr. Óscar Guzmán Piedrahita, Ph.D.

UNIVERSIDAD DE CALDAS, COLOMBIA

Ing. Agr. Arnaldo Esquivel Fariña, Ph.D.
MINISTERIO DE AGRICULTURA Y GANADERÍA DE PARAGUAY

Ing. Agr. MSc. Ernesto Raúl Galliani Granada
SECRETARÍA NACIONAL DE SANIDAD VEGETAL DE PARAGUAY (SENAVE)

Ing. Agr. MSc. Lidia Pedrozo Fleitas

INSTITUTO PARAGUAYO DE TECNOLOGÍA AGRARIA (IPTA)

Ing. Agr. MSc. Hugo Valiente Raidán

INSTITUTO PARAGUAYO DE TECNOLOGÍA AGRARIA (IPTA)

Ing. Agr. MSc. Andrés Armadans Rojas

UNIVERSIDAD SAN CARLOS (USC), PARAGUAY

Ing. Agr. Horacio Lopez-Nicora, Ph.D.

UNIVERSIDAD SAN CARLOS (USC), PARAGUAY

DEPARTMENT OF PLANT PATHOLOGY, THE OHIO STATE UNIVERSITY, COLUMBUS, OH USA

Ing. Agr. MSc. Cristhian Grabowski Ocampos

FACULTAD DE CIENCIAS AGRARIAS (FCA) DE LA UNIVERSIDAD NACIONAL DE ASUNCIÓN (UNA), PARAGUAY

Ing. Agr. Adáns Colmán, Ph.D.

FACULTAD DE CIENCIAS AGRARIAS (FCA) DE LA UNIVERSIDAD NACIONAL DE ASUNCIÓN (UNA), PARAGUAY

Ing. Agr. MSc. Laura Soilán Duarte
FACULTAD DE CIENCIAS AGRARIAS (FCA) DE LA UNIVERSIDAD NACIONAL DE ASUNCIÓN (UNA), PARAGUAY

Ing. Agr. Gloria Resquín Romero, Ph.D.
FACULTAD DE CIENCIAS AGRARIAS (FCA) DE LA UNIVERSIDAD NACIONAL DE ASUNCIÓN (UNA), PARAGUAY 
Ing. Agr. MSc. Cinthia Cazal Martinez

CENTRO MULTIDISCIPLINARIO DE INVESTIGACIONES TECNOLÓGICAS (CEMIT)

DE LA UNIVERSIDAD NACIONAL DE ASUNCIÓN (UNA), PARAGUAY

\section{Ing. Agr. Andrea Arrúa, Ph.D.}

CENTRO MULTIDISCIPLINARIO DE INVESTIGACIONES TECNOLOGICAS (CEMIT) DE LA

UNIVERSIDAD NACIONAL DE ASUNCIÓN (UNA), PARAGUAY

RED IBEROAMERICANA DE INVESTIGADORES DE MICOLOGíA I MICOTOXICOLOGÍA (RIIMICO)

\section{Ing. Agr. MSc. Martín Cubilla Andrada}

CONSULTORA NUESTRO SUELO

\section{Ing. Agr. Miguel Colmán}

CÄMARA DE FITOSANITARIOS Y FERTILIZANTES (CAFYF), PARAGUAY

\section{Ing. Agr. Mag. Liz Rojas Caballero}

CÁMARA DE FITOSANITARIOS Y FERTILIZANTES (CAFYF), PARAGUAY

\section{Ing. Agr. Darío Pino}

SOCIEDAD PARAGUAYA DE FITOPATOLOGía (SPF), PARAGUAY

\section{Dra. Alicia Beatriz Albrecht Encina}

CENTRO DE DESARROLLO E INNOVACIÓN TECNOLÓGICA (CEDIT), PARAGUAY

Ing. Agr. MSc. Guillermo Andrés Enciso Maldonado

CENTRO DE DESARROLLO E INNOVACIÓN TECNOLÓGICA (CEDIT), PARAGUAY

Ing. Agr. MSc. Marta Alicia Fernández Gamarra

CENTRO DE DESARROLLO E INNOVACIÓN TECNOLÓGICA (CEDIT), PARAGUAY
Ing. Agr. MSc. Ronaldo Dietze Junghanns

Rector

Lic. Arturo Villate Yaluk

Presidente

Ing. Agr. Horacio Lopez-Nicora, Ph.D.

Coordinador general de la $1 \underline{a}$ Conferencia Internacional de Fitopatología
Ing. Qca. Mónica Casanueva Ojed

Lic. Chris Paloma Fisch Ferreira

Est. Monserrat Pedrozo Gómez

Paula Mayra Gil
Dirección de Investigación, Innovación y Extensión

Lic. Fernanda Chamorro

Rebeca Bracho

Adriana Ginzo

Héctor Latorre

Direción de Comunicaciones

Lic. Carlos Trapani

Lic. Tania Torales

Lic. Lucas Suârez 


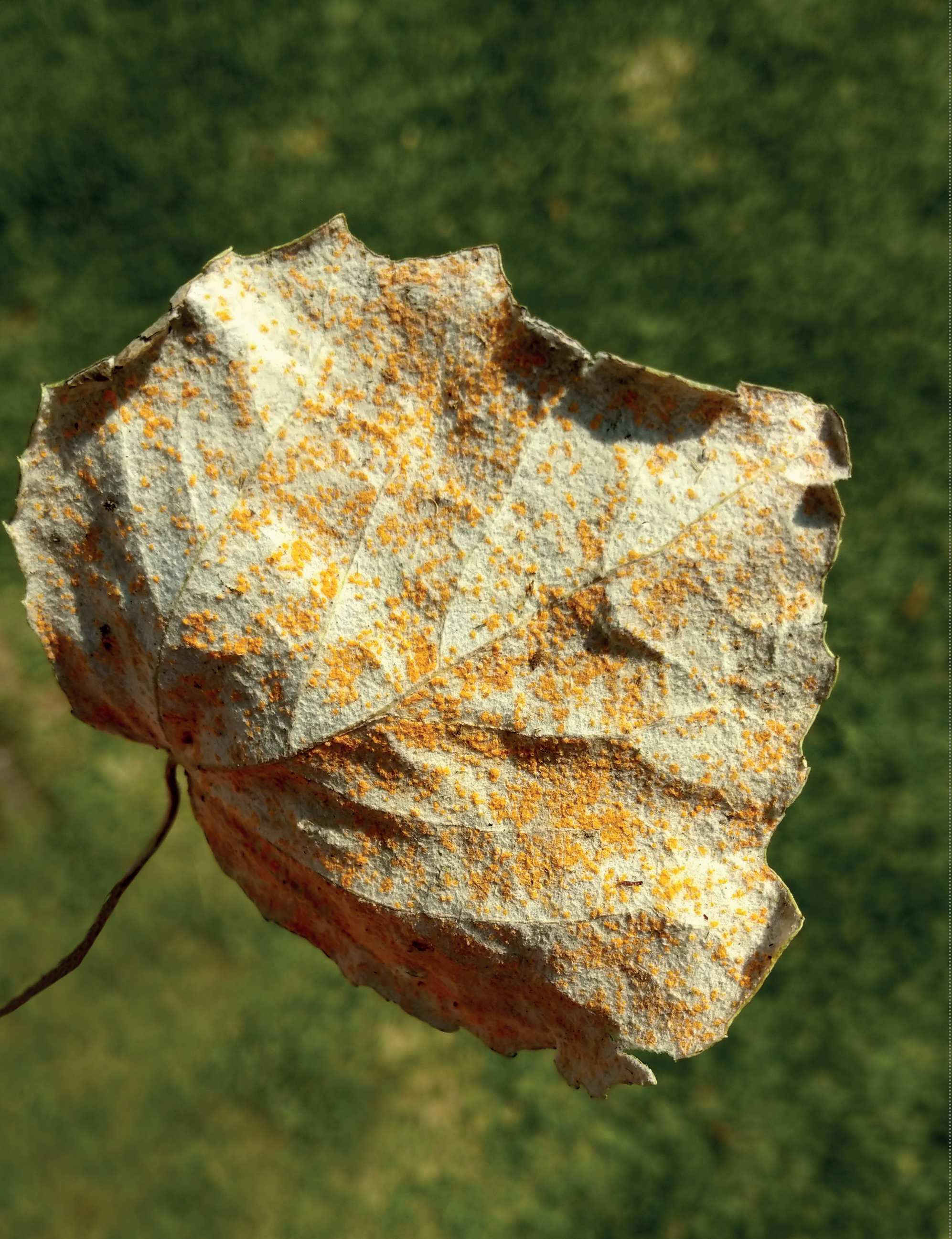

- a agricultura es un pilar importante para la economía del Paraguay y de muchos países en la región. Uno de los mayores desafíos con los que la agricultura se enfrenta actualmente es generar seguridad alimentaria para un mundo con una población que no cesa de crecer. Un limitante en la producción de alimentos, muchas veces pasado por alto, es el daño al cultivo ocasionado por patógenos de plantas: entre estos podemos citar a los hongos (y pseudohongos), bacterias, virus y nematodos fitopatógenos. La fitopatología es la ciencia encargada de estudiar a estos patógenos, diagnosticar las enfermedades que estos causan y en dicho proceso generar tácticas de manejo integrado. Son los fitopatólogos los que investigan a estos organismos y sus interacciones con los cultivos. Estas investigaciones resultan en estrategias para lograr una producción sostenible de alimentos en un ecosistema saludable. Lastimosamente, en Paraguay y otros países, si bien se reconoce que la investigación científica es importante para mejorar los conocimientos en diversas áreas, los recursos destinados a la investigación siguen siendo escasos y en muchas instancias el proceso de adjudicación de fondos para la investigación es muy engorroso por los excesivos trámites burocráticos y la falta de criterio; en algunos casos, en la evaluación de proyectos por no nombrar a gente idónea en los cargos de decisión. El investigador debe, por lo tanto, volverse creativo e innovar para poder seguir generando nuevos conocimientos y aś ir cerrando brechas.

Esta Primera Conferencia Internacional de Fitopatología del Paraguay es uno de los tantos ejemplos donde un grupo de fitopatólogos con diferentes especialidades se reúne y decide organizar un evento para poder compartir el conocimiento acumulado en esta área. Lo hacen por un sentimiento de deber y compromiso y, asimismo, para dar el puntapié inicial con el fin de comenzar una tradición que los futuros fitopatólogos del Paraguay ahora deberán continuar. Con ello buscamos compartir lo aprendido en el área de fitopatología en una reunión internacional 
con colegas, productores, estudiantes, docentes y el público en general interesado en conocer aquello que los fitopatólogos hacen para proteger la producción mundial de alimento.

El siguiente libro de resúmenes de la Primera Conferencia Internacional de Fitopatología el Paraguay contiene no solamente la evidencia del compromiso de los fitopatólogos para mejorar la producción agrícola de la región, sino también la esperanza y el deseo de que este evento sea el primer paso para una conversación fructífera y continua entre a academia, el sector productivo y la comunidad en general. Cada resumen narra una historia única de colaboradores decididos a resolver un enigma fitopatológico, aquel sobre la interacción planta-patógeno y cómo con los nuevos conocimientos se pueden desarrollar estrategias de manejo integrado de enfermedades. Cada resumen es una historia que empieza y termina, pero que abre puertas disparadoras de muchas otras historias. Son el trabajo arduo de investigadores, docentes, estudiantes, productores tanto del sector público como del privado. Nuestro deseo es que se sigan expresando estas narraciones y que la Conferencia Internacional de Fitopatología del Paraguay continúe siendo el motivo para reunirnos con vistas a construir una producción agrícola saludable para la humanidad.

Horacio Lopez-Nicora, Ph.D. Clínica Vegetal, Universidad San Carlos, Asunción PY Department of Plant Pathology, The Ohio State University, Columbus, OH USA
Comité Científico...

Autoridades....

Comité Organizador.

Prólogo.

\section{Programa...}

CONTENIDO

RESÚMENES DE LOS PONENTES

BACTERIAS

Del campo al laboratorio y de vuelta al campo: contribuciones al estudio y manejo de patógenos bacterianos en

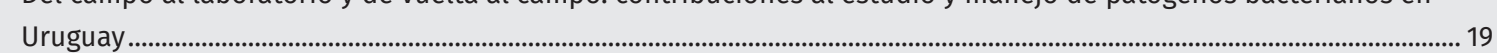

HONGOS

Solid-state fer

te fermentation for production of biological control agents

$\ldots \ldots$

NEMATODOS

Biosíntesis y composición de la lignina en la interacción planta-nematodos endoparásitos...

Brote epidémico de achaparramiento del maíz y otras infecciones mixtas en el norte argentino en 2020/21 ..............23

The

BACTERIAS

HONGOS

Sigatoka negra, una historia de desafios y aprendizajes

VIRUS

La cooperación Brasil-Paraguay en las investigaciones sobre virosis de plantas en Paraguay ...........................................28

NEMATODOS

fitófagos que afectan principales cultivos en Argentina

BACTERIAS

Bacterias fitopatosnas en

RESÚMENES PARA POSTERS

. .34

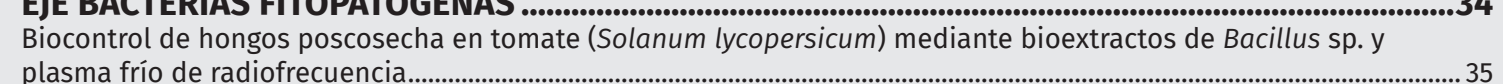

Secuenciación parcial del genoma del Argentinean Alfalfa witches' broom phytoplasma (ArAWB, 16SRVII-C)

Aplicación de nuevas tecnologias de secuenciación para la obtención de genomas completos de bacterias

patígenas en trigos de Argenis 


\section{EJE HONGOS FITOPATÓGENOS}

.. .38

lentificación de géneros de hongos endófitos asociados a siete variedades de soja cultivadas en el departamento

Análisis de la importación de fungicidas en el Paraguay en el periodo 2009 - 2019.................

Expresión de genes codificantes de defensinas en variedades de soja resistente y susceptible a Macrophomina

Evaluación de la tasa de crecimiento de aislados Pyricularia oryzae frente a fungicidas de origen químico.....................4 42 Identificación de Fusarium sp. en ramas de yerba mate con signos de necrosis en el departamento de Guairá...........43 Detección de Pyricularia oryzae patotipo Triticum en malezas poáceas mediante marcadores moleculares..................44 Tasa de crecimiento de cepas de Trichodema asperellum y trichoderma spp. a diferentes temperaturas y pH. Tasa de crecimiento de cepas de Trichodema asperellum y evaluación de actividad antagónica de Trichoderma

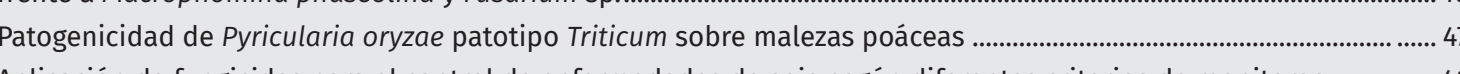

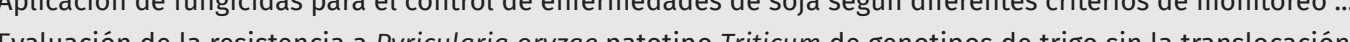
2NS/2AS en condiciones de ampo e invernadero

Resistencia a Pyricularia oryzee patotipo Triticum de líneas de trigo de la familia Caninde 2/Milán . Cuantificación de conidios de Pyriculario oryzoe en hojes de trigo durante el ciclo 2018. chacto

Comparación de la expresión de genes codificantes de pectinasas en dos aislados de Macrophomina phaseolina Efecto in vitro de productos botánicos y químicos contra Colletotrichum gloeosporioides Penz. patógeno de yaca

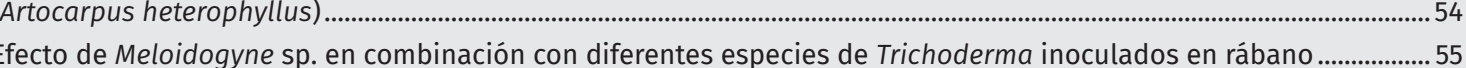
Efectividad de fungicidas químicos y orgánicos in vitro contra Rhizoctonia solani .......................................................56 Control químico y biológico de Rhizoctonia solani (Kühn) en frutos de calabaza pipiana en invernadero .....................57 Actinomicetos y su efecto antagónico contra patógenos causantes de pudrición poscosecha en frutilla (Fragaria $x$

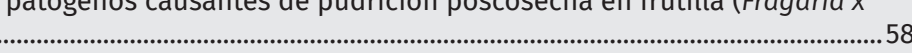
Combinación de Trichoderma sp. con fungicidas en el manejo de Alternaria alternata en calabaza ................................59 Efecto de la temperatura y el pH sobre la esporulación de cepas nativas de Trichoderma sp. ……............................. 60

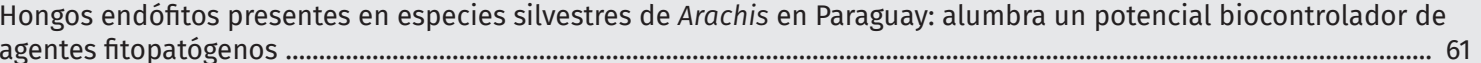
Efectos de la desinfestación anaeróbica del suelo sobre algunas características fisico-químicas del suelo en

Frecuencia de aplicación de fungicidas sobre rendimiento de soja (Glycine max L.) para el control de roya asiática
(Phakopsora pachyrhizi S.)

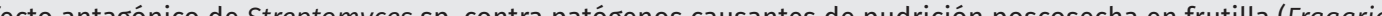
ananassa Duch) . Ste

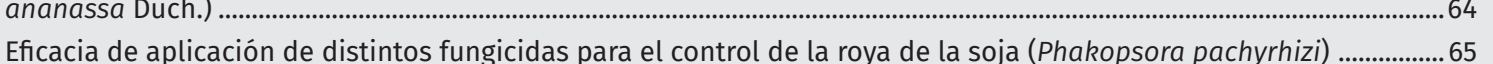

Severidad de la roya (Phakopsora pachyrhizi Sydow) en el cultivo de la soja con diferentes espaciamientos ...............66 Efecto del uso de fosfitos en el manejo de enfermedades de final de ciclo en soja (Glycine max [L.] Merril) ................67 Eficacia de aplicación de distintos fungicidas para el control de la roya de la soja (Phakopsora pachyrizi) ................68 Efecto de epocas de siembra y la aplicación foliar de fungicidas sobre la incidencia de Bipolaris oryzae en semillas de arroz

Incidencia de brusone en la panícula de arroz irrigado en diferentes épocas de siembra 政 Patógenos que afectan a especies Silvestres de arachis en Paraguay

\section{EJE NEMATODOS FITOPATÓGENOS}

Incidencia de nematodos en diferentes sistemas de cultivos protegidos de sandía (Citrullus lanatus [Thunb.]

Uso de extractos naturales para el control de Meloidogyne incognita en el cultivo de la okra (Hibiscus Efecto del nematodo agallador....................................................................................................... San Pedro, Paraguay .............................................................................................................................................77 Efecto Trichoderma en el cultivo de la okra (Abelmoschus esculentus (I.) Moench) inoculado con Meloidogyne

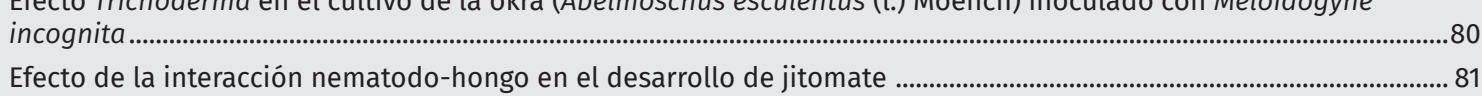
Control biológico de poblaciones de Meloidogyne sp. en el crecimiento del cultivo de Jamaica (Hibiscus Control biológico con Bacillus subtilis y Streptomyces de Meloidogyne incognita en rábano (Raphanus sativus) .........83 Nematodos fitoparásitos asociados a solanáceas cultivadas en el departamento de Cordillera, Paraguay .....................84

\section{CICLO DE WEBINARS}

WEBINAR: "NEMATODOS EN CULTIVOS EXTENSIVOS E INTENSIVOS" . .87 Primer webinar

Segundo webin

Tercer webinar.

Cuarto webinar

Quinto webinar

Sexto webinar ..

Séptimo webinar.

octavo webinar

Taller de OGIS

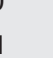
82 . .83 


\section{(9) PRIMERA \\ CONFERENCIA INTERNACIONAL \\ - de FITOPATOLOGÍA

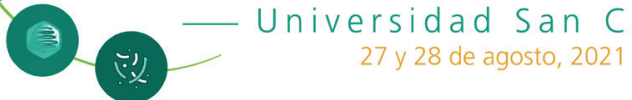

\section{Programa}

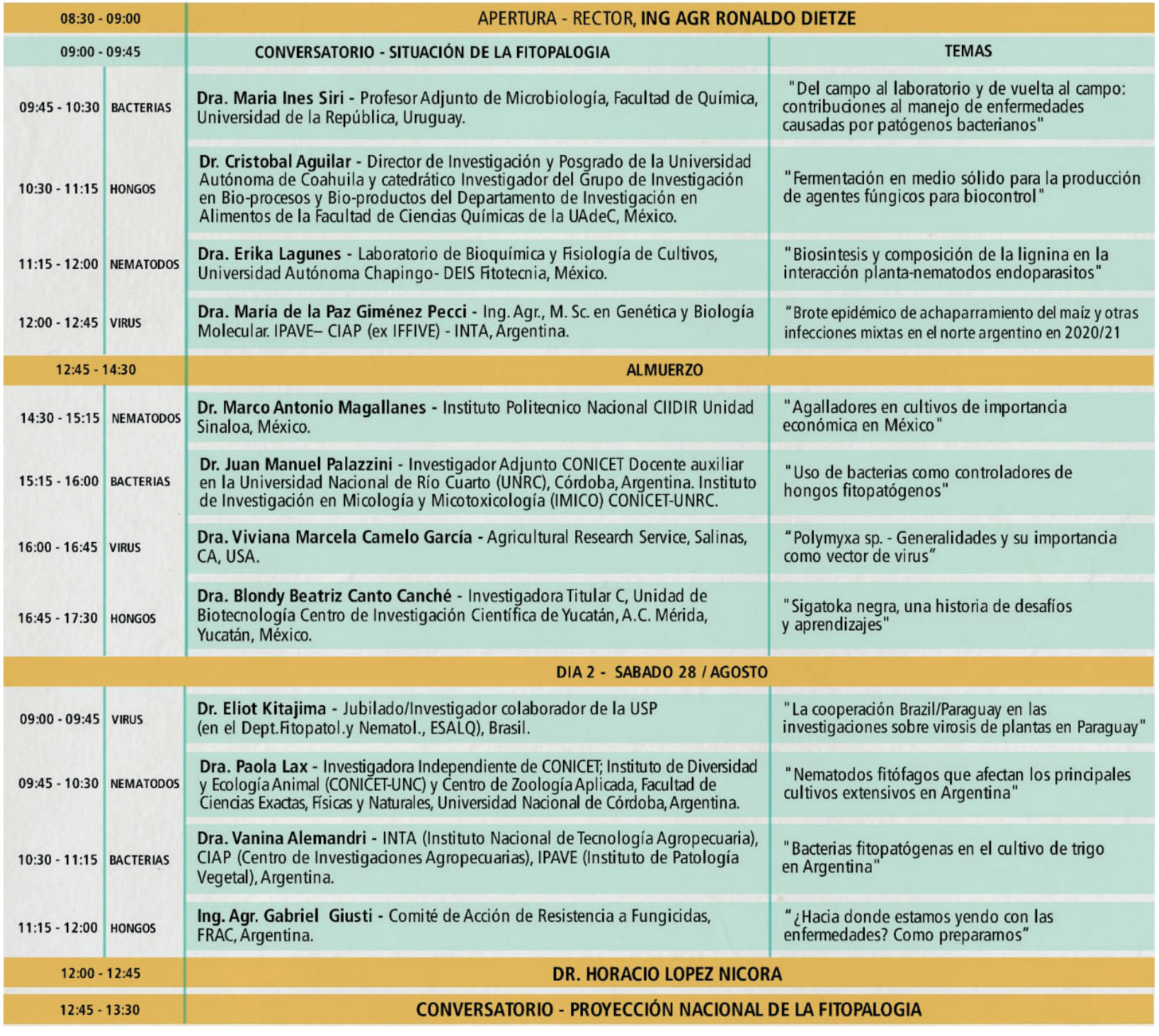




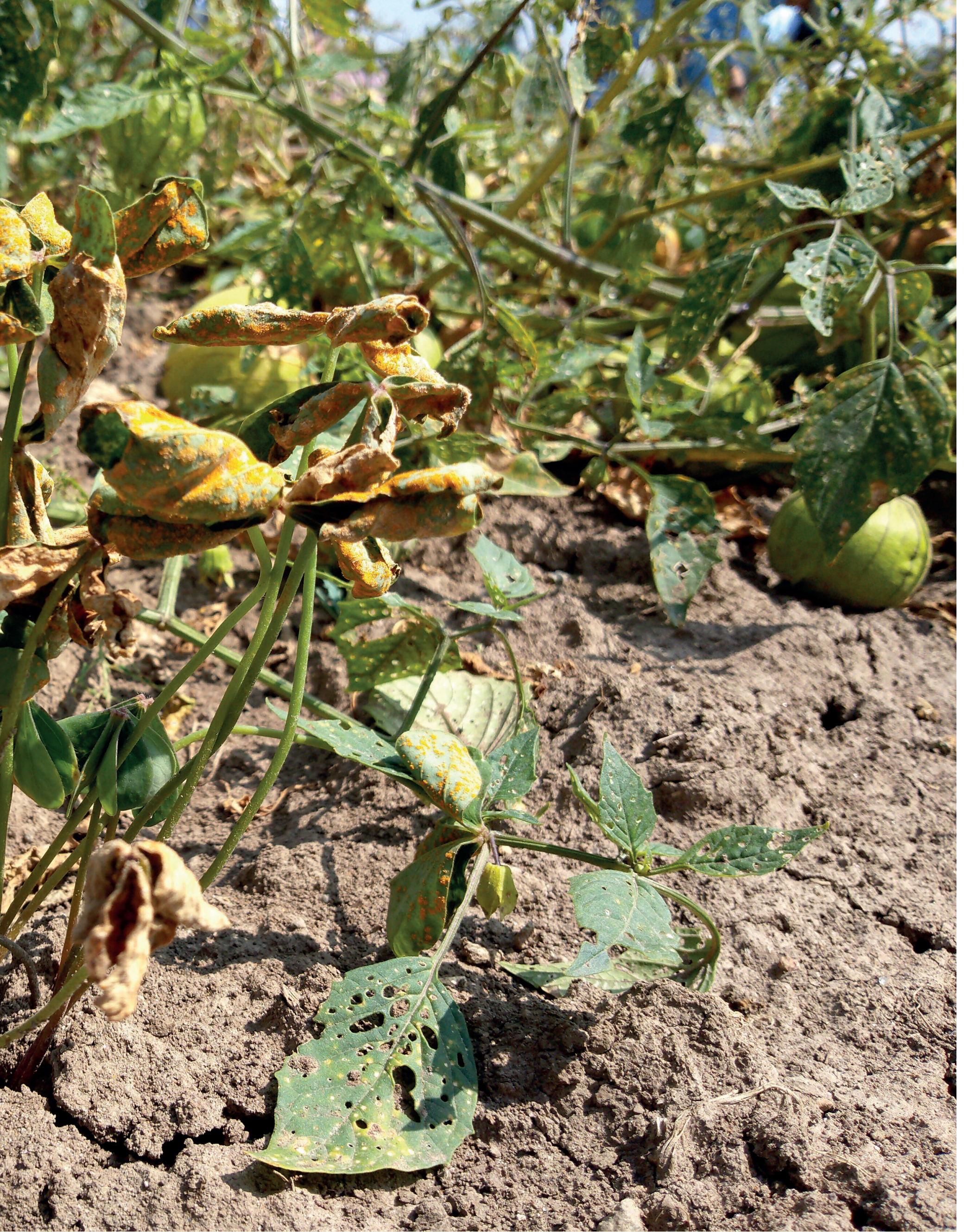

\section{CONSEJO NACIONAL \\ CONCYT YTECNOLOAA \\ PR\&CIENCIA \\ Ges Sanvesidad Carlos \\ DEL CAMPO AL LABORATORIO Y DE VUELTA AL CAMPO: CONTRIBUCIONES AL ESTUDIO Y MANEJO DE PATÓGENOS BACTERIANOS EN URUGUAY}

Feei

Dra. María Inés Siri

'Laboratorio de Microbiología Molecular, Departamento de Biociencias, Facultad de Química, Universidad de la República, Montevideo, Uruguay.

Todos los cultivos de importancia alimentaria a nivel mundial son afectados por enfermedades de origen bacteriano que tienen consecuencias negativas en la agricultura debido a las pérdidas económicas y al impacto medioambiental que conllevan. Junto con otros factores de estrés biótico y abiótico, estas enfermedades suponen una amenaza para la producción mundial de alimentos. Los patógenos bacterianos que afectan a los cultivos se caracterizan por su gran capacidad de persistencia en el ambiente y su rápida multiplicación en los tejidos del hospedero. Bajo condiciones ambientales favorables, son capaces de diseminarse extensamente causando brotes importantes y de muy difícil manejo. En este contexto, resulta esencial desarrollar investigaciones a nivel local para generar conocimientos y herramientas aplicables al manejo y control de cada problemática abordada. En esta charla, se presentarán las diferentes líneas de investigación desarrolladas en Uruguay para el manejo de enfermedades bacterianas en cultivos de papa, tomate, cebolla y trigo. Se realiza un trabajo interdisciplinario e interinstitucional, que implica el uso de diferentes abordajes experimentales incluyendo herramientas moleculares y genómicas de identificación y tipificación de las cepas patógenas, desarrollo de métodos de diagnóstico, estudios de interacción planta-patógeno y desarrollo de variedades resistentes a través de programas de mejoramiento. Se profundizará en particular en dos patosistemas y experiencias de investigación: I) la identificación y caracterización de las especies patógenas de Xanthomonas patógenas de trigo y II) la introducción de resistencia a Ralstonia solanacearum en papa y estudios de interacción planta-patógeno 
CONSEJONACIONAL

DE CIENCIA

SOLID-STATE FERMENTATION FOR

PRODUCTION OF BIOLOGICAL CONTROL AGENTS

Reynaldo de la Cruz-Quiroz'; Sevastianos Roussos²; Raúl Rodríguez-Herrera'; Daniel Hernández³; José L. Martínez-Hernández'; Nathiely Ramírez-Guzman ${ }^{1}$ and Cristóbal N. Aguilar*.

'Group of Bioprocesses. Food Research Department. Universidad Autónoma de Coahuila. Saltillo, 25280, Coahuila, Mexico; 'Institut Mèditerranéen de Biodiversité et d' Ecologie Marine et Contnientale (IMBE - IRD-Biotrans, France; ${ }^{3}$ Department of Agro-parasitology. Universidad Autónoma Agraria Antonio Narro. Saltillo, 25280, Coahuila, México.

In recent years, production and use of bio-pesticides have increased and replaced some synthetic chemical pesticides applied to food commodities. In this work, biological control is focused as an alternative to some synthetic chemical treatments which cause environmental, human health, and food quality risks. In addition, several phytopathogenic microorganisms have developed resistance to some of these synthetic chemicals, and their control became more difficult. Worldwide, the bio-pesticides market is growing annually in a $44 \%$ in North America, $20 \%$ in Europe and Oceania, $10 \%$ in Latin and South American countries and $6 \%$ in Asia. Use of agro-industrial wastes and solid state fermentation technology (SSF) offers an alternative to bio-pesticide production with advantages on conventional submerged fermentations, as reduced cost and energy consumption, low production of residual water and high stability products. SSF can be defined as a microbial process that generally occurs on solid material in absence of free water. Trichoderma strains have the ability to produce antibiotic metabolites as defense mechanism when they are in contact with another microorganism. On the present study, a solid state fermentation by Trichoderma asperellum on a mix of corn cob and phytopathogen biomass (P. capsici or C. gloeosporioides) using a polyethylene bag as bioreactor was performed. All compounds released during the fermentation were eluted using water, ethanol and toluene. After that, assays to test the antifungalactivity of the fermentation extracts against P. capsici and C. gloeosporioides were performed. The extracts with biological activity were fractioned using Amberlite XAD16 ${ }^{\circledR}$ and each fraction was analyzed by LC-ESI-MS. The molecular masses obtained on the present study had a coincidence with acetyltetrahydroxyanthraquinone, viridepyronone, dihydroxybergamotene, koninginin $\mathrm{D}$, virone, gliotoxin and an unknown compound. All of them had been reported on literature with high antifungal effect. Worldwide there are several companies producing biological control agents which include the Trichoderma genera. Commonly, this kind of production is carried out on liquid systems, which have some disadvantages such as; lower spore viability and high probabilities for bacterial contamination. Therefore, those disadvantages can be eliminated using a solid state production system with agroindustrial wastes as substrate. Also a feasibility study was carried out analyzing the possibility to create a biopesticide unity from Trichoderma spp. biomass, produced under SSF conditions using polyethylene bioreactors. Such bioreactors have functional characteristics that allow an easy packing and they are intended to be used under field crops as biological control product. After the economic analysis, the evaluation parameters PBP (0.86 years), NPV (171,044.62 $\$$ USD) and IRR (93\%) indicated a good process feasibility. 
BIOSÍNTESIS Y COMPOSICIÓN

DE LA LIGNINA EN LA INTERACCIÓN

PLANTA-NEMATODOS ENDOPARÁSITOS

Dra. Erika Lagunes

Laboratorio de Bioquímica y Fisiología de Cultivos.

Universidad Autónoma Chapingo-DEIS Fitotecnia, México.

\begin{tabular}{|c|c|c|c|}
\hline 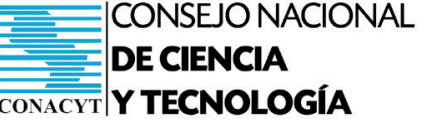 & PR\&DIENCIA & 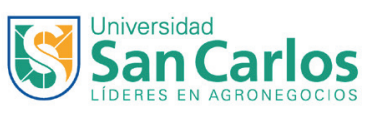 & Feei \\
\hline
\end{tabular}

\section{BROTE EPIDÉMICO DE ACHAPARRAMIENTO DEL MAÍZ Y OTRAS INFECCIONES MIXTAS EN EL NORTE ARGENTINO EN 2020/21}

Giménez Pecci, M. P.

'Ipave-CIAP-INTA-Ufyma Conicet, camino 60 Cuadras, km 5,5, Córdoba, Argentina.
Los nematodos endoparásitos sedentarios inducen la formación de Sitios Especializados de Alimentación (SEA), estructura en la que ocurre un engrosamiento importante de la pared celular secundaria y abundante lignificación) y constituyen su única fuente de alimentación, se localizan principalmente en el cilindro vascular, donde los elementos vasculares son deformados y colapsados durante su formación, de tal manera que la modificación de la pared celular es un requisito importante para el establecimiento de los nematodos endoparásitos sedentarios.

Las paredes celulares lignificadas constituyen barreras físicas potenciales para la migración y alimentación de los nematodos y además pueden limitar el acceso a los polisacáridos de la pared celular por las enzimas producidas por el nematodo, por lo que la posibilidad de que la infección y reproducción de los nematodos agalladores sea afectada por cambios en el contenido y composición de la lignina aún está en debate. De igual forma, la inducción de la biosíntesis de lignina se ha asociado frecuentemente con la respuesta a heridas o con otros mecanismos de defensa durante las relaciones planta-patógeno, además se ha observado que enzimas de la vía biosintética de los fenilpropanoides (a través de la cual se sintetizan compuestos fenólicos, como estilbenos, coumarinas, flavonoides, algunas fitoalexinas y lignina) son inducidas en plantas después de la infección por nematodos; por lo que la composición, distribución y regulación de la síntesis de lignina podría desempeñar una importante función durante el establecimiento del SEA, lo cual constituye un factor que contribuye a determinar el tipo de interacción planta-patógeno resultante (compatible o incompatible).
Spiroplasma kunkelii y Maize rayado fino virus (MRFV) son patógenos que forman parte del complejo causal del achaparramiento del maíz, también denominado palmado o corn stunt disease. El primero es un mollicute (bacteria sin pared celular) y el segundo un virus, ambos transmitidos por la chicharrita del maíz Dalbulus maidis. Están presentes en Argentina, siendo S. kunkelli ampliamente dominante por encima de los $30^{\circ} \mathrm{LS}$ donde el vector es endémico. Desde 2005 su incidencia en Argentina disminuyó notablemente, debido probablemente al empleo de semillas tratadas con insecticidas. Sin embargo, desde hace algunas campañas, su reaparición generó alerta y en la campaña 2020/21, la enfermedad causada por ambos patógenos se observó en toda la región agrícola del centro-norte de Argentina, principalmente en cultivos tardíos, acompañada de abundantes poblaciones del vector. La infección conjunta se registró en lotes de cuatro provincias argentinas (Formosa, Chaco, Santiago del Estero y Santa Fe), la provincia de Córdoba presentó ambos patógenos en lotes diferentes; la de Salta solo registró S. kunkelii y la de Corrientes sólo MRFV. Los síntomas fueron severos en las provincias del norte y los patógenos se reportaron hasta el paralelo $33^{\circ} \mathrm{LS}$, zona central templada del país, siendo la primera vez que la presencia de MRFV se registra simultáneamente en toda esta amplia región de diferentes ambientes y en la mayoría de los lotes estudiados. Análisis serológicos para otros siete virus de maíz frecuentes en el país (Maize dwarf mosaic virus [MDMV], Sugarcane mosaic virus [SCMV] y su variante SCMV-JM Wheat streak mosaic virus [WSMV], Maize chlorotic mottle virus [MCMV], High Plains wheat mosaic virus [HPWMoV], Mal de Río Cuarto virus [MRCV], Maize yellow striate virus [MYSV]) permitieron identificar en la presente campaña, infecciones de SCMV, SCMV-JM, MCMV, HPWMoV y MRCV, en infecciones simples, dobles o triples, incluyendo casos de necrosis letal del maíz.

Financiamiento: Proy. INTA I090, Proy. COFECYT ESPRO 22/17, Proy. PUE UFYMA CONICET 


\section{NEMATODOS AGALLADORES Y SU MANEJO EN CULTIVOS DE} IMPORTANCIA ECONÓMICA EN MÉXICO

Marco Antonio Magallanes Tapia

CIIDIR-IPN Unidad Sinaloa, Juan de Dios Bátiz Paredes n.o 250, CP 81101, Guasave, Sinaloa, México.

En México, la agricultura representa una de las actividades del sector primario más importantes. Las principales hortalizas cultivadas incluyen al tomate (Solanum lycopersicum), la papa (Solanum tuberosum), el tomatillo (Physalis ixocarpa) y el chile (Capsicum annumm). Meloidogyne spp. y Nacobbus aberrans son los nematodos agalladores de mayor importancia económica que infectan a hortalizas en México. Estos fitoparásitos reducen su crecimiento y rendimiento. El grado de daño depende del hospedante, de la densidad de población inicial, de las condiciones climáticas, del tipo de suelo y de la interacción con otros organismos de la rizósfera. El manejo de nematodos formadores de agallas incluye, principalmente, el uso de nematicidas químicos por su rápido efecto; también, las prácticas agrícolas del cultivo, agentes de control biológico (Pochonia cblamydosporia, Purpureocillium lilacinum, etc.), la incorporación de enmiendas orgánicas al suelo (vermicomposta, estiércol de bovinos y aves) que contienen sustancias nematotóxicas y, además, mejoran la fertilidad del suelo y los rendimientos del cultivo, sistemas de cultivos intercalados (Tagetes erecta), biofumigación (brócoli [Brassica oleracea], sorgo [Sorghum vulgare], alfalfa [Medicago sativa]), biosolarización, entre otros. Es necesario continuar con la aplicación de programas de investigación nematológica que integren estas prácticas de manejo de nematodos formadores de agallas, como un paquete tecnológico, que asegure la sostenibilidad de cultivos agrícolas.
CONSEJONACIONAL

\section{USO DE BACTERIAS COMO CONTROLADORES \\ DE HONGOS FITOPATÓGENOS}

Dr. Juan Manuel Palazzini ${ }^{1 ; 2}$

Universidad Nacional de Río Cuarto (UNRC), Córdoba, Argentina. 2Instituto de Investigación en Micología y Micotoxicología (IMICO) CONICET-UNRC. Argentina.

La actividad de hongos fitopatógenos a nivel mundial provoca la pérdida de hasta el $30 \%$ de los cultivos tanto sea por la merma en los rendimientos como por la reducción de la calidad y la seguridad por la presencia de micotoxinas. El control de enfermedades incluye el control químico, rotaciones de cultivos, tareas de laboreo y el uso de variedades más tolerantes; optando los productores por una combinación de dichas estrategias. En el sector agroalimentario, el concepto de la calidad de los productos agrícolas ha ido cambiando a través del tiempo y, en los últimos años, algunos sectores han comenzado a valorar los productos obtenidos mediante métodos más ecológicos y respetuosos con el medioambiente. En este marco, el control biológico emerge como una estrategia ambientalmente amigable que podría ser incorporada al manejo integrado de las enfermedades. El uso de microorganismos data desde hace más de un siglo, cuando se aplicaban en el suelo cultivos de estos o sus metabolitos para mitigar enfermedades fúngicas del suelo, previniendo el ingreso de los patógenos a través de la raíz. Diversos mecanismos de acción, tales como la excreción de antibióticos, toxinas, producción de sideróforos, enzimas líticas e induciendo la resistencia, o desplazando al patógeno por ocupación del nicho son las características destacables para utilizar un microorganismo como agente de control biológico. Sin embargo, para su aplicación, evaluación y establecimiento efectivo para ejercer biocontrol, se deben tener en cuenta diversos factores pre y pos selección del microorganismo en cuestión. En esta presentación, se abordarán cuestiones técnicas y los principales criterios indispensables a la hora de seleccionar agentes de control biológico promisorios para su uso en el control de hongos fitopatógenos. 
CONSEJONACIONAL

DE CIENCIA

\section{SIGATOKA NEGRA, UNA HISTORIA DE}

DESAFÍOS Y APRENDIZAJES

Canto-Canché, Blondy*, 1; Canul-Burgos, Yamily'; Carreón-Anguiano, Karla Gisel'; Todd Jewel, Nicole Anna'; Gómez-Tah, Rufino'; Chi-Manzanero, Bartolomé', Tzec-Simá, Miguel²; Vázquez-Euán, Roberto³; Islas-Flores, Ignacio².

1Unidad de Biotecnología. Centro de Investigación Científica de Yucatán, A.C., Calle 43 n.o 130 X 32 y 34 , Col. Chuburná de Hidalgo, C.P. 97205 , Mérida, Yucatán, México; ${ }^{2}$ Unidad de Bioquímica y Biología Molecul de Plantas. Centro de Investigación Científica de Yucatán, A.C., Calle 43 n.o 130 X 32 y 34, Co

Departamento de Investigaciones Científicas y Tecnológicas de la Universidad de Sonora, México.

La sigatoka negra es una enfermedad foliar de bananos y plátanos, que constituye una de las principales limitaciones fitosanitarias en estos cultivos. Su distribución es mundial, lo que conlleva a considerarla una pandemia en las zonas bananeras. El control es principalmente químico y su manejo representa uno de los programas más demandantes de fungicidas en el campo, por lo que disminuir el uso excesivo de estos agroquímicos representa uno de los principales objetivos en la agricultura. La pérdida por sigatoka negra puede ser total, si la enfermedad no se controla. Esta enfermedad es causada por Pseudocercospora (Mycosphaerella) fjiensis, un hongo ascomiceto con reproducción heterotálica y forma de vida hemibiotrófica. Las hifas penetran por los estomas y el patógeno permanece en fase biotrófica durante un largo y variable periodo de tiempo (Chi-Manzanero et al., 2021). Posteriormente, cambia a su fase más agresiva, la etapa necrotrófica, en la que produce toxinas que dañan el tejido foliar, interfieren en la capacidad fotosintética de la planta y causan las lesiones oscuras típicas, a las que se debe el nombre de la enfermedad. A pesar de lo exitoso que es el patógeno en el campo, su estudio en el laboratorio representa muchos retos. El hongo tiene un crecimiento muy lento in vitro; la pared celular contiene melaninas que dificultan el aislamiento y el análisis de proteínas y ácidos nucleicos, y la infección artificial no siempre es exitosa. Durante varios años el Centro de Investigación Científica de Yucatán ha desarrollado protocolos para el estudio de la sigatoka negra, con los cuales hemos podido avanzar en el entendimiento de la biología y patogénesis de P. fijiensis. Los análisis de datos masivos (genómico, transcriptómico y proteómico, minería de datos) evidencian la complejidad del hongo (Burgos-Canul et al., 2019; Carreón-Anguiano et al., 2020)
CONSEJONACIO

DECIENCIA

y en parte permiten entender las dificultades para su estudio in vitro y su manejo en el campo. Basándonos en resultados de algunos estudios básicos, nuestro grupo propone innovar el manejo integrado de la sigatoka negra, monitoreando en el campo la biomasa del hongo para hacer un diagnóstico temprano, así como para evaluar la eficiencia de los tratamientos de control (Vázquez-Euán et al., 2012), e incluir también el tratamiento de reservorios u hospederos alternativos de P. fijiensis en el manejo de la sigatoka negra (Vázquez-Euán et al., 2019). La investigación sobre sigatoka negra ha sido un recorrido con muchos desafíos. Los hallazgos encontrados nos dejan aprendizajes que permiten presentar propuestas para el manejo de esta enfermedad en el campo. Estos aprendizajes en sigatoka negra pueden contribuir también a enriquecer las estrategias de estudio y control de otros patógenos.

\section{BIBLIOGRAFÍA}

Burgos-Canul, Y.Y.; Canto-Canché, B.; Berezovski, M.V.; Mironov, G.; Loyola-Vargas, V.M.; Barba de Rosa, A.P.; Tzec-Simá, M. Brito-Argáez, L.; Carrillo-Pech, M. G two strains of Pseuddoceras.pora fijiennis with differences in virulence. World J Microbiol Biotechnol. 35(7): 105.

Carreón-Anguiano, Karla Gisel; Islas-Flores, Ignacio; Vega-Arreguín, Julio; Sáenz-Carbonell, Luis; Canto-Canché, Blond (1) Chi-Manzanero, B.; Carreón-Anguiano, K.G.; Todd, J.N.A.; Gómez-Tah, R.; Grijalva Arango, R.; Tzec Sima, M.A.; CantoCanché, B. (2021). Analysis of Pseudocercospora fjjiensis genes upregulated during early interaction with Musa acuminata (var

Vazquez-Euan, R.; Hernandez-Velazquez, I.; Tzec-Sima, M.; Chi-Manzanero, B.; Islas-Flores, I.; Martínez-Bolaños, L.; HernándezGomez, E., Garrido-Ramirce, E., Canto-Canché, B. (2012). Presencia de Mycosphaerella fyrensisis, agente causal de la sigatoka negra la sigatoka negra en México. Aportaciones de la investiración básica. Canto Canché, Blondy (coordinadora) (pp. 7-20). -

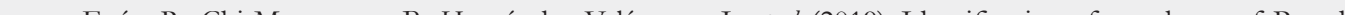
fijensis sugsests innovative pest management programs for black sigatola disease in https://doi.org/10.3390/agronomy9100666. 
CONSEJO NACIONAL

DE CIENCIA

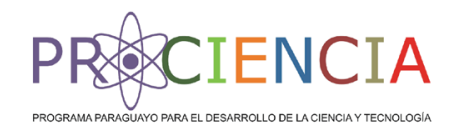

\section{LA COOPERACIÓN BRASIL-PARAGUAY EN LAS INVESTIGACIONES} SOBRE VIROSIS DE PLANTAS EN PARAGUAY

Kitajima, E.W.'; Rezende, J.A.M.'; Esquivel-Fariña, A. ${ }^{2}$ y González-Segnana, L.R. ${ }^{3}$.

Departamento de Fitopatología y Nematología, ESALQ/USP, Piracicaba, SP, Brasil; ${ }^{2}$ Ministerio de Agricultura y Ganadería, Asunción, Paraguay; Departamento de Biología; ${ }^{3}$ Universidad Nacional de Asunción San Lorenzo, Paraguay.

Paraguay tiene una economía basada fuertemente en los agronegocios, con un gran espectro de cultivos, pero cuenta con relativamente pocas informaciones sobre las virosis que los afectan (identificación, importancia y su manejo). Esto resulta de un número aún reducido de fitopatólogos. Pero, aun así, virólogos paraguayos y consultores del exterior, en especial del Japón, describieron inicialmente varios virus de plantas en el territorio paraguayo. Recientemente, gracias a los esfuerzos del Prof. L.R. González-Segnana (L.R.G.S.), de la Universidad Nacional de Asunción (UNA), se estableció, a partir de 2010, una activa cooperación entre el grupo de fitopatólogos de la Escuela Superior de Agricultura Luiz de Queiroz (E.S.A.L.Q.), de la Universidad de São Paulo (USP), en el campus de Piracicaba, en particular, con el virólogo Prof. E.W. Kitajima (E.W.K.). Los trabajos iniciales se concentraron en una importante enfermedad viral en el cultivo del sésamo en el departamento de San Pedro, conocida como ka’arẽ. Las investigaciones conjuntas identificaron el agente causal como el virus del mosaico del poroto (CABMV), transmitido por áfidos, aclarando su epidemiología y estableciendo las estrategias de control. Otras inspecciones han sido realizadas en los departamentos de Boquerón, Itapúa, Concepción, Cordillera, Caacupé, Caazapá y en la capital, abarcando cultivos como ornamentales, cítricos, granos, hortalizas, etc., que resultaron en la identificación de varios virus aún no reportados en el Paraguay. Otra consecuencia de esta cooperación fue el entrenamiento de A. Esquivel-Fariña (A.E.F.), que fue su alumno en el curso de Agronomía de la UNA, y por sugerencia de L.R.G.S., en el curso de posgrado en Fitopatología, en la E.S.A.L.Q., bajo supervisión del Prof. J.A.M. Rezende (J.A.M.R.), teniendo como tema el virus de la clorosis del tomate (ToCV). A.E.F. completó su maestría en 2016, y doctorado en 2020, incluyendo una estancia en la Estación Experimental del USDA, en Salinas, CA, EE. UU. De esta colaboración resultaron varias publicaciones sobre virosis de plantas en

el Paraguay. Actualmente, está en progreso un proyecto para organizar una lista de los virus de plantas descritos en el Paraguay, de manera similar a una lista de virus de plantas del Brasil, publicada por E.W.K. Esta publicación será una importante referencia a los futuros trabajos en virología de plantas en el Paraguay, y un repositorio histórico de las investigaciones en esta área. Se espera que esta cooperación se intensifique más para el beneficio mutuo en los conocimientos sobre virus de plantas. 


\section{NEMATODOS FITÓFAGOS QUE AFECTAN LOS \\ PRINCIPALES CULTIVOS EN ARGENTINA}

Lax, P. y Doucet, M.E.

Instituto de Diversidad y Ecología Animal (IDEA-CONICET). Facultad de Ciencias Exactas, Físicas y Naturales, Universidad Nacional de Córdoba. Córdoba, Argentina.

Los nematodos fitófagos son responsables de ocasionar significativas pérdidas en la producción agrícola. Dada la gran superficie destinada a la siembra en Argentina, ciertas especies tienen una amplia dispersión y se encuentran asociadas con distintos cultivos extensivos e intensivos. Debido a la falta de síntomas específicos, en muchas ocasiones su presencia pasa desapercibida, incrementando los niveles de densidad poblacional en el suelo e, incluso, favoreciendo su diseminación. Entre los principales géneros, se destacan: Meloidogyne, Nacobbus, Heterodera, Globodera, Helicotylenchus y Pratylenchus. La significación de estos organismos depende del cultivo que afectan así como de su manejo.

\section{BACTERIAS FITOPATÓGENAS EN EL CULTIVO DE TRIGO EN ARGENTINA}

Alemandri, V. M. ${ }^{1}$

Ilpave-CIAP-INTA, UFyMA-INTA-Conicet, Córdoba, Argentina.

A nivel mundial, se han descripto diversas bacterias fitopatógenas en trigo (Triticum aestivum L.) responsables de ocasionar mermas en el rendimiento de este cultivo. En esta ponencia se presentarán las metodologías empleadas para el aislamiento e identificación de bacterias fitopatógenas en plantas de trigo pan con sintomatología característica de bacteriosis provenientes de diferentes regiones productoras de Argentina, así como también los resultados obtenidos hasta el momento. Las muestras analizadas fueron a partir de semillas, hojas, tallo y/o espiga con sintomatología que podría indicar la presencia de enfermedades bacterianas, provenientes de las principales zonas trigueras de Argentina (provincias de Córdoba y Buenos Aires). Se mostrará el proceso de aislamiento, a través de la desinfección, molienda y dilución seriada en medio de cultivo sólido a fin de obtener colonias bacterianas puras, a las cuales se les realizan pruebas biológicas y moleculares, para la correcta identificación de los patógenos. Se detallarán las metodologías empleadas, tales como pruebas bioquímicas (tinción de Gram), de solubilidad en $\mathrm{KOH} 3 \%$, técnica de MALDI-TOF, así como también, pruebas moleculares de PCR. Ésta técnica, se lleva a cabo a partir de ADN de cultivos puros, empleando cebadores generales y/o específicos para diversas especies de los géneros Xanthomonas y Pseudomonas, y Pantoea ananatis. Además, la utilización de cebadores universales para bacterias que amplifican la región intergénica del 16S y su posterior secuenciación. Se mostrarán pruebas, inoculando hojas con una suspensión bacteriana de concentración conocida, comprobando la patogenicidad de diversos aislamientos en trigo. Por último, presentaremos la experiencia de la utilización de la técnica de secuenciación de tercera generación, Oxford Nanopore, para la obtención de genomas completos de bacterias patógenas en cereales. Se discutirán los resultados obtenidos, con las bacterias fitopatógenas identificadas, y las que están aún en proceso, incluyendo aquellas que infectan también otros cultivos. 


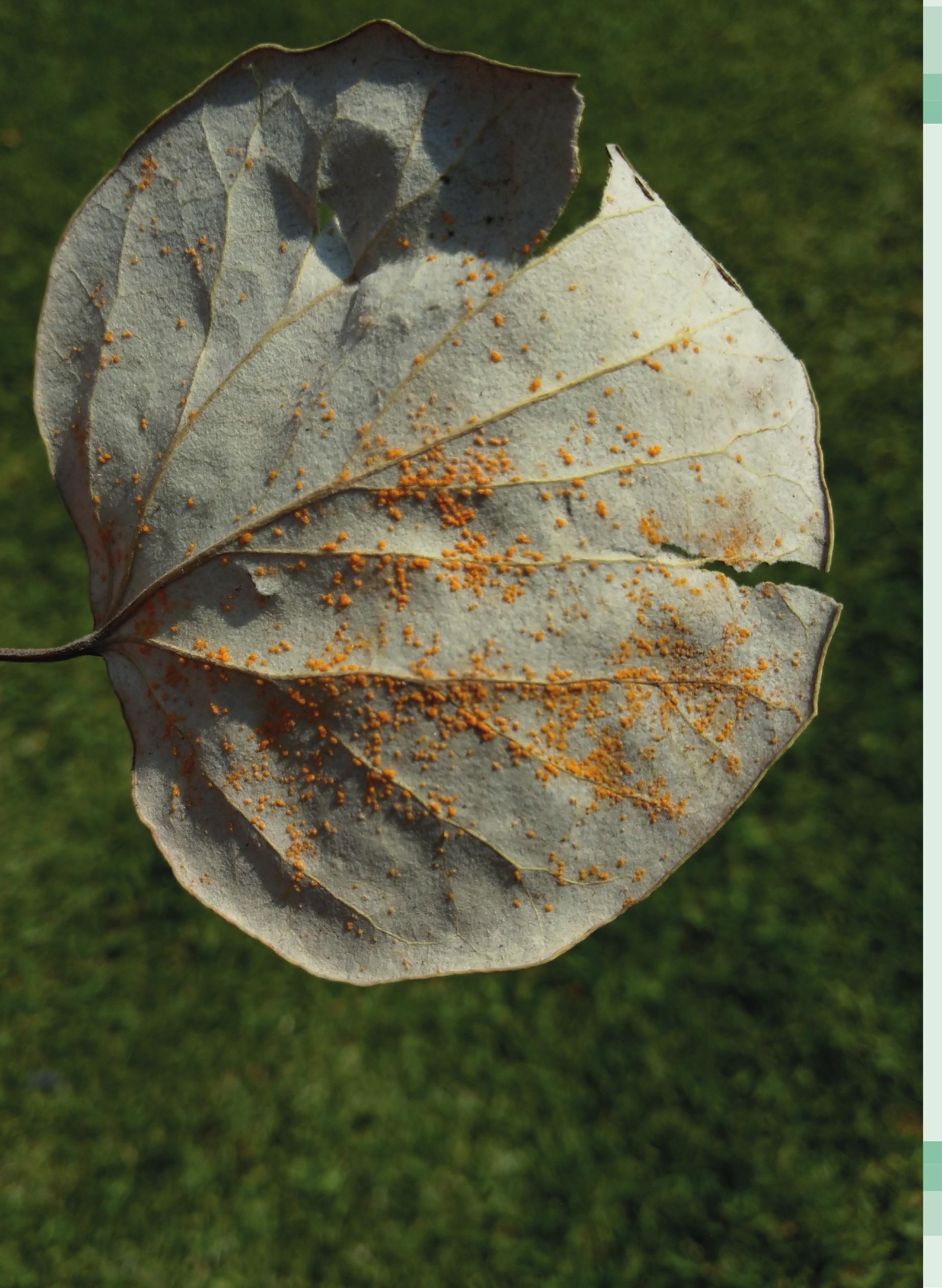

\section{RESÚMENES de POSTERS}




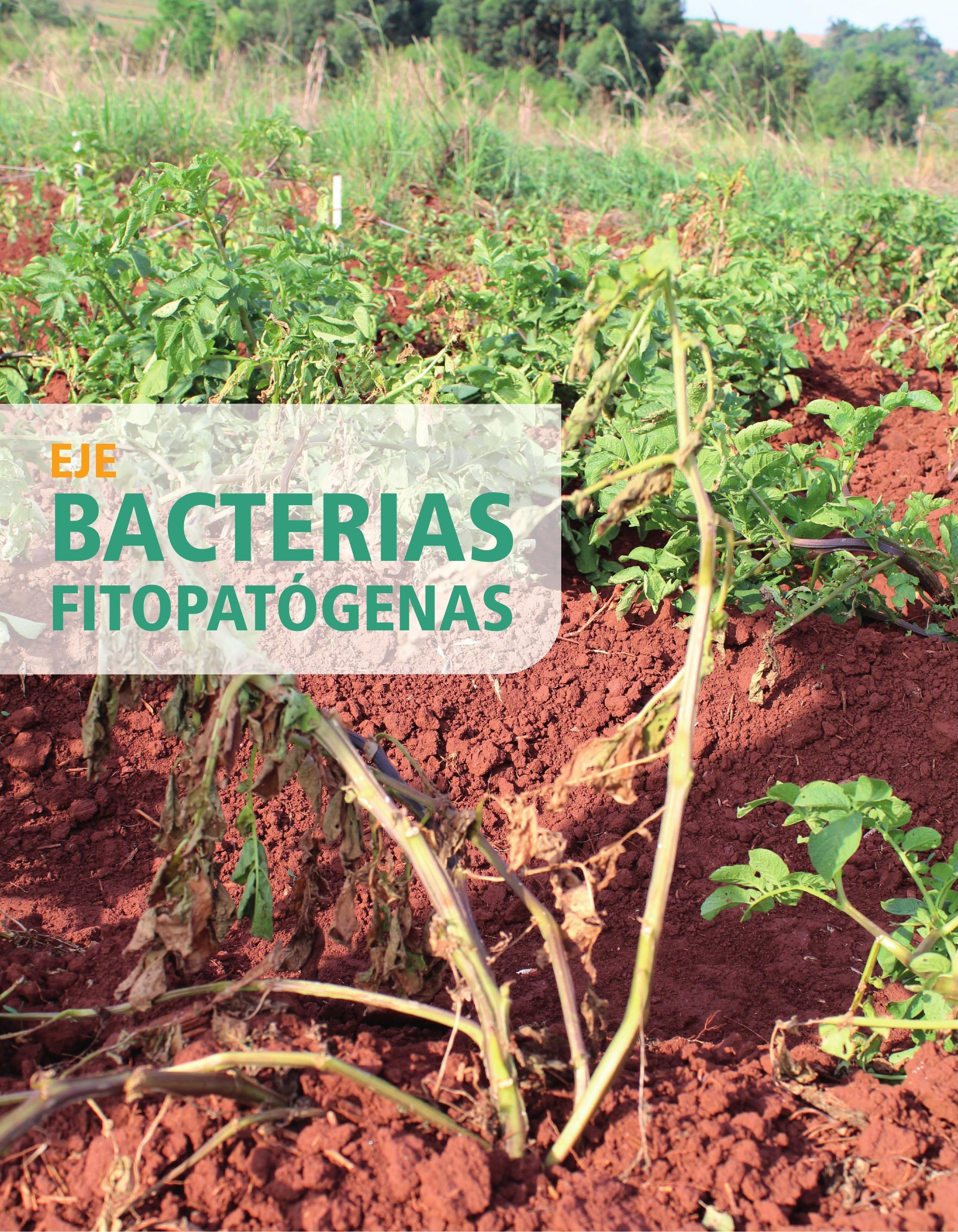

\section{ECONSEONACIONAL \\ COVICYT YTECIA \\ PR\&CIENCIA \\ Sis San Carlos \\ BIOCONTROL DE HONGOS POSCOSECHA EN TOMATE \\ (Solanum lycopersicum) MEDIANTE BIOEXTRACTOS DE \\ Bacillus sp. Y PLASMA FRIO DE RADIOFRECUENCIA}

Feei

Cano Reséndez L. P.; Salas Méndez E. J.; Hernández Torres C. J.; Reyes Acosta Y. K.1; Sepúlveda Torre L.'; *Dávila Medina M. D.?

'Facultad de Ciencias Químicas, Universidad Autónoma de Coahuila, Ing. J. Cárdenas Valdez S/N, República, 25080 Saltillo, Coahuila, México.

Las enfermedades poscosecha causadas por hongos fitopatógenos provocan pérdidas económicas, Alternaria solani representa un problema fitosanitario en tomate. El objetivo de esta investigación fue utilizar plasma frío de radiofrecuencia (PFR) con bioextracto libre de células de Bacillus sp. (BCFB) en tomate, como una alternativa para alargar la vida de anaquel. Los bioensayos de antagonismo se realizaron por confrontación de Bacillus sp. y BCFB contra $A$. solani en agar dextrosa papa - extracto de malta y levadura (PDA-EML). Se realizó una prueba de anaquel en tomates, asperjando $\mathrm{BCFB}$ y esporas de $A$. solani, a temperatura ambiente, se evaluó peso, análisis microbiológico, incidencia (cantidad de frutos dañados) y severidad (escala) en diferentes tiempos ( 5 a 25 d). Se realizaron tres repeticiones con seis tomates cada una, con estadístico ANOVA. Posteriormente, se trataron los tomates con PFR y se agregó BCFB; se midió incidencia y severidad. En los bioensayos Bacillus sp. y el BCFB presentaron actividad antagonista contra $A$. solani. En la vida de anaquel de tomates con BCFB se observó antagonismo contra A. solani y otros hongos presentes en el control. No se observaron diferencias en peso hasta que se degradó el fruto en el control. La incidencia del BCFB fue de $66,66 \%$ y la severidad en escala 2 (20 \% daño), en comparación con el control que presentó $100 \%$ de incidencia y escala 5 (100\% daño). Los tomates tratados con PFR- BCFB presentaron mayor efecto antagónico, la incidencia de $A$. solani fue del $0 \%$ frente al control que mostró incidencia del $100 \%$, y el tratamiento presentó una escala 0 , comparado con 5 del control, los tomates tratados estaban sanos a los 25 d del ensayo. El plasma frío de radiofrecuencia en combinación con Bacillus sp. demuestra ser una alternativa biológica eficaz en el control de fitopatógenos, aumentando así la vida de anaquel del tomate. 
SECUENCIACIÓN PARCIAL DEL GENOMA DEL Argentinean Alfalfa witches' broom phytoplasma (ArAWB, 16SRVII-C) ASOCIADO CON LA ESCOBA DE BRUJA EN ALFALFARES DE ARGENTINA

Fernández, F.D.1, 2; Conci, L.R.1, 2 .

IIPAVE-CIAP-INTA; ${ }^{2}$ UFYMA-CONICET, Córdoba, Argentina.

Los fitoplasmas son bacterias fitopatógenas que afectan numerosas especies mundialmente. En Argentina, la infección causada por el fitoplasma ArAWB ha sido reportada de manera recurrente en alfalfares de la región árida andina, generando muertes de plantas y pérdidas en la producción de semillas. No hay datos a nivel genómico de este patógeno, limitando el estudio de características biológicas relevantes. En este trabajo se propone secuenciar el genoma del fitoplasma ArAWB y analizar sus características generales. Para ello se extrajo ADN genómico a partir de una planta vinca (hospedante experimental) infectada con ArAWB. El gDNA fue secuenciado en dos plataformas, Illumina (lecturas cortas) y Oxford Nanopore Technologies (ONT) (lecturas largas). Las lecturas cortas se mapean en contra del genoma de referencia de vinca (limpieza ADN del hospedante) y luego se ensamblan usando el programa Unicycler. Posteriormente se identificaron contigs de fitoplasmas usando BLASTx. Las lecturas de ONT se mapean en contra de los contigs finales y se rehicieron los ensamblados de manera iterativa. El ensamblado final se anotó usando Prokka y la identificación de proteínas efectoras se realizó siguiendo protocolos estandarizados. Se obtuvo un ensamblado final de 2 contigs con $580.230 \mathrm{pb}$ secuenciados (GC\% 22.90, $\sim 90 \mathrm{X}$ de cobertura) y un plásmido putativo de $5.577 \mathrm{pb}$ (GC\% 23.2). Se lograron anotar un total de $467 \mathrm{CDSs}, 2$ operones rRNA y un secretoma compuesto por 23 proteínas. En este último se identificaron proteínas efectoras putativas previamente descritas y otras únicas de este patógeno. Se identificaron también genes aptos como marcadores de diversidad ( $\sec A, \sec Y, \operatorname{groEL}$, tuf, otros). Este es el primer reporte de secuenciación de un genoma para fitoplasmas del grupo 16SrVII (Ash Yellows) a nivel mundial, lo cual resulta clave en el estudio de la patogenicidad, aspectos evolutivos, y el desarrollo de insumos para la detección especifica de estos patógenos.

Financiación: INTA: FONCYT

\begin{tabular}{|c|c|c|c|}
\hline $\begin{array}{l}\text { CONSEJONACIONAL } \\
\text { DE CIENCIA } \\
\text { YTECNOLOGÍA }\end{array}$ & PR\&CIENCIA & 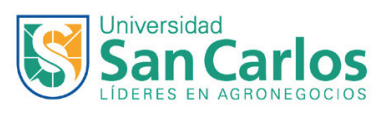 & Fee; \\
\hline
\end{tabular}

\section{APLICACIÓN DE NUEVAS TECNOLOGÍAS DE SECUENCIACIÓN PARA LA OBTENCIÓN DE GENOMAS COMPLETOS DE BACTERIAS PATÓGENAS EN TRIGOS DE ARGENTINA}

Martino, J.; Alemandri, V.; Conci, L.; Fernández, F.?

IPAVE-CIAP-INTA, UFYMA-INTA-CONICET, Córdoba, Argentina.

Diversas bacterias patógenas fueron descritas infectando cereales de importancia económica, entre ellas las que afectan trigo (Triticum aestivum L.), responsables de ocasionar pérdidas en la producción. Actualmente, están siendo muy utilizadas para la identificación y caracterización adecuada de patógenos las tecnologías de secuenciación de tercera generación, como la de Oxford Nanopore (ONT). Estas tecnologías presentan ventajas como la simplicidad en la preparación de la muestra, resultado en tiempo real y la obtención de lecturas largas. El objetivo del presente trabajo fue secuenciar genomas completos de dos bacterias que afectan trigo en Argentina empleando la plataforma de secuenciación ONT. Se procedió a la extracción del ADN genómico a partir de cultivos puros de Psendomonas syringae, obtenidos a partir de plantas con sintomatología característica de bacteriosis, y de Curtobacterium flaccumfaciens desde semillas, identificadas biológicamente y corroboradas por secuenciación de la región intergénica del 16S y/o MALDITOF. Se utilizó el método de extracción con CTAB para la primera bacteria y un kit comercial (QIAGEN) para la segunda. La calidad y cantidad de ADN fue evaluada mediante NanoDrop-1000 y Quantus Fluorometer. El ADN purificado fue utilizado para la generación de librerías de secuenciación empleando un kit comercial (Ligation Sequencing Kit). Las librerías fueron secuenciadas empleando la plataforma ONT en un dispositivo MinION 1kb. Las secuencias crudas fueron filtradas empleando Filtlong y ensambladas usando Trycycler (https://github. $\mathrm{com} / \mathrm{rrwick} /$ Trycycler/wiki). Se logró ensamblar en un solo contig el cromosoma de ambas especies en estudio, P. syringae (6065829 pb, GC $59 \%$ y C. flaccumfaciens (3685167 pb, GC $70.9 \%$ ). Los resultados obtenidos demuestran que la plataforma ONT resultó una herramienta eficaz, rápida, accesible y de baja complejidad, permitiendo confirmar de manera precisa los agentes causales, además de generar cuantiosa información genómica imprescindible para el desarrollo de diagnósticos específicos, entendimiento de los patosistemas y el diseño de estrategias de manejo. 


\begin{tabular}{|c|c|c|}
\hline $\begin{array}{l}\text { CONSEONACIONAL } \\
\text { DECIENIA }\end{array}$ & PR CIENCIA & San Carlos \\
\hline
\end{tabular}

\section{IDENTIFICACIÓN DE GÉNEROS DE HONGOS ENDÓFITOS ASOCIADOS A SIETE VARIEDADES DE SOJA CULTIVADAS EN EL DEPARTAMENTO DE SAN PEDRO, PARAGUAY}

Resquín-Romero, G.'; Lezcano, J.; Enciso, V1.

'Facultad de Ciencias Agrarias, Universidad Nacional de Asunción, San Lorenzo, Paraguay.

Dentro de los ordenes Hypocreales, Botryosphaeriales, Pleosporales, Diaporthales, Phyllachorales, Sordariales, Glomerellales existen varias familias y géneros de hongos ecológicamente diversos que se aíslan comúnmente como endófitos o patógenos de varios huéspedes tanto herbáceos como semileñosos y leñosos. E objetivo del presente trabajo fue obtener conocimientos sobre la diversidad de hongos endófitos asociados a tallos de siete variedades de soja (Glycine max L. Merril) (R3), cultivadas a campo abierto en el campo experimental de la Facultad de Ciencias Agrarias (FCA-UNA), Filial Ycuamandyju, San Pedro, ubicada a $330 \mathrm{~km}$ de Asunción, Paraguay. La identificación de los agentes causantes de enfermedades se realizó en el Laboratorio de Protección Vegetal de la FCA-UNA, casa matriz. Se utilizó el método de cámara húmeda para el crecimiento fúngico y su posterior identificación y aislamiento a través de medios de cultivos a base de PDA selectivos y agar agua $(2 \%)$ para el crecimiento de la colonia fúngica y la obtención de la etapa reproductiva. El diseño experimental fue el de bloque completo al azar con siete variedades y cuatro repeticiones; por cada repetición se utilizaron tres unidades experimentales. Las variables utilizadas fueron incidencia de enfermedades, identificación y caracterización morfológica-estructural y prueba de colonización endófitos. Los datos fueron sometidos a ANAVA, con posterior prueba Tukey al $5 \%$. Los resultados de las interacciones entre variedad y la incidencia de géneros Fusarium se obtuvieron entre 17 y $67 \%$ para las variedades Potencia y 6909, respectivamente; mientras que para Macrophomina phaseolina la incidencia fue de $17 \%$ para Potencia, 6505 y 6248, y $100 \%$ para 6909. Se concluye que en las variedades estudiadas se identificó la presencia de Fusarium spp. y Macrophomina phaseolina en tallo y en menor incidencia de Phyllachora sp., Gibberella sp., Phoma sp., Phomopsis sp., Chaetomium sp. Phyllachora sp., y Sclerotium rolfsii y un hongo atípico Verticillium sp. 
CONSEJONACIONA

DE CIENCIA

ANÁLISIS DE LA IMPORTACIÓN DE FUNGICIDAS EN EL PARAGUAY PERIODO 2009 - 2019

Valenzuela, M. A. ${ }^{1 ;}$ Villanueva, L. E. ${ }^{\text {; }}$ Dietze, R. E. ${ }^{\text {; }}$ Borgognon, J. A. ${ }^{1 ;}$ Rojas, S. M. ${ }^{1}$

'Universidad San Carlos (USC), Asunción - Paraguay

En la presente investigación se analizó la importación de fungicidas en el Paraguay periodo 2009 al 2019, debido a que a nivel país el aumento de la superficie de los cultivos soja, trigo y maíz ha provocado el aumento de los insumos fitosanitarios entre ellos los fungicidas y no habiendo registros ni estudios precisos de cómo ha variado la importación a través del tiempo se realiza esta investigación. Los objetivos fueron analizar la importación de fungicidas en el Paraguay periodo 2009 - 2019. Cuantificar el volumen, los tipos y el valor monetario de la importación de fungicida en el periodo 2009 - 2019. Clasificar los fungicidas importados por categoría toxicológica. Evaluar los resultados económicamente. La investigación se realizó en Asunción en base a recopilación, revisión y analisis de información relacionadas a la importación de fungicidas utilizando la base de datos de la Aduana. Para el método de control de calidad de datos se recurrió a entrevista técnicas y revisiones bibliográficas disponibles. En cuanto a volumen de importación se pudo comprobar que hubo un aumento en los últimos años. El fungicida más importado en el 2019 fue Fluxapirosad 5\% + Epoxiconazole 5\% + Pyraclostrobyn $8,1 \%$ con un $10.05 \%$ en comparación a los demás fungicidas. En el año 2009 la clase toxicológica más importada corresponde a $62 \%$ a la clase II-Moderadamente peligroso y en el año 2019 es la clase IV-Poco peligroso, en cuanto al valor de importación se observó que el aumento para el año 2009 fue 41.853.944 U\$S y en el 2019 fue de 124.968.652 U\$S debido a que en el mercado hay una diversificación de ingredientes activos. La importación de fungicidas se encuentra mayormente influenciadas por las condiciones climáticas e incidencias de las enfermedades fúngicas. La clase toxicológica más importada corresponde a la clase IV Poco peligroso con un $42 \%$, por tener un enfoque sostenible. En la evaluación económica el valor de la importación para el año 2009 fue 41.853.944 U\$S y en el 2019 fue de 124.968.652 U\$S, aumento observado pero el precio unitario disminuyó para el año 2009 fue 24,83 U\$S/kg y en el 2019 fue de 18,44 $\mathrm{U} \$ \mathrm{~S} / \mathrm{Kg}$ esto puede deberse por una mayor competencia comercial en el mercado nacional.
CONSEJONACIONAL

EXPRESIÓN DE GENES CODIFICANTES DE DEFENSINAS EN VARIEDADES DE SOJA RESISTENTE Y SUSCEPTIBLE A Macrophomina phaseolina

Ortiz, A. B ${ }^{1,} ;$ Orrego, A. A ${ }^{1}$; Kohli, M. M. ${ }^{2}$; lehisa, J. C. M. ${ }^{1}$

'Departamento de Biotecnología, Facultad de Ciencias Químicas, Universidad Nacional de Asunción, San Lorenzo, Paraguay/ 'Cámara Paraguaya de Exportadores y Comercializadores de Cereales y Oleaginosas (CAPECO), Asunción, Paraguay

La pudrición carbonosa es una enfermedad causada por el hongo fitopatógeno Macrophomina phaseolina, el cual afecta a varios cultivos de interés agronómico como a la soja (Glycine max). Aunque se han reportado algunas variedades de soja con mayor resistencia a $M$. phaseolina, se desconoce su mecanismo de defensa contra dicho hongo. En las plantas, las defensinas, pequeños péptidos ricos en cisteína con actividad antifúngica, pueden ser responsables de mecanismos de acción contra patógenos. En el presente trabajo se realizó una búsqueda de estos en el genoma de la soja y su análisis de expresión durante la infección de $M$. phaseolina en una variedad de soja resistente (DT974290) y otra susceptible (A4910). Se encontraron nueve genes codificantes de defensinas en el genoma de la soja. Para el análisis de expresión, ambas variedades fueron inoculadas con un aislado de $M$. phaseolina utilizando el método de cut-stem. El ARN fue extraído a los 1, 3 y 6 días post-inoculación (dpi). La expresión de seis defensinas fue confirmada mediante la reacción en cadena de la polimerasa en tiempo real con retro-transcripción. A los 1 dpi, una de ellas fue inducida en la variedad resistente. La mayoría de estas defensinas fueron inducidas a los 3 dpi en la variedad resistente, pero no en la susceptible. Por otro lado, a los 6 dpi, la mayor parte presentó una disminución en la expresión. Se sugiere que la Defensina 6 de soja podría contribuir a la resistencia de la variedad DT974290 con respecto a la variedad A4910. Además, la diferencia en la inducción de los genes codificantes de defensinas entre las variedades indica que existe una activación diferencial de alguna vía de señalización que contribuya a la resistencia de DT974290. 
CONSEJONACIONA

EVALUACION DE LA TASA CRECIMIENTO DE AISLADOS DE Pyricularia oryzae FRENTE A FUNGICIDAS DE ORIGEN QUÍMICO

Reyes. $\mathrm{M}^{*}$, Chávez. $\mathrm{A}^{2}$, Kolhi. $\mathrm{M}^{2}$

Instituto Paraguayo de Tecnología Agraria (IPTA)

${ }^{2}$ Cámara Paraguaya de Exportadores y Comercializadores de Cereales y Oleaginosas (CAPECO), Paraguay.

Una de las enfermedades más importantes del cultivo de Trigo es la Pyricularia. Las condiciones favorables para su desarrollo (humedad elevada y temperaturas cálidas) propician perdidas elevadas (hasta 100\%). Una de las estrategias ampliamente utilizada para su control es el empleo de fungicidas. Ante reportes de resistencia y por la importancia económica del cultivo es necesario monitorear el comportamiento del patógeno frente a productos químicos empleados. Con el objetivo de evaluar la tasa de crecimiento de aislados de P. oryzae frente a fungicidas se seleccionaron cinco aislados monospóricos y se inocularon en medio de cultivo a base de papa, dextrosa y agar conteniendo principio activo de 0 (Control), 1, 10, 20 y 40 ppm de Fluxapyrosad $333 \mathrm{~g} \mathrm{~L}^{-1}$, Azoxystrobin $500 \mathrm{~g} \mathrm{~L}^{-1}$ y Pyraclostrobin + Thiofanato metilico respectivamente, con 5 repeticiones. Se realizaron las mediciones y los datos fueron sometidos análisis de varianza (ANOVA) y test de comparación de medias por Tukey al 0,05\% con el software estadístico Infostat. Se observó diferencias significativas en la tasa de crecimiento de los aislados en las diferentes dosis de fungicida. Los fungicidas no inhibieron el crecimiento de los aislados a una concentración de $1 \mathrm{ppm}$ y siendo esto no significativo con el control $(0 \mathrm{ppm})$. Sin embargo se logró determinar que a partir de una dosis correspondiente a $10 \mathrm{ppm}$ de Pyraclostrobin 50 $\mathrm{g} \mathrm{L}^{-1}+$ Thiofanato metilico 450 $\mathrm{g} \mathrm{L}^{-1}$ la tasa de crecimiento de los aislados fue $0 \mathrm{~cm}$ por día, lo cual indica que este principio activo es efectivo para inhibir el crecimiento micelial a partir de esa concentración. El fungicida Pyraclostrobin $50 \mathrm{~g}+$ Thiofanato metilico $450 \mathrm{~g}$ es capaz de inhibir el crecimiento de P. oryzae, por lo cual se hace factible su empleo como estrategia de control de la Pyricularia del trigo.

\begin{tabular}{|c|c|c|}
\hline $\begin{array}{l}\text { CONSEO NACIONAL } \\
\text { DE CIINCIA } \\
\text { Y TENOLOGIA }\end{array}$ & PR\&CIENCIA & (5) Universidad \\
\hline
\end{tabular}

\section{IDENTIFICACION DE Fusarium sp. EN RAMAS DE YERBA MATE CON SIGNOS DE NECROSIS EN EL DEPARTAMENTO DE GUAIRÁ}

Masloff, V'; Burgos Cantoni C. N. ${ }^{2}$, Gonzalez Coria, Johana², Talavera Stefani L. N. ${ }^{2,3}$

'Consultora Arandu Ka'aty. Trinidad, Itapúa. ${ }^{2}$ Facultad de Ciencias y Tecnologías, Universidad Nacional de Itapúa. Abg. Lorenzo Zacarías № 255 c/Ruta № 1 km 2.5. Encarnación, Paraguay. ${ }^{3}$ CEDIT, Centro de Desarrollo
Innovación Tecnológica. Km 38 ruta 6 "Dr. Juan León Mallorquín”, Hohenau, Departamento de Itapúa, CP 6290, Paraguay

La yerba mate, concentra su producción principalmente en los departamentos de Itapúa y Guairá. Este cultivo es afectado por diferentes patógenos que pueden causar la disminución de la producción y hasta incluso la muerte de la planta. En yerbales de la zona de Pireca, distrito de Independencia, fueron identificadas plantas muertas y otras con necrosis en ramas. El objetivo de este trabajo fue aislar e identificar posibles hongos fitopatógenos causantes de la necrosis en ramas de yerba en el distrito de Independencia. Para ello, se tomaron ramas con necrosis de una planta ubicada en un predio productivo. Se realizaron cortes longitudinales de la muestra y se tomaron tres porciones de aproximadamente $3 \mathrm{~mm}$ de diámetro, se desinfectaron con agua destilada estéril, hipoclorito de sodio al $5 \%$, alcohol al 70 $\%$ y agua destilada estéril, sucesivamente, durante 10 segundos, luego se colocaron en cajas Petri con Papa Dextrosa Agar (PDA), este procedimiento fue realizado por triplicado. Las placas fueron incubadas por 7 días a $28{ }^{\circ} \mathrm{C}$. Se registraron las características de las colonias y el diámetro de las mismas, posteriormente se extrajeron estructuras reproductivas para su observación microscópica. Se obtuvieron colonias cuyas características eran compatibles con el género Fusarium sp. Se confirmó la obtención de cultivos monospóricos mediante la observación al microscopio, las características de las hifas y esporas permitieron identificar a Fusarium sp. como único género presente. Probablemente estos hongos estén relacionados con la necrosis de ramas y muerte de plantas en yerbales. Siendo un patógeno que puede causar grandes pérdidas, es necesario continuar con estudios para llegar a nivel de especie y determinar su patogenicidad. 
CONSEJONACIONA

DE CIENCIA

\section{DETECCIÓN DE Pyricularia oryzae PATOTIPO Triticum EN MALEZAS} POÁCEAS MEDIANTE MARCADORES MOLECULARES

Alvarenga Cañiza, L.V ${ }^{1}$, Cardozo Téllez, L. M. ${ }^{2}$, Chávez, A.R. ${ }^{1}$, Kohli, M.M. ${ }^{1}$

'Cámara Paraguaya de Exportadores y Comercializadores de Cereales y Oleaginosas CAPECO ${ }_{2}^{2}$ Instituto Paraguayo de Tecnología Agraria IPTA, Paraguay.

\begin{tabular}{|c|c|c|c|}
\hline $\begin{array}{l}\text { CONSEJONACIONAL } \\
\text { DE CIENCIA }\end{array}$ & PR\&CIENCIA & (5) San Carlos & Feei \\
\hline
\end{tabular}

\section{TASA DE CRECIMIENTO DE CEPAS DE Trichodema asperellum $Y$ Trichoderma spp. A DIFERENTES TEMPERATURAS Y pH.}

Rodríguez, P ${ }^{1}$. ; Amarilla, F. ${ }^{1}$; Bobadilla, N. ${ }^{1}$; Reyes, M. ${ }^{1}$; Leguizamón, G. ${ }^{2}$

IInstituto Paraguayo de Tecnología Agraria-Capitán Miranda- Itapuá Facultad de ciencias Agrarias Universidad Católica Hohenau- Itapuá, Paraguay.

Los hongos pertenecientes al género Trichoderma, son ampliamente estudiados como biocontroladores, poseen una gran importancia en la agricultura por su capacidad antagónica que ejerce sobre fitopatógenos. La capacidad de crecimiento de los hongos depende de factores como $\mathrm{pH}$ y temperatura entre otros. El objetivo fue evaluar la tasa de crecimiento (TC) de aislados de Trichoderma asperellum y Trichodema spp. del Laboratorio de Control Biológico del IPTA de Capitán Miranda, expuestas a diferentes temperaturas y $\mathrm{pH}$. Se utilizaron dos aislados de T. asperellum denominados MS12 y MS19 y un aislado de Trichodema spp. denominado TyE. Los aislados fueron inoculados en medio de cultivo PDA a $\mathrm{pH} 4,5$ y 6 y fueron colocados a temperaturas de $25^{\circ} \mathrm{C}$ y $28^{\circ} \mathrm{C}$. El diseño experimental fue consistió en bloques completos al azar con tres repeticiones. Se midió la TC a las 24, 48, 72 y 96 horas después de la inoculación. Los aislados MS12 y MS19 no presentan diferencias significativas para las diferentes temperaturas y $\mathrm{pH}$, sin embargo, MS12 aumentó levemente su TC $(5,13 \mathrm{~mm} /$ día $)$ a $28^{\circ} \mathrm{C}$ y $\mathrm{pH} 6$, mientras que la TC de MS19 fue máxima $\left(3,62 \mathrm{~mm} /\right.$ día) a $28^{\circ} \mathrm{C}$ y pH 4. La TC del aislado TyE fue estadísticamente diferente a $25^{\circ} \mathrm{C}$; no hubo influencia del $\mathrm{pH}$, sin embargo, presentó una mayor TC $(3.57 \mathrm{~mm} /$ día $)$ a $25^{\circ} \mathrm{C}$ y $\mathrm{pH} 4$. Con estos resultados, se concluye que la temperatura y $\mathrm{pH}$ no afectan la TC de MS12 y MS19. TyE posee mayor $\mathrm{TC}$ a $25^{\circ} \mathrm{C}$, independientemente del $\mathrm{pH}$. 
CONSEJO NACIONAL

DE CIENCIA

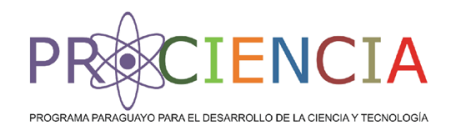

San Carlos

TASA DE CRECIMIENTO DE CEPAS DE Trichodema asperellum $Y$ EVALUACIÓN DE ACTIVIDAD ANTAGÓNICA DE Trichoderma FRENTE A Macrophomina phaseolina Y Fusarium sp.

Rodríguez, P. ${ }^{1}$; Amarilla, F. ${ }^{1}$; Bobadilla, N. ${ }^{1}$; Reyes, M. ${ }^{1}$; Leguizamón, G. ${ }^{2}$

Innstituto Paraguayo de Tecnología Agraria-Capitán Miranda- Itapúa

${ }^{2}$ Facultad de Ciencias Agrarias - Universidad Católica Hohenau- Itapúa, Paraguay.

\begin{tabular}{|c|c|c|c|}
\hline $\begin{array}{l}\text { CONSEOO NACIONAL } \\
\text { DE CIENCIA } \\
\text { Y CONACCNOLOGÍA }\end{array}$ & PR\&CIENCIA & 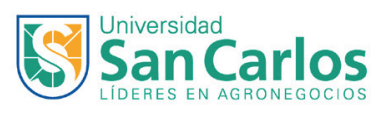 & Feei \\
\hline
\end{tabular}

\section{PATOGENICIDAD DE Pyricularia oryzae PATOTIPO Triticum SOBRE MALEZAS POÁCEAS}

Maldonado Ávalos, R. B.; Alvarenga, L. V. ${ }^{2}$; Kohli, M. M. ${ }^{2}$; Chávez, A. R. ${ }^{2}$.

IUniversidad Católica Nuestra Señora de la Asunción, Unidad Pedagógica de Caacupé; 2 Cámara Paraguaya de Exportadores y Comercializadores de Cereales y Oleaginosas (Capeco), Paraguay.

Pyricularia oryzae patotipo Triticum (Po'T) es el agente causal del brusone del trigo, una enfermedad importante en el país; sin embargo, existe poca información acerca de la capacidad del patógeno de infectar malezas poáceas comunes en los campos de trigo, por lo que es necesario estudiar posibles hospedantes alternativos del hongo. El objetivo fue evaluar la patogenicidad de una cepa de PoT sobre malezas poáceas comunes en los campos de trigo. El trabajo se realizó en el Centro de Investigación Hernando Bertoni, Caacupé. Se utilizó el diseño completamente al azar, donde se inocularon plantas de Cenchrus echinatus, Brachiaria sp., Digitaria horizontalis, Chloris distichophylla, Eleusine indica, Digitaria insularis, Lolium multiflorum, Bromus catharticus y Avena strigosa. Se inocularon 4 plantas de cada especie de maleza con una suspensión de 5.104 conidios $/ \mathrm{ml}^{-1}$, de la cepa de PoT P13-005. Una vez inoculadas las plantas se mantuvieron en una sala climatizada con $28{ }^{\circ} \mathrm{C}$ de temperatura y $80 \%$ de humedad. La evaluación se realizó 15 días después de la inoculación, la que consistió en la toma de fotografías, observación de esporulación mediante el método de cámara húmeda y cultivo de porciones de hojas infectadas en medio PDA. Entre los resultados se observó la aparición de síntomas en hojas de A. strigosa, E. indica, C. distichophylla, B. catharticus y D. horizontalis; también se observó el crecimiento micelial del hongo en muestras sembradas en medio PDA, de estas especies; mientras que, en muestras puestas en cámara húmeda, se observaron conidios de PoT en muestras de $D$. horizontalis, C. echinatus, C. distichophylla, E. indica, D. insularis, L. multiflorum, B. catharticus y $A$. strigosa. Se concluye que las malezas Digitaria insularis, Lolium multiflorum, Cenchrus echinatus, Avena strigosa, Eleusine indica, Chloris distichophylla, Bromus catharticus y Digitaria horizontalis tienen la capacitad de hospedar al agente causal del brusone del trigo. 
CONSEJONACIONA

DE CIENCIA

APLICACIÓN DE FUNGICIDAS PARA EL CONTROL DE ENFERMEDADES DE SOJA SEGÚN DIFERENTES CRITERIOS DE MONITOREO

Francisco Sander'; Lorena Zacaría Villalba'; Marco Maidana-Ojeda²; Daniela Rosana Pagel'; Guillermo Andrés Enciso Maldonado².

IUniversidad Católica, Itapúa, Paraguay; ²Centro de Desarrollo e Innovación Tecnológica, Itapúa, Paraguay.

Los fungicidas se aplican a la soja generalmente según la ocurrencia de las fases fenológicas. Sin embargo, la soja es susceptible a las enfermedades de final de ciclo (EFC) y a la roya asiática (RAS) en cualquier etapa, por lo que considerar el nivel de inóculo en el ambiente, para tomar la decisión de aplicar fungicidas, reduciría los daños causados por enfermedades. El objetivo fue evaluar el efecto de aplicar fungicidas según distintos criterios de monitoreo de RAS. El experimento se realizó en Natalio, Itapúa, Paraguay. Los criterios fueron no aplicar (testigo) (T1); aplicar según aparición de las fases fenológicas R1, R3 y R5 (calendarizado) (T2); aplicar cuando se detecte $1 \%$ de severidad de roya asiática a través de monitoreo periódico en la parcela (T3); aplicar cuando se detecten seis o más uredosporas cm-2 en el aire por medio de un cazaesporas (T4). Se utilizó el diseño en Cuadrado Latino con cuatro repeticiones. Se evaluó la severidad de EFC y RAS, el peso de mil semillas (PMS) y el rendimiento. Se realizó el análisis de varianza y la prueba de comparación de medias de Tukey al $5 \%$. Existió diferencia significativa entre tratamientos para las EFC, RAS y PMS. T2 y T4 redujeron las EFC en 11,4 y 13,9 $\%$, respectivamente, seguido por T3 y T4 con 16,1 y 38,2 \%, respectivamente. La RAS fue menor con T4 y T3 con 2,5 y $2,7 \%$, respectivamente, seguido por T2 y T1 con 3,2 y 7,88 \%, respectivamente. El PMS de T2, T3 y T4 fue de 172,0, 168,9 y 165,3 g, respectivamente, superiores a T1 con 156,9 g. El rendimiento no fue significativo y osciló entre 1631 a $2238 \mathrm{~kg}$ ha-1. Con los criterios T3 y T4 la severidad de RAS es menor y con T2 se obtiene menor EFC y mayor PMS.
CONSEJONACIONAL

EVALUACIÓN DE LA RESISTENCIA A Pyricularia oryzae PATOTIPO

Triticum DE GENOTIPOS DE TRIGO SIN LA TRANSLOCACIÓN 2NS/2AS EN CONDICIONES DE CAMPO E INVERNADERO

Ortiz Ruiz Díaz, M. E.; Reyes Caballero, Y. M.'; Alvarenga, L. V. ${ }^{3}$; Kohli, M. M. ${ }^{3}$; Chávez, A. R. ${ }^{3}$.

'Universidad Católica Nuestra Señora de la Asunción, Unidad Pedagógica de Caacupé; 2Instituto Paraguayo de Tecnología Agraria (IPTA); ${ }^{3}$ Cámara Paraguaya de Exportadores y Comercializadores de Cereales y Oleaginosas (Capeco), Paraguay.

Las variedades nacionales de trigo actualmente poseen una única fuente de resistencia a Pyricularia oryzae patotipo Triticum (Pot), la translocación 2NS/2AS. Por lo que es necesario ampliar la base de resistencia del programa de mejoramiento. El objetivo fue evaluar la resistencia a (Pot) de genotipos de trigo que no poseen la translocación 2NS/2AS en condiciones de campo e invernadero. En el Centro de Investigación Hernando Bertoni, se inocularon 42 genotipos de trigo, con una suspensión de 5.104 conidios $/ \mathrm{ml}$ formada por 4 cepas de (Pot). Se evaluó el tipo de reacción en espiga con una escala (0-4), y se clasificaron los genotipos de acuerdo con la moda del tipo de síntoma como sigue: resistentes (0-1), moderadamente resistentes (2), moderadamente susceptibles (3) y susceptibles (4). La inoculación se realizó al momento de espigazón; se inocularon 10 espigas de cada genotipo en cada ambiente. La evaluación se realizó 15 días luego de la inoculación. En invernadero, una vez asperjadas las plantas se mantuvieron a $25^{\circ} \mathrm{C}$ y $80 \%$ de humedad por 24 horas. Luego, a la misma temperatura, con $60 \pm 10 \%$ de humedad, hasta la evaluación. En campo, se aplicó riego por aspersión dos horas antes de la inoculación para elevar la humedad ambiental. Tras la aspersión, las espigas fueron cubiertas con una bolsa de polietileno. Las bolsas fueron retiradas 16 horas después de la inoculación. Posteriormente se siguió aplicando riego durante 20 minutos/día, hasta la evaluación. Se observó que 12 genotipos fueron resistentes y 3 fueron susceptibles tanto en campo como en invernadero. Los demás genotipos evaluados presentaron discrepancia en su comportamiento, siendo resistentes en campo, pero susceptibles en invernadero y viceversa. Los 12 genotipos resistentes en ambos ambientes deben estudiarse con detalle para utilizarlos en los programas de mejoramiento y ampliar la base de resistencia de las variedades nacionales. 
CONSEJO NACIONAL

DE CIENCIA

RESISTENCIA A Pyricularia oryzae PATOTIPO Triticum DE LÍNEAS DE TRIGO DE LA FAMILIA CANINDE 2/MILÁN

Bobadilla, C. A.; Reyes Caballero, Y. M. ${ }^{2}$; Alvarenga, L. V. ${ }^{3}$; Kohli M. M. ${ }^{3}$; Chávez, A. R. ${ }^{3}$.

'Universidad Católica Nuestra Señora de la Asunción, Unidad Pedagógica de Caacupé; 'Instituto Paraguayo de Tecnología Agraria (IPTA); 3 Cámara Paraguaya de Exportadores

La Pyricularia del trigo es una enfermedad de gran importancia para el trigo en Paraguay y el mundo, siendo urgente el desarrollo de variedades resistentes. Para ello es necesario evaluar distintas cruzas en las que se combinen resistencia a la enfermedad y características agronómicas. Tal es el caso de las líneas de la familia Caninde 2/Milán. El objetivo fue evaluar la resistencia a Pyricularia oryzae, patotipo Triticum de líneas pertenecientes a la familia Caninde 2/Milán en condiciones de campo. El trabajo se realizó en el Centro de Investigación Hernando Bertoni de Caacupé. Se utilizó un diseño completamente al azar, donde se evaluaron 64 genotipos. Dos horas antes de la inoculación y en los días siguientes se aplicó riego en toda la parcela para mantener la humedad ambiental. Para la inoculación se seleccionaron 10 espigas de cada genotipo, las cuales fueron asperjadas con una suspensión de 5.104 conidios/ml. Luego de la aspersión se cubrieron con bolsitas de plástico, las cuales se retiraron 16 horas después. La evaluación de los síntomas se realizó 15 días después de la inoculación utilizando una escala de clasificación de síntomas de $0-4$, siendo los genotipos clasificados en resistente (0-1), moderadamente resistente (2), moderadamente susceptible (3) y susceptible (4). Donde se observó que 35 genotipos fueron resistentes, 9 moderadamente resistentes y 20 susceptibles. Mostrando que existe potencial en la familia Caninde 2/Milán para el desarrollo de nuevas variedades con resistencia al hongo. En conclusión, las líneas de la familia Caninde 2/Milán son en su mayoría resistentes, por lo que podrían incorporarse a programas de mejoramiento para el desarrollo de variedades con resistencia a Pyricularia oryzae patotipo Triticum.

\begin{tabular}{|c|c|c|}
\hline $\begin{array}{l}\text { CONSEJO NACIONAL } \\
\text { DE CIENCIA } \\
\text { IIENOA }\end{array}$ & PR\&CIENCIA & 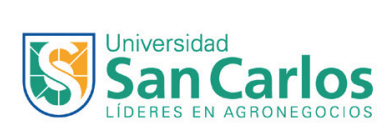 \\
\hline
\end{tabular}

\section{CUANTIFICACIÓN DE CONIDIOS DE Pyricularia oryzae EN HOJAS DE TRIGO DURANTE EL CICLO 2018}

Chávez, A. R.'; Cazal, C. ${ }^{2}$; Kohli, M. M.'; Carmona, M. A. ${ }^{3}$.

'Cámara Paraguaya de Exportadores y Comercializadores de Cereales y Oleaginosas (Capeco); ${ }^{2}$ Centro Multidisciplinario de Investigaciones Tecnológicas (Cemit), Universidad Nacional de Asunción (UNA), Paraguay. ${ }^{3}$ Facultad de Agronomía, Universidad de Buenos Aires (UBA), Argentina.

Pyricularia oryzae patotipo Triticum (PoT) es un patógeno importante para el trigo. Los síntomas en hojas de trigo no son tan evidentes en el campo; sin embargo, se considera que las mismas son una potencial fuente de inóculo. Por ello es necesario estudiar este aspecto epidemiológico de la enfermedad. El objetivo fue cuantificar los conidios de PoT en hojas de trigo durante el ciclo del cultivo en campos comerciales. Se realizaron muestreos mensuales durante el 2018, en tres campos comerciales de los departamentos de Canindeyú, Alto Paraná e Itapúa. Se colectó la hoja más vieja, tomando 10 hojas en 10 puntos al azar en cada campo. Las hojas de cada punto fueron secadas a temperatura ambiente, separadas en grupos de 5 hojas, pesadas, cortadas en trozos de $1,5 \mathrm{~cm}$, y puestas en cámara húmeda en placas de petri por tres días a $25^{\circ} \mathrm{C}$. Luego fueron colocadas en tubos de ensayo con $5 \mathrm{ml}$ de solución de Tween 20 al 0,01\%, los cuales fueron agitados utilizando vortex. El conteo fue realizado empleando un hematocitómetro, tomando una muestra de $100 \mu \mathrm{L}$ de la suspensión, realizando cinco conteos por tubo. Los datos fueron expresados en conidios/g de hojas secas, y fueron analizados mediante la prueba de Kruskall-Wallis utilizando el software estadístico PAST v.4.03. Se observaron diferencias significativas en la cantidad de conidios/g de hojas secas en cada departamento. En Canindeyú la media fue de 1.816, en Alto Paraná fue de 287 y en Itapúa de 929. Estas diferencias pudieron deberse a factores ambientales y de manejo agronómico que deben estudiarse con detalle. Se constató que los conidios del hongo se encuentran presentes en las hojas de trigo durante el ciclo de cultivo, por lo que se debe profundizar acerca del rol de las hojas como fuente de inoculo para la enfermedad. 


\section{EFECTO DE EXTRACTOS ORGÁNICOS CONTRA}

Rhizoctonia solani AISLADO DE TOMATE

Ayvar, S. S.', Díaz, N. J. F. ${ }^{2}$, Enciso, M. G. A. ${ }^{2}$, Mena, B. A.', Salmerón, E. J.?

La infección por Rhizoctonia solani es una de las enfermedades más antiguas y de mayor dispersión a nivel mundial. Este hongo causa ahogamiento, cancrosis del tallo, pudrición de raíces, entre otros síntomas. En los últimos años se busca lograr el equilibrio entre el ambiente y la producción, se ha comenzado a utilizar extractos de ajo, ruda, neem, etc., para el control de enfermedades; la presente investigación tuvo como objetivo evaluar el comportamiento de R. solani ante la presencia de compuestos orgánicos in vitro. Se colectaron raíces de tomate en invernadero que presentaban amarillamiento, marchitez y pudrición radical. Se evaluaron cuatro productos comerciales y un tratamiento testigo, $\mathrm{T} 1=$ Capsioil (extracto de chile), T2= Lippoil (extracto de Lippia spp.), T3= Cinnoil (extracto de canela), T4= Regalia Maxx (extracto de Reynoutria spp.), T5= testigo. Al momento de agregar el medio de cultivo a cada una de las cajas Petri, se adicionó la dosis correspondiente recomendada por el fabricante de cada producto. Una caja Petri de plástico constituyó cada unidad experimental en un arreglo completamente al azar con cuatro repeticiones, los datos se sometieron a un análisis de varianza y prueba de Tukey $(\mathrm{P}=0.05)$. Los extractos presentaron acción fungistática ante el crecimiento de Rhizoctonia solani a partir de la primera medición. Todos los extractos disminuyeron significativamente el crecimiento del hongo; Regalia Maxx presentó una efectividad del 100 \%, Capsioil, Lippoil y Cinnoil inhibieron el crecimiento micelial en 42,9, 42,3 y 42,3\%, respectivamente. Los extractos orgánicos de chile, canela y lippia ejercieron acción fungistática, por otro lado, Reynoutria spp. presentó efecto fungicida ante Rbizoctonia solani.
CONSEJONACIONAL

\section{COMPARACIÓN DE LA EXPRESIÓN DE GENES CODIFICANTES DE \\ PECTINASAS EN DOS AISLADOS DE Macrophomina phaseolina CON DISTINTOS GRADOS DE VIRULENCIA \\ DURANTE LA INFECCIÓN DE SOJA}

Arévalos, A. R., *; Orrego, A.'; Ortiz, B.'; Galeano, J.'; Kohli, M. M..; lehisa, J. C. M.1

'Departamento de Biotecnología, Facultad de Ciencias Químicas, Universidad Nacional de Asunción, San Lorenzo Paraguay; 'Cámara Paraguaya de Exportadores y Comercializadores de Cereales y Oleaginosas (Capeco), Asunción, Paraguay.

Macrophomina phaseolina es uno de los patógenos fúngicos necrotróficos más devastadores a nivel mundial caracterizado por afectar a varios cultivos de importancia económica, entre ellos, la soja (Glycine max). Los hongos necrotróficos causan la muerte de las células del huésped mediante la secreción de toxinas y enzimas, para luego nutrir de sus restos. Sin embargo, no se ha demostrado cuáles de las enzimas implicadas en la degradación de la pared celular vegetal son fundamentales para la patogénesis de este hongo. Uno de los componentes importantes de la pared celular es la pectina. El objetivo del trabajo fue comparar la expresión de genes codificantes de pectinasas en dos aislados del hongo con distintos grados de virulencia. Primeramente, se realizó la búsqueda de genes codificantes de pectinasas en el genoma de $M$. phaseolina donde se encontraron 21 genes, de los cuales 16 contenían péptido señal necesario para su secreción. Para el análisis de expresión, dos aislados de $M$. phaseolina fueron inoculados en raíces de plántulas de soja cultivadas en medio Hoagland con agar. El ARN fue extraído de las raíces infectadas a los 2 y 4 días posinoculación (dpi), y del hongo no expuesto a las raíces como control. De los seis genes analizados mediante la reacción en cadena de la polimerasa con retrotranscripción (RT-qPCR), cuatro presentaron mayor expresión a los $4 \mathrm{dpi}$, mientras que dos fueron mayormente expresados a los 2 dpi. Los niveles de expresión de estos dos últimos genes fueron significativamente superiores en el aislado más virulento, sugiriendo su contribución en la virulencia del hongo. Los resultados del presente trabajo pueden contribuir en la dilucidación del mecanismo implicado en la variación de la virulencia entre los aislados de $M$. phaseolina. 
CONSEJONACIONA

EFECTO in vitro DE PRODUCTOS BOTÁNICOS Y QUÍMICOS CONTRA Colletotrichum gloeosporioides Penz. PATÓGENO DE YACA (Artocarpus hetorephyllus)

Hernández, G. A.; Ayvar, S. S.'; Díaz, N. J. F.'; Mena, B. A.; Apáez, B. M. ${ }^{2}$.

'Centro de Estudios Profesionales del Colegio Superior Agropecuario del estado de Guerrero; 2Universidad Michoacana Sapn Nicolás de Hidalgo, México.

La antracnosis es causada por Colletotrichum gloeosporioides y es un patógeno que puede afectar hojas, ramas y frutos; ocasionando el mayor daño en este último en diferentes frutos tropicales. Es por eso que la presente investigación tuvo como objetivo evaluar productos químicos y orgánicos in vitro contra C. gloeosporioides aislada del cultivo de jaca. Los tratamientos estudiados fueron: T1 = Aradirachta indica + Cinnamomum zeylanicu (PROGRANIC ${ }^{\circledR}$ NeemAcar), T2= Reynoutria sachalinensis (Regalia Maxx ${ }^{\circledR}$ ), T3= Extracto de gobernadora + Larrea tridentata (Progranic ${ }^{\circledR}$ Mega), T4= cyprodinil + fludioxonil $\left(\right.$ Switch $\left.^{\circledR}\right)$, T5= piraclostrobina $\left(\right.$ Headline $\left.^{\circledR}\right), \mathrm{T} 6=$ fluopiram + tebuconazole $\left(\right.$ Luna Experence $\left.{ }^{\circledR}\right), \mathrm{T} 7=$ procloraz $\left(\right.$ Sportak $\left.^{\circledR}\right), \mathrm{T} 8=$ oxicloruro de cobre $\left(\mathrm{Oxicob}^{\circledR}\right)$, T9 $=$ mancozeb (Manzate $\left.200 \mathrm{WP}^{\circledR}\right), \mathrm{T} 10=\operatorname{captan}\left(\right.$ Captan $\left.50 \mathrm{PLUS}^{\circledR}\right)$, T11 $=$ clorotalonil (Talonil 720 $\left.\mathrm{SC}^{\circledR}\right)$ y T12= Testigo; con $20 \mathrm{ml}$ de PDA envenenado por cada caja Petri; se utilizó un diseño completamente al azar con 5 repeticiones. Se midieron las colonias de Colletotrichum en cm por día utilizando una regla. A los datos de la variable de estudio se le realizó un análisis de varianza y una prueba múltiple de medias por el método de Tukey con el software estadístico SAS. Los análisis de varianza evidenciaron que los tratamientos con extractos prestaron una acción fungistática, ante el crecimiento de Colletotrichum gloeosporioides Penz, destacando el producto PROGRANIC ${ }^{\circledR}$ NeemAcar por presentar un $100 \%$ de efectividad, los productos Regalia Maxx ${ }^{\circledR}$ y Progranic ${ }^{\circledR}$ Mega presentaron una inhibición del 75, $37 \%$, respectivamente. Los productos químicos Headline ${ }^{\circledR}$, Luna Experence ${ }^{\circledR}$, Sportak $^{\circledR}$, Oxicob ${ }^{\circledR}$, Manzate 200 WP $^{\circledR}$ y Captan 50 PLUS $^{\circledR}$ presentaron un 100 $\%$ de inhibición miceliar; en cambio, Switch ${ }^{\circledR}$ y Talonil 720 SC $^{\circledR}$ presentaron 75 y $76 \%$ respectivamente. De acuerdo con los resultados obtenidos, PROGRANIC ${ }^{\circledR}$ NeemAcar resultó ser eficaz inhibidor de Colletotrichum gloeosporioides en el cultivo de jaca y con esto ayudar a disminuir la contaminación con productos químicos.
CONSEJONACIONAL

\section{EFECTO DE Meloidogyne sp. EN COMBINACIÓN CON DIFERENTES} ESPECIES DE Trichoderma INOCULADOS EN RÁBANO

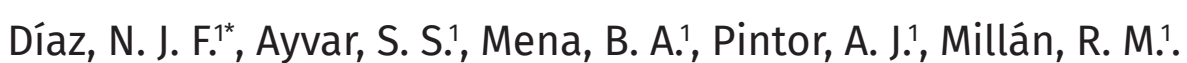

'Colegio Superior Agropecuario del Estado de Guerrero, departamento de Fitotecnia, carretera Iguala-Cocula, km 14,5, Cocula, Guerrero, México.

El nematodo Meloidogyne sp. es uno de los patógenos que ataca a la mayoría de las hortalizas lo que provoca pérdidas severas. El objetivo de esta investigación fue evaluar el efecto de Meloidogyne sp. en la inoculación en plantas sanas de rábano en combinación con diferentes cepas de Trichoderma spp. El experimento se realizó en invernadero bajo un diseño de bloques al azar con 8 tratamientos y 4 repeticiones, una unidad experimental consistió en una maceta de 4,5 kg de capacidad, los tratamientos utilizados son las siguientes: $\mathrm{T} 1=$ Testigo $+M$. incognita, $\mathrm{T} 2=$ Trichoderma sp. cepa nativa de Cocula $+M$. incognita, $\mathrm{T} 3=$ Trichoderma virens $\mathrm{PHC}$ RootMate ${ }^{\circledR}+M$. incognita, $\mathrm{T} 4=$ Trichoderma sp. cepa nativa de Chilapa + M. incognita, $\mathrm{T} 5=$ Testigo, $\mathrm{T} 6=$ Trichoderma $\mathrm{sp}$. cepa nativa de Cocula, $\mathrm{T} 7=$ Trichoderma virens PHC RootMate ${ }^{\circledR}$ y T8 = Trichoderma sp. cepa nativa de Chilapa, a los tratamientos $\operatorname{con} M$. incognita se inocularon 3000 huevos a los 4 días después del trasplante. Las variables de estudio fueron número de hojas $(\mathrm{NH})$, peso del follaje fresco (PFF) y seco (PFS), longitud de raíz principal (LRP) y peso de bulbo más raíz (PB+R). Los datos obtenidos de las variables respuesta se les realizó un análisis varianza y de comparación de medias Tukey $(\alpha=0,05)$. Se encontró que con los tratamientos T1 y T4 se obtuvo mayor NH y PFF con 6,7 y 6 para el número de hojas, mientras que para el PFF con 24,3 y 23,6 respectivamente, en cuanto a $\mathrm{PB}+\mathrm{R}$ la mayor fue en el T5 con 130,3 gramos y la menor la obtuvieron los tratamientos T2, T3 y T6 con 64,6, 61 y 67,8 respectivamente, el peso de bulbo con la raíz tuvo un efecto estadísticamente significativo cuando no se aplicó $M$. incognita o alguna especie de Trichoderma. 
CONSEJONACIONAL

\section{EFECTIVIDAD DE FUNGICIDAS QUÍMICOS Y ORGÁNICOS in vitro}

CONTRA Rhizoctonia solani

Ayvar, S. S., Díaz, N. J. F. ${ }^{*}$, Pintor, A. J.', Mena, B. A.1, Anicasio, A. B. ${ }^{1}$

'Colegio Superior Agropecuario del Estado de Guerrero, departamento de Fitotecnia,

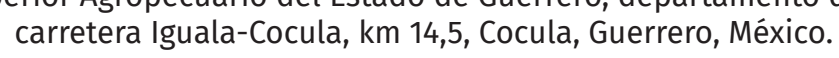

\begin{tabular}{|c|c|c|c|}
\hline $\begin{array}{l}\text { CONSEJONACIONAL } \\
\text { DE CIENCIA } \\
\text { Y } \\
\text { YTECNOLOGÍA }\end{array}$ & PR & 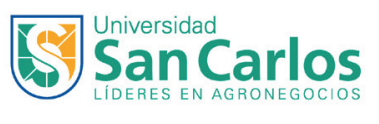 & Fee; \\
\hline
\end{tabular}

\section{CONTROL QUÍMICO Y BIOLÓGICO DE Rhizoctonia solani (Kühn) EN FRUTOS DE CALABAZA PIPIANA EN INVERNADERO}

Díaz, N. J. F.", Ayvar, S. S.', Mena, B. A.', Pintor, A. J.?

'Colegio Superior Agropecuario del Estado de Guerrero, departamento de Fitotecnia, carretera Iguala-Cocula, km 14,5, Cocula, Guerrero, México.
El tomate es afectado por diversas enfermedades, las cuales no le permiten alcanzar su potencial productivo, entre esas enfermedades está la pudrición radical del tomate causada por el hongo Rhizoctonia solani, la cual provoca pérdidas importantes en el rendimiento. El objetivo de esta investigación fue evaluar in vitro la efectividad de productos orgánicos y químicos para el control de $R$. solani. El estudio se realizó en el laboratorio de fitopatología del Csaegro. Se estableció un diseño completamente al azar con diez tratamientos y cinco repeticiones. Como unidad experimental se utilizó una caja Petri de $8,5 \mathrm{~cm}$ de diámetro y $1,5 \mathrm{~cm}$ de altura con un medio de cultivo PDA envenenado con las dosis recomendadas por el fabricante. De esa manera se generaron los siguientes tratamientos: (T1) Testigo, (T2) Captan 50 Plus $^{\circledR}$, (T3) Manzate $200 \mathrm{WP}^{\circledR}$, (T4) extracto de ajo, (T5) Antrax $^{\circledR},\left(\right.$ T6) Neemax ${ }^{\circledR},\left(\right.$ T7) extracto de canela, (T8) Ziner ${ }^{\circledR},\left(\right.$ T9) Prosal $^{\circledR}$ y (T10) Cupravit $^{\circledR}$. Se evaluó el efecto de los tratamientos midiendo el diámetro de las colonias cada 24 horas durante 4 días, los datos obtenidos fueron analizados en SAS. Los tratamientos con el $100 \%$ de inhibición corresponden al T2, T3, T5, T8, T9 y T10 respectivamente, mientras que los tratamientos con menor porcentaje de inhibición fueron el T4, T6 y T7 con $90 \%$, $65 \%$ y $64 \%$. Los fungicidas y productos orgánicos utilizados exhibieron acción fungicida y fungistática contra R. solani en condiciones in vitro.
Rhizoctonia solani Kühn es un hongo habitante del suelo con capacidad saprofítico. En cucurbitáceas es una enfermedad de gran importancia por las pérdidas severas que provoca, sin embargo, existe dificultad para combatirlo eficientemente debido a su capacidad de persistir mediante la formación de microesclerocios. El objetivo de la investigación fue evaluar alternativas químicas y biológicas en el control de R. solani sobre frutos de calabaza pipiana (Cucurbita argyrosperma) en invernadero. El experimento se realizó bajo un diseño completamente al azar con 7 tratamientos y 5 repeticiones, una unidad experimental consistió de cuatro frutos tiernos de calabaza pipiana de $150 \mathrm{~g}$ cada una, los tratamientos utilizados fueron los siguientes: $\mathrm{T} 1=$ Trichoderma asperellum cepa Csaegro, $\mathrm{T} 2=\mathrm{Phc}^{\circledR}$ Biopak- $F^{\circledR}$ (Bacilus spp., Streptomyces spp., Trichoderma spp.), T3= Phc ${ }^{\circledR}$ RootMate $^{\circledR}$ (Trichoderma virens cepa G-41), T4= Q 2000 (iodo libre), T5= Benomil (benomilo $50 \%$ ), T6= Pentaclor* $600 \mathrm{~F}$ (quintozeno: PCNB $46 \%$ ) y T7= Testigo, con las dosis recomendadas por el fabricante. Se realizó primeramente la aplicación de los tratamientos asperjando sobre la superficie de los frutos con un gasto de agua de $300 \mathrm{~L}$ ha-1, posteriormente se esperó 5 horas para permitir la reentrada de los productos, después se asperjó $2,5 \mathrm{~mL}$ de la concentración de $5 \times 106 \mathrm{UFC} \mathrm{mL}^{-1} \mathrm{de}$ R. solani. La variable evaluada fue los días a la presencia del patógeno. Se realizó un análisis varianza y de comparación de medias de Tukey $(\alpha=0.05)$. Se encontró que el T5 obtuvo mayor tiempo de retraso en la presencia de R. solani, con 5,83 días, mientras que en los tratamientos T1, T2, T3, T4, T6 y T7 solo retardaron con 4,6, 4,5, 4,9, 5,0, 5,2 y 4,4 días respectivamente, el ingrediente activo quintozeno (pentacloronitrobenceno), fue el más eficaz al controlar y retardar la presencia de R. solani, en frutos de calabaza pipiana en invernadero. 


\section{ACTINOMICETOS Y SU EFECTO ANTAGÓNICO CONTRA PATÓGENOS CAUSANTES DE PUDRICIÓN POSCOSECHA EN FRUTILLA (Fragaria $x$ ananassa Duch.)}

Pintos Olmedo, A.B.'; Grabowski Ocampos, C.J.1; Soilán Duarte, L.C.1.

Las pudriciones poscosecha en frutilla causan pérdidas en términos de rendimiento y calidad de los frutos. Las principales son de etiología fúngica; Botrytis cinerea $(\mathrm{Bc})$, Pestalotiopsis longisetula (Pl) y Colletotrichum acutatum (Ca), los mismos representan un problema para la producción de frutilla. El control químico no es viable por seguridad alimentaria y que el uso de esta estrategia puede propiciar la resistencia de patógenos. El control biológico de enfermedades surge como alternativa. El objetivo de la investigación fue evaluar el efecto antagónico in vitro de actinomicetos ante patógenos fúngicos causantes de pudrición poscosecha en frutilla. El experimento se llevó a cabo en el Laboratorio de Fitopatología - Área de Protección Vegetal de la FCA-UNA, durante los meses de mayo a julio de 2021. Los patógenos evaluados fueron $\mathrm{Bc}, \mathrm{Ca}$ y $\mathrm{Pl}$, aislados de frutas con síntomas de pudrición y signos del patógeno. Se aislaron actinomicetos de muestras de suelo de zonas productoras de frutilla de Areguá y Caacupé, por el método de dilución seriada en solución peptona al 0,1\% (factor de dilución 4) y siembra en Ágar-Avena (6\% Avena, 1,5\% Agar). Para verificar el antagonismo ejercido por la producción de compuestos antimicrobianos hidrosolubles y volátiles sobre el crecimiento de los patógenos en condiciones in vitro se utilizaron los métodos de cultivo pareado y pareado de placas. Un total de 12 actinomicetos fueron aislados, caracterizados fenotípicamente por el crecimiento en medio selectivo como Streptomyces sp. El aislado SC-6 presentó mejor desempeño, con un porcentaje de inhibición de 38 $\%(\mathrm{Ca}), 23 \%(\mathrm{Pl})$ y $26 \%(\mathrm{Bc})$; redujo el crecimiento del micelio en $20 \%(\mathrm{Pl}, \mathrm{Bc})$ y $3 \%(\mathrm{Ca})$. El aislado SC-6 evidenció características como potencial agente de control biológico. El mecanismo de acción confirmado es de competencia y la producción de compuestos volátiles que reducen el crecimiento micelial de los patógenos.

\section{COMBINACIÓN DE Trichoderma sp. CON FUNGICIDAS Y \\ FITOEXTRACTOS EN EL MANEJO DE Alternaria alternata EN CALABAZA}

Escobar-Bahena, E.'; Díaz-Nájera, J.F.'; Ayvar-Serna, S. ${ }^{3}$; Mena-Bahena, A. ${ }^{4}$.

'Estudiante en el Centro de Estudios Profesionales del Colegio Superior Agropecuario del Estado de Guerrero (CEP-Csaegro); 2,3,4Profesor investigador del CEP-Csaegro, México.

La calabacita (Cucurbita pepo L.) es una hortaliza de importancia en México. Sus propiedades nutricionales y amplia versatilidad otorgan beneficios tanto alimenticios como económicos. Sin embargo, en cada ciclo el cultivo se ve afectado por enfermedades fungosas del género Alternaria sp. El objetivo del estudio fue determinar y comparar la efectividad de fungicidas químicos y botánicos en combinación con Trichoderma sp. en el control de Alternaria alternata inoculado en plantas de calabacita. El estudio se realizó en instalaciones del Colegio Superior Agropecuario del Estado de Guerrero. Durante el mes de agosto del 2020 se colectaron muestras de hojas de calabaza tipo Gray Zucchini que presentaban síntomas característicos de Alternaria sp. en el campo experimental del CEPCsaegro. Después se realizaron los procedimientos correspondientes para su aislamiento e identificación morfológica. Como agentes de control biológico, químico y botánico se utilizaron respectivamente: Trichoderma harzianum; oxicloruro de cobre, Captan, Azoxystrobin, Fluopiram + Tebuconazol; extracto de Neem + extracto de canela, extracto de Reynoutria sachalinensis. Para determinar el efecto integrado de los métodos de control sobre el fitopatógeno se establecieron en un invernadero plantas de calabacita. Se aplicó un control protectante y tres días después se inoculó el hongo de estudio en las unidades experimentales (UE). El porcentaje de severidad se obtuvo a partir de la sintomatología presente en el área foliar de las UE. Para ello, se realizaron cuatro muestreos con intervalos de cinco días en tres hojas de cada planta de calabacita. Los datos obtenidos de la variable de estudio se sometieron a un análisis de varianza y prueba de comparación múltiple de medias utilizando el método de Tukey con un nivel de significancia al $10 \%$. Los mejores tratamientos fueron el T3 (Azoxystrobin + oxicloruro de cobre + Trichoderma harzianum) y T12 (Azoxystrobin + Oxicloruro de cobre) cuando el porcentaje de severidad fue de $2.379 \%$ y $2.606 \%$, respectivamente. Los resultados indican que el control del tizón en calabacita es más eficiente cuando en la integración de los métodos de control se incluye el agente biológico Trichoderma sp. 
CONSEJO NACIONAL

EFECTO DE LA TEMPERATURA Y EL PH SOBRE LA ESPORULACIÓN DE CEPAS NATIVAS DE Trichoderma sp.

Reyes, Y.M*; Rodríguez, P.'; Bobadilla, N; Amarilla, F.; Leguizamón, G.².

IInstituto Paraguayo de Tecnología Agraria (IPTA); 2universidad Católica Nuestra Señora de la Asunción, Facultad de Agronomía, Paraguay.

El género de hongos Trichoderma sp. se constituye en uno de los microorganismos más utilizados para el control biológico de enfermedades como agente promotor del crecimiento en plantas, materia prima para extracción de metabolitos entre otros. La esporulación es un factor muy importante en el proceso de manipulación del microorganismo para su uso en los fines seleccionados. El proceso de formación de esporas está condicionado a factores abióticos como la temperatura y $\mathrm{pH}$ del medio empleado, esto hace necesario establecer las condiciones óptimas para la esporulación del hongo y garantizar la disponibilidad de concentración suficiente de células para las aplicaciones correspondientes. Con el objetivo de evaluar la esporulación de cepas nativas de Trichoderma sp. bajo la influencia de condiciones de temperatura y $\mathrm{pH}$ del medio de cultivo, se seleccionaron tres cepas y se sembraron en medio de cultivo papa-dextrosa-agar ajustando los $\mathrm{pH}$ a $4 ; 5$ y 6 . El experimento fue realizado por triplicado y las cepas fueron mantenidas a 25 y 28 ${ }^{\circ} \mathrm{C}$. Se realizó el conteo de esporas con la cámara de Neubauer a los 10 días después de la inoculación. Los datos fueron sometidos a análisis de varianza (ANOVA) y comparación de medias por el test de Tukey. con el software estadístico InfoStat. Se presentaron diferencias en la esporulación de las cepas siendo el pH 5 el que presentó el mayor número ( $>800.000 .000$ esporas por mililitro de suspensión) de esporas para las tres cepas evaluadas. En cuanto a la temperatura se observó que a $28^{\circ} \mathrm{C}$ se establece una condición más favorable para la esporulación. El proceso de esporulación de las cepas de Trichoderma sp. testadas en el experimento se ve optimizado a una temperatura de $28^{\circ} \mathrm{C}$ y un $\mathrm{pH}$ de 5 . Se logró determinar que bajo estas condiciones de $\mathrm{pH}$ y temperatura se estimula la formación de esporas en el hongo. Con estas observaciones se hace posible optimizar el proceso de producción de biomasa para el hongo biocontrolador y así garantizar la disponibilidad en cantidad suficiente para las aplicaciones correspondientes ya sea a escala laboratorio a en campo.

\begin{tabular}{|c|c|c|c|}
\hline $\begin{array}{l}\text { CONSEJO NACIONAL } \\
\text { DE CIENCIA } \\
\text { DE } \\
\text { YTECNOLOGÍA }\end{array}$ & PRßCIENCIA & 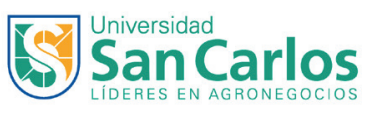 & Feei \\
\hline
\end{tabular}

HONGOS ENDÓFITOS PRESENTES EN ESPECIES SILVESTRES DE Arachis EN PARAGUAY: ALUMBRA UN POTENCIAL BIOCONTROLADOR DE AGENTES FITOPATÓGENOS

Resquín-Romero, G. ${ }^{1 *}$; Macchi-Leite, G.*; García-López, T.2.; Moral, J..2; Seijo, J. G. ${ }^{3}$

'Facultad de Ciencias Agrarias, Universidad Nacional de Asunción (FCA, UNA), San Lorenzo, Paraguay; Universidad de Córdoba, España - Instituto de Botánica del Nordeste (UNNE-Conicet) y ${ }^{3}$ Facultad de Ciencias Exactas y Naturales y Agrimensura, Universidad Nacional del Nordeste, Corrientes, Argentina.

Las plantas albergan diversas comunidades de especies de hongos en sus tejidos internos llamados endofíticos que pueden ayudar a las plantas a mostrar mayor persistencia frente a condiciones adversas. Su presencia representa potencialidades para el control biológico, principalmente para aquellos agentes fitopatógenos asociados a su huésped. El objetivo del presente trabajo fue realizar una prospección de hongos endófitos presentes en especies silvestres de maní conservadas ex situ en la Colección Nacional de Arachis de Paraguay (FCA, UNA). Se tomaron muestras de tallos y hojas con síntomas de enfermedades de plantas cultivadas en invernáculo y procesadas en el Laboratorio de Protección Vegetal, durante los años 2020-2021. Para inducir el crecimiento fúngico, se utilizó el método de cámara húmeda, previa desinfestación de las muestras. Para el aislamiento se utilizaron medios PDA selectivo y agar agua (2\%). Se realizó la identificación morfológica y molecular de los aislados por amplificación (PCR) de las regiones génicas ITS, $\beta$-tubulina (BTUB), Calmodulina (CMD) y/o Factor de elongación (EF). La identificación molecular se realizó por comparación (Blast) de los amplicones con la base de datos del NCBI. Se analizaron un total de 115 fragmentos entre tallos y hojas y se aislaron 121 hongos, de los cuales $3 \%$ fueron identificados como hongos endofíticos biocontroladores ascomicetos en un total de $3 \%$ de las accesiones. Tres aislados se identificaron a nivel de especies, Arcopilus cupreus (Sordariomicetos, Chaetomiaceae), que fueron aisladas de hojas y tallos asociadas a síntomas de antracnosis (Colletotrichum siamense). Se aplicó el postulado de Koch para recuperar nuevamente el hongo de plantas inoculadas artificialmente. En conclusión, se reporta por vez primera la especie Arcopilus cupreus como hongo endófito asociada a plantas silvestres de arachis con potencial biocontrolador de agentes fitopatógenos. Esta información es relevante para su evaluación frente a agentes fitopatógenos del maní en Paraguay. 
EFECTOS DE LA DESINFESTACIÓN ANAERÓBICA SOBRE ALGUNAS CARACTERÍSTICAS FÍSICO-QUÍMICAS DEL

\section{SUELO EN PARAGUAY}

Sanabria-Velázquez, Andrés D.; Enciso-Maldonado, Guillermo A.

La desinfestación anaeróbica de suelos (DAS) es una técnica en la que se incorporan fuentes de carbono (FC) como afrecho de trigo (ADT) y/o melaza, que son aprovechadas por bacterias anaeróbicas para la producción de ácidos grasos volátiles, que se acumulan en el suelo y son tóxicos para patógenos. Anteriormente, fue comprobado que la DAS es eficaz contra Sclerotinia sclerotiorum, sin embargo, no se conoce su efecto sobre las propiedades físico-químicas del suelo. Se evaluó el efecto de la DAS sobre las propiedades físico-químicas del suelo en Yguazú, Paraguay. Se hizo un experimento en bloques completos al azar con 5 repeticiones, donde se incorporó a las parcelas 20,2 Mg/ha de ADT (T1), 10,1 Mg/ha de melaza (T2), la combinación de T1+T2 (T3). Luego las parcelas fueron saturadas con agua hasta capacidad de campo y fueron cubiertas con plástico negro durante 3 semanas. Hubo un testigo anaeróbico saturado con agua y con cobertura plástica (T4) un testigo aerobio sin cobertura; ambos sin FD. Luego de 3 semanas se removió la cobertura plástica y se tomaron muestras de suelo aleatoriamente a 15 $\mathrm{cm}$ de profundidad en cada parcela hasta obtener $1 \mathrm{Kg}$ de suelo y se enviaron al laboratorio para su análisis. Se realizó el ANOVA y la prueba de comparación de medias de Tukey $(5 \%)$. El pH del suelo aumentó significativamente $(\mathrm{p}=0.0001)$ con T1 (7.23) y T3 (7.38) comparadas con los testigos (6.64). Igualmente, la materia orgánica fue significativamente mayor $(\mathrm{p}=0.0002)$ con T1 $(4.62 \%)$ y T3 $(4.85$ $\%$ ) comparadas con las parcelas testigo $(2.86 \%)$. No se observaron diferencias significativas en cuanto al contenido de $\mathrm{K}$ entre parcelas tratadas y testigos $(p=0.109)$. Se registraron valores significativamente menores de $P(p=0.0049)$ con T2 (181.08 mg/LS). La DAS altera las propiedades físico-químicas del suelo, provcando un aumento del $\mathrm{pH}$ y de la materia orgánica cundo se incorpora ADT o ADT+Melaza. Estas FD podrían brindar a los pequeños agricultores una nueva opción para el manejo sostenible de patógenos potencialmente transmitidos por el suelo.

La soja es uno de los cultivos más importante en Paraguay. Su potencial de rendimiento puede ser influenciado por enfermedades como la roya asiática de la soja (RAS); existiendo variedades resistentes y susceptibles, la prevención se basa en la aplicación de fungicidas de diferentes grupos químicos. El objetivo de la investigación fue determinar las frecuencias de aplicaciones de fungicidas para controlar RAS en dos variedades en diferentes estadios del cultivo. Se instaló una parcela experimental con dos variedades de soja, Nidera AG 5909 y Sojapar R24, en el Centro de Investigación Pecuaria de Itapúa, Paraguay. El diseño experimental fue parcela dividida donde la parcela principal fue 2 variedades y la sub parcela tres momentos de aplicación con los siguientes fungicidas: Protioconazole $17,5 \%+$ Trifloxystrobin 15\% (una aplicación en R1), T2: Protioconazole $17,5 \%+$ Trifloxystrobin 15\% (una aplicación en R1) más Bezovindiflupyr 15\% + Azoxystrobin 30\% (una aplicación en R3), T3: Protioconazole 17,5\% + Trifloxystrobin 15\% (una aplicación en R1) más Bezovindiflupyr 15\% + Azoxystrobin 30\% (una aplicación en R3) más Picoxystrobin 9\% + Ciproconazol 4\% (una aplicación en R5) y el testigo. Se evaluó el rendimiento y la severidad de la RAS. Los datos obtenidos fueron analizados mediante ANAVA y la comparación de medias mediante el test de Duncan. Los rendimientos de las dos variedades presentaron diferencia no significativa, aunque la variedad Sojapar R24 superó $240 \mathrm{~kg}$ ha-1 a la variedad Nidera AG 5909, respecto a la severidad se observó que fue mayor en la variedad Nidera AG - 5909 comparado con la variedad Sojapar R24. En conclusión, el mayor rendimiento de la variedad Sojapar R24 superó en $464 \mathrm{~kg}$ ha-1 al rendimiento obtenido con la variedad Nidera AG-5909 aunque la severidad no mostró significancia estadística. 
EFECTO ANTAGÓNICO DE Streptomyces sp. CONTRA PATÓGENOS CAUSANTES DE PUDRICIÓN POSCOSECHA EN FRUTILLA (Fragaria $x$ ananassa Duch.)

Pintos Olmedo, A.B.'; Grabowski Ocampos, C.J.1; Soilán Duarte, L.C.1.

Las pudriciones poscosecha en frutilla causan pérdidas en términos de rendimiento y calidad de los frutos. Las principales son de etiología fúngica; Botrytis cinerea (Bc), Pestalotiopsis longisetula (Pl) y Colletotrichum acutatum (Ca). El control químico no es viable por seguridad alimentaria y el uso de esta estrategia puede propiciar la resistencia de patógenos. El control biológico de enfermedades surge como alternativa. El objetivo de la investigación fue evaluar el efecto antagónico in vitro de actinomicetos ante patógenos fúngicos causantes de pudrición poscosecha en frutilla. El experimento se llevó a cabo en el Laboratorio de Fitopatología - Área de Protección Vegetal de la FCA-UNA, San Lorenzo, Paraguay. Los patógenos evaluados fueron $\mathrm{Bc}, \mathrm{Ca}$ y $\mathrm{Pl}$, aislados de frutas con síntomas de pudrición y signos del patógeno. Se aislaron actinomicetos de muestras de suelo de zonas productoras de frutilla de Areguá y Caacupé, por el método de dilución seriada en solución peptona al $0,1 \%$ (factor de dilución 4) y siembra en Agar-Avena (6\% Avena, 1,5\% Agar). Se utilizaron los métodos in vitro de cultivo pareado y pareado de placas para verificar el antagonismo de compuestos antimicrobianos hidrosolubles y volátiles sobre el crecimiento de los patógenos Un total de 12 actinomicetos fueron aislados, caracterizados todos fenotípicamente por el crecimiento en medio selectivo como Streptomyces sp.; de los cuales el aislado SC-6 presentó mejor desempeño, con un porcentaje de inhibición de $38 \%$ (Ca), $23 \%(\mathrm{Pl})$ y $26 \%(\mathrm{Bc})$; redujo el crecimiento del micelio en $20 \%(\mathrm{Pl}, \mathrm{Bc})$ y $3 \%$ (Ca). El aislado SC-6 evidenció características como potencial agente de control biológico. El mecanismo de acción confirmado es de competencia y la producción de compuestos volátiles que reducen el crecimiento micelial de los patógenos.

\section{CONSEJONACIONAL

EFICACIA DE APLICACIÓN DE DISTINTOS FUNGICIDAS PARA EL CONTROL DE LA ROYA DE LA SOJA (Phakopsora pachyrhizi)

Zimmer, D.; Marafon'; Ortiz, A., 2, 3, Quintana, L.?.

1 Universidad Nacional de Itapúa, Facultad de Ciencias Agropecuarias y Forestales; ${ }^{2}$ Universidad San Carlos, filial Encarnación; ${ }^{3}$ Centro de Desarrollo e Innovación Tecnológica (CEDIT), Paraguay.

La soja es uno de los cultivos más importantes en la agricultura paraguaya. Paraguay es uno de los mayores productores y exportadores de esta oleaginosa La disminución de los rendimientos obtenidos se asocia con distintos factores entre las que se destaca la roya asiática de la soja (RAS). El control químico es una de las alternativas más utilizada para el control de la RAS en el país. La aplicación correcta de los fungicidas resulta como una de las prácticas para la eficiencia en el control, ya que del mismo depende conseguir una buena distribución del principio activo, una buena densidad y un buen tamaño de gotas. Se realizó un experimento con el objetivo de evaluar la eficacia de la aplicación de fungicida (Azoxystrobin $30 \%+$ Benzobindiflupyr $15 \%$ ) con la utilización de diferentes tecnologías para el control de la RAS, comparando distintos volúmenes de caldo, adyuvantes y horarios de aplicación. Se instaló un ensayo en la localidad de Carlos Antonio López, Itapúa, los tratamientos evaluados fueron tres caudales de agua (50, 100 y 150 L ha-1) combinados con dos adyuvantes ( N SOL H2O 10\% + P2O5 SOL $\mathrm{H} 2 \mathrm{O} 10 \%$ y adyuvante mineral parafínico $42,8 \%$ aplicados en dos horas distintas (9:00 y 18:00 horas). Las variables evaluadas fueron: tamaño de gotas cm-2, severidad de la RAS, peso de 1000 granos y rendimiento. El horario de aplicación del fungicida con los distintos caudales de agua y adyuvantes no influyó sobre las variables evaluadas, estadísticamente el rendimiento y la severidad de la RAS no fueron afectados por la combinación de los tratamientos por lo que se considera que la aplicación del fungicida con un caudal de agua de 50 L ha-1 es la más recomendada por ser el caudal de más fácil manejo por el bajo volumen y el de mayor cobertura en los estratos superior e inferior del cultivo. 


\section{SEVERIDAD DE LA ROYA (Phakopsora pachyrhizi Sydow) EN EL CULTIVO DE LA SOJA CON DIFERENTES ESPACIAMIENTOS}

Mattos, J.R'., Aguayo Trinidad, S. Karajallo Figueredo J. C.

EFECTO DEL USO DE FOSFITOS EN EL MANEJO DE ENFERMEDADES DE FINAL DE CICLO EN SOJA (Glycine max [L.] Merril)

Santos, A.V.2; Grabowski, C.J.2; Ayala, L.²; Soilán, L.2; Domínguez, J. ².

2Facultad de Ciencias Agrarias, Universidad Nacional de Asunción, San Lorenzo, Paraguay.

El espaciamiento entre hileras en el cultivo de soja es una variable muy estudiada en la actualidad ya que es una práctica de manejo que influencia directamente en la severidad de la roya (Phakopsora pachyrbizi Sidow). El presente experimento se llevó a cabo en una propiedad privada en el Distrito de Santa Fe del Paraná, Alto Paraná, con el objetivo de evaluar la severidad de la roya en soja, utilizando diferentes espaciamientos con y sin funguicida. Los tratamientos considerados fueron los siguientes: T1: $35 \mathrm{~cm}$ entre hileras con fungicida, T2: $35 \mathrm{~cm}$ entre hileras sin fungicida, T3: $45 \mathrm{~cm}$ entre hileras con fungicida, T4: $45 \mathrm{~cm}$ entre hileras sin fungicida, T5: $55 \mathrm{~cm}$ entre hileras con fungicida, T6: $55 \mathrm{~cm}$. entre hileras sin fungicida, T7: $65 \mathrm{~cm}$ entre hileras con fungicida, T8: $65 \mathrm{~cm}$ entre hileras sin fungicida. El diseño experimental utilizado fue bloques completos al azar con arreglo bifactorial con 8 tratamientos y 4 repeticiones, para la comparación de medias se realizó la prueba de Tukey al 5\%. Se evaluó la variable severidad de la roya. La severidad de la roya en el primer análisis no tuvo diferencia significativa, $(1,8 \%)$ en la segunda, $(10,7 \%)$ en la tercera, y $(15,8 \%)$ en el cuarto, siendo que el espaciamiento de $35 \mathrm{~cm}$ entre hileras el que en todas las observaciones presentó mayor severidad de la roya, para el factor B (fungicida) también proporcionó diferencia altamente significativa, donde la aplicación de fungicida disminuyó notablemente la severidad.

Las enfermedades foliares en soja son la principal causa de las pérdidas en el rendimiento. El uso de fungicidas para el control de estas enfermedades aumenta los costos y propicia la pérdida de sensibilidad de los patógenos a los principios activos de fungicidas, debido a que en esta problemática han ganado espacio los fosfitos como una alternativa para el manejo de enfermedades, debiendo su eficiencia ser comprobada. Esta investigación tuvo como objetivo evaluar la eficiencia de fosfitos en el manejo de enfermedades en soja. El experimento se llevó a cabo en la Facultad de Ciencias Agrarias de la Universidad Nacional de Asunción. El diseño utilizado fue completamente al azar, con un arreglo unifactorial, cuyo factor correspondía a los productos utilizados, formando seis tratamientos con tres repeticiones, las variables evaluadas fueron índice de severidad de roya y las enfermedades de fin de ciclo, contenido de clorofila, rendimiento y peso de mil semillas. Los resultados fueron sometidos a análisis de varianza y a prueba Tukey con $5 \%$ de error. Para la variable severidad y contenido de clorofila no se observaron diferencias significativas; sin embargo, el testigo absoluto fue el que presentó mayor severidad de la mancha causada por Cercospora spp., para la variable rendimiento sí se observaron diferencias significativas, destacándose los tratamientos Fosfito de K + Fungicida y Fosfito de K con valores de $4151 \mathrm{~kg} / \mathrm{ha}$ y $3882 \mathrm{~kg} / \mathrm{ha}$, respectivamente, el testigo absoluto presentó el menor rendimiento con un valor de $2840 \mathrm{~kg} / \mathrm{ha}$. Sobre el peso de mil semillas los tratamientos no tuvieron efectos significativos. Debido a las condiciones no se pudo comprobar la eficiencia de los fosfitos debido a la escasa aparición de enfermedades en el periodo de realización del experimento; sin embargo, los fosfitos sí tienen efectos positivos sobre el rendimiento del cultivo. 
EFICACIA DE APLICACIÓN DE DISTINTOS FUNGICIDAS PARA EL CONTROL DE LA ROYA DE LA SOJA (Phakopsora pachyrizi)

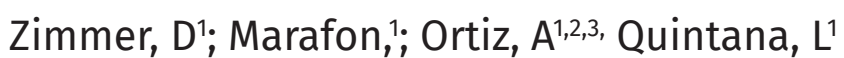

'Universidad Nacional de Itapúa, Facultad de Ciencias Agropecuarias y Forestales. ${ }^{2}$ Universidad San Carlos, Filial Encarnación. ${ }^{3}$ Centro de Desarrollo e Innovación Tecnológica (CEDIT), Paraguay.

La soja es uno de los cultivos más importantes en la agricultura paraguaya, Paraguay es uno de los mayores productores y exportadores de esta oleaginosa. La disminución de los rendimientos obtenidos se asocia con distintos factores entre las que se destaca la roya asiática de la soja (RAS). El control químico es una de las alternativas mas utilizada para el control de la RAS en el país. La aplicación correcta de los fungicidas resulta como una de las prácticas para la eficiencia en el control, ya que del mismo depende conseguir una buena distribución del principio activo, una buena densidad y un buen tamaño de gotas. Se realizó un experimento con el objetivo de evaluar la eficacia de la aplicación de fungicida (Azoxystrobin 30\%+ Benzobindiflupyr 15\%) con la utilización de diferentes tecnologías para el control de la RAS, comparando distintos volúmenes de caldo, adyuvantes y horarios de aplicación. Se instaló un ensayo en la localidad de Carlos Antonio López, Itapúa, los tratamientos evaluados fueron tres caudales de agua $\left(50,100\right.$ y $\left.150 \mathrm{~L} \mathrm{ha}^{-1}\right)$ combinados con dos adyuvantes ( $\mathrm{N}$ SOL $\mathrm{H}_{2} \mathrm{O} 10 \%+\mathrm{P}_{2} \mathrm{O}_{5} \mathrm{SOL} \mathrm{H}_{2} \mathrm{O} 10 \%$ y adyuvante mineral parafínico 42,8\%) aplicados en dos horas distintas (9:00 y 18:00 horas). Las variables evaluadas fueron: tamaño de gotas $\mathrm{cm}^{-2}$, severidad de la RAS, peso de 1000 granos y rendimiento. El horario de aplicación del fungicida con los distintos caudales de agua y adyuvantes no influyó sobre las variables evaluadas, estadísticamente el rendimiento y la severidad de la RAS no fueron afectados por la combinación de los tratamientos por lo que se considera que la aplicación del fungicida con un caudal de agua de $50 \mathrm{~L} \mathrm{ha}^{-1}$ es la más recomendada por ser el caudal de más fácil manejo por el bajo volumen y el de mayor cobertura en los estratos superior e inferior del cultivo.

\begin{tabular}{|c|c|c|c|}
\hline $\begin{array}{l}\text { CONSEJO NACIONAL } \\
\text { DE CIENCIA }\end{array}$ & PR\&CIENCIA & 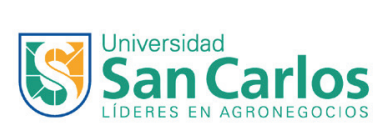 & Fee \\
\hline
\end{tabular}

\section{EFECTO DE ÉPOCAS DE SIEMBRA Y LA APLICACIÓN FOLIAR DE FUNGICIDAS SOBRE LA INCIDENCIA DE Bipolaris oryzae \\ EN SEMILLAS DE ARROZ}

Zelaya Arce, M.S.; Grabowski, C.J.; Soilán, L.C.; Ramírez, H.V.².

'Facultad de Ciencias Agrarias, Universidad Nacional de Asunción, San Lorenzo, Paraguay; ${ }^{2}$ Empresa Arrozal S. A., Coronel Bogado, Itapúa, Paraguay.

Las semillas de arroz son fuente importante de inóculo primario para varios patógenos así como Bipolaris oryzae (Bo), agente causal de la Mancha Parda en arroz. Prácticas culturales como la época de siembra y fungicidas pueden ser estrategias para el manejo de enfermedades. El objetivo de la investigación fue evaluar el efecto de diferentes épocas de siembra y la aplicación de fungicidas en la calidad sanitaria y fisiológica de semillas de arroz. El experimento fue conducido en el laboratorio de Fitopatología del Área de Protección Vegetal de la FCA-UNA. El diseño utilizado fue DCA con 8 tratamientos y 4 repeticiones Se utilizaron semillas IRGA 424, provenientes de la estación experimental de la empresa Arrozal S. A., se cosecharon 10 panículas por tratamiento. Las fechas de siembra fueron las siguientes: $01 / 09 ; 29 / 09,23 / 10,25 / 11$, correspondientes a 1. ${ }^{a}, 2 .^{a}, 3 .^{a}$, y 4. ${ }^{a}$ época, respectivamente, correspondientes a la zafra 2020/2021. Para la detección del patógeno fúngico se emplearon el método de incubación en papel de filtro (Blotter Test) y en medio de cultivo PDA (papa-dextrosa-agar). Se utilizaron 400 semillas por tratamiento, desinfestadas con hipoclorito de sodio 1 $\%$ y enjuagadas con agua destilada esterilizada. La siembra fue en cajas gerbox bajo campana de aislamiento, e incubadas a $25 \pm 2{ }^{\circ} \mathrm{C}$ por 7 días. Se evaluaron la incidencia y germinación. Para el \% de germinación no se observaron diferencias significativas en todos los tratamientos, mientras que, para la incidencia (\%), la menor $(4 \%)$ se observó en la 1. época con protección, mientras que el mayor $\left(46 \%\right.$ ) fue determinado para la $4 .^{a}$ época de siembra sin protección. Por tanto, siembras tardías propician mayor presión de inóculo y aumento de la incidencia de Bo en semillas de arroz; la aplicación de fungicidas redujo en todas las épocas el $\%$ de incidencia. 
CONSEJONACIONAL

INCIDENCIA DE BRUSONE EN LA PANICCULA DE ARROZ IRRIGADO EN DIFERENTES ÉPOCAS DE SIEMBRA

Zelaya Arce, M.S.'; Grabowski, C.J.'; Soilán, L.C.; Ramírez, H.V.².

'Facultad de Ciencias Agrarias, Universidad Nacional de Asunción, San Lorenzo, Paraguay; ${ }^{2}$ Empresa Arrozal S. A., Coronel Bogado, Itapúa, Paraguay.

La enfermedad brusone causada por Pyricularia oryzae es la principal limitante del potencial productivo en el cultivo de arroz irrigado. Prácticas culturales como la época de siembra pueden ser estrategias viables para el manejo de enfermedades. El objetivo del trabajo fue evaluar el efecto de las épocas de siembra sobre la incidencia de brusone. El experimento fue conducido durante la zafra 2020/2021 en la estación experimental de la empresa Arrozal S. A, distrito de Coronel Bogado, departamento de Itapúa. El diseño utilizado fue DBCA con 4 repeticiones, en esquema de parcelas subdivididas. Las parcelas consistieron en las épocas de siembra y las subparcelas en áreas sin protección y con protección con fungicida (ciproconazol + azoxistrobina) a $550 \mathrm{ml} / \mathrm{ha}$. Cada unidad experimental (UE) constó $5 \mathrm{~m} 2$, constituida de 8 hileras de plantas, con una densidad de $80 \mathrm{~kg}$ ha-1 de semillas del cultivar Irga 424. Las fechas de siembra fueron: 01/09, 29/09, $23 / 10,25 / 11$. Se evaluaron la incidencia y el rendimiento. La cuantificación de la enfermedad fue realizada en etapa de maduración, por la presencia de síntomas en panículas contenidas en $1 \mathrm{~m}$ lineal de las líneas centrales de cada UE. No se observaron síntomas de la enfermedad en la $1 .^{\mathrm{a}}, 2 .^{\mathrm{a}}$ y $3 .^{\mathrm{a}}$ época de siembra; mientras que, en la 4. ${ }^{a}$ época de siembra la incidencia aumentó significativamente, en áreas tratadas y no tratadas, en $22,15 \%$ y 56,67 \%, respectivamente. En cuanto a productividad, se obtuvo en las épocas incremento significativo en rendimiento por la aplicación de fungicidas y una reducción de la misma a medida que se retrasa la siembra, especialmente en la 4. ${ }^{a}$ época. Por lo que siembras tardías propician mayor presión de inóculo y aumento de la incidencia de brusone; la aplicación de fungicidas mantiene el potencial productivo independiente de la incidencia de enfermedades y las épocas.

\begin{tabular}{|c|c|c|c|}
\hline $\begin{array}{l}\text { CONSEJO NACIONAL } \\
\text { DE CIENCIA } \\
\text { YTECNOLOGÍA }\end{array}$ & PR\&CIENCIA & (S) Sanversidad Carlos & Fee; \\
\hline
\end{tabular}

\section{CONTROL BIOLÓGICO DEL NEMATODO AGALLADOR DE LA RAíz Meloidogyne incognita EN EL CULTIVO DE MELÓN Cucumis melo (L.)}

Ayvar, S. S.?: Díaz, N.J.F.1: De la cruz, A.J.': Delgado, N. E..2: Mena, B.A.'; Guzmán, G.P.J.?

'Centro de Estudios Profesionales del Colegio Superior Agropecuario del Estado de Guerrero, avenida Vicente Guerrero n.o 81 , Iguala, Guerrero, C.P. 40000; '2Universidad Autónoma,
Facultad de Ciencias Agropecuarias y Ambientales, Iguala, Guerrero, México.

El melón pertenece a la familia de las cucurbitáceas, la cual ocupa el tercer lugar de importancia de esta familia y es afectada por el nematodo agallador Meloidogyne incognita. La presente investigación se llevó a cabo con el fin de evaluar el efecto de cuatro agentes biológicos (Bacillus subtilisis, Bacillus thuringiensis, Myrothecium verrucaria y Paecilomyces lilacinus) contra Meloidog yne incognita. Se utilizó un diseño experimental completamente al azar con 5 tratamientos y 4 repeticiones; es decir, 20 unidades experimentales, cada una estuvo conformada por 2 plantas de melón por maceta con capacidad de 2,5 kg de suelo. En la preparación del inóculo el nematodo fue extraído previamente de plantas de tomate infectadas. La inoculación se llevó acabo aplicando 2 gramos de inóculo de raíces por maceta con un total de 2800 huevecillos por maceta. A los 24 días posteriores a la inoculación se realizaron 4 aplicaciones de los tratamientos biológicos con un intervalo de 7 días entre cada aplicación. Como variables de estudio se tomaron en cuenta el número de huevecillos, agallas y larvas. Los datos se sometieron a un análisis estadístico en el programa SAS. Adicionalmente se realizó una prueba de medias. Se detectaron diferencias estadísticas entre tratamientos para todas las variables. Para el número de huevecillos el tratamiento con Myrothecium verrucaria fue el más sobresaliente; disminuyó la incidencia de huevecillos con respecto al testigo. El tratamiento con Paecilomyces obtuvo el menor número de agallas con 386. Por último, el número de larvas disminuyó con el agente biológico Myrothecium verrucaria. Ninguna de las bacterias y hongos utilizados inhibió por completo el agallamiento provocado por Meloidogyne en el cultivo de melón. Los agentes biológicos Bacillus subtilisis, Bacillus thuringiensis, Myrothecium verrucaria y Paecilomyces lilacinus afectan la reproducción de Meloidogyne incognita en el cultivo de melón. 
CONSEJO NACIONA

\section{PATÓGENOS QUE AFECTAN A ESPECIES SILVESTRES}

\section{DE Arachis EN PARAGUAY}

Resquín-Romero, G.*; Macchi-Leite, G.1,3*; Sarubbi-Orué, H.1, García-López, T.2; Moral, J.2. Seijo, J. G. ${ }^{3}$

${ }^{1}$ Facultad de Ciencias Agrarias, Universidad Nacional de Asunción (FCA, UNA), San Lorenzo, Paraguay 2Universidad de Córdoba, España

${ }^{3}$ Instituto de Botánica del Nordeste (UNNE-CONICET) y Facultad de Ciencias Exactas y Naturales y Agrimensura, Universidad Nacional del Nordeste, Corrientes, Argentina.

Paraguay presenta una gran diversidad de especies silvestres de Arachis, las que constituyen fuentes valiosas de genes para ampliar la base genética del maní cultivado. Entre los caracteres más destacados se encuentran elevados niveles de resistencia/tolerancia a patógenos. El objetivo del presente trabajo fue realizar una prospección de los patógenos que afectan a especies silvestres de maní conservadas ex situ en la Colección Nacional de Arachis de Paraguay, (FCA, UNA) La colección de germoplasma y el análisis fenotípico de las enfermedades se realizó en el marco de la Tesis doctoral de Guillermina Machi en la UNNE, Argentina. Se tomaron muestras de tallos, hojas e inflorescencias con síntomas de enfermedad de plantas cultivadas en invernáculo y procesadas en el Laboratorio de Protección Vegetal, durante los años 2020-2021. Para inducir el crecimiento fúngico, se utilizó el método de cámara húmeda, previa desinfestación de las muestras. Para el aislamiento se utilizarón medios PDA selectivo y Agar Agua (2\%). Se realizó la identificación morfológica y molecular de los aislados por amplificación (PCR) de las regiones génicas ITS, $\beta$-tubulina (BTUB), Calmodulina (CMD) y/o Factor de elongación (EF). La identificación molecular se realizó por comparación (Blast) de los amplicones con la base de datos del NCBI. En total se realizaron 121 aislamientos, 98 de hongos y 23 pseudohongos de 115 accesiones de Arachis. Los aislamientos se identificaron como pertenecientes a 22 géneros distintos [Alternaria, Athelia, Cercospora, Cercosporidium, Cladosporium, Colletotrichum, Curvularia, Fusarium, Glomerella, Golovinomyces (Erysiphe), Leptosphaerulina, Macrophomina, Mycosphaerella, Muyocopron, Penicillium, Phoma, Phyllosticta, Phytophthora, Pythium, Rhizoctonia, Sclerotium, Tremateia]. Diez aislamientos se identificaron a nivel de especies y sus respectivas accesiones en GeneBank. A continuación, se citan las especies, Fusarium equiseti (MN636869.1), Fusarium solani (MN186664.1), Fusarium sp. (MW493181.1),
Athelia rolfsii, Sclerotinia sp., Tremateia sp. (MN481606.1), causantes de marchitez y pudrición en tallos y raíces; dos cepas de Colletotrichum siamense (MT450691.1 y MK693705.1) y Alternaria porri (MT554514.1), que ocasionaron manchas foliares y el hongo Muyocopron laterale (MT012103.1). En conclusión, se reveló por vez primera diez diferentes especies de hongos asociadas a plantas silvestres de Arachis y una gran diversidad de patógenos presentes en diferentes genotipos del germoplasma de especies silvestres de Arachis, información relevante para la evaluación del germoplasma secundario del maní en Paraguay. También, las pruebas de patogenicidad permitirán identificar el carácter patogénico de las especies identificadas. 


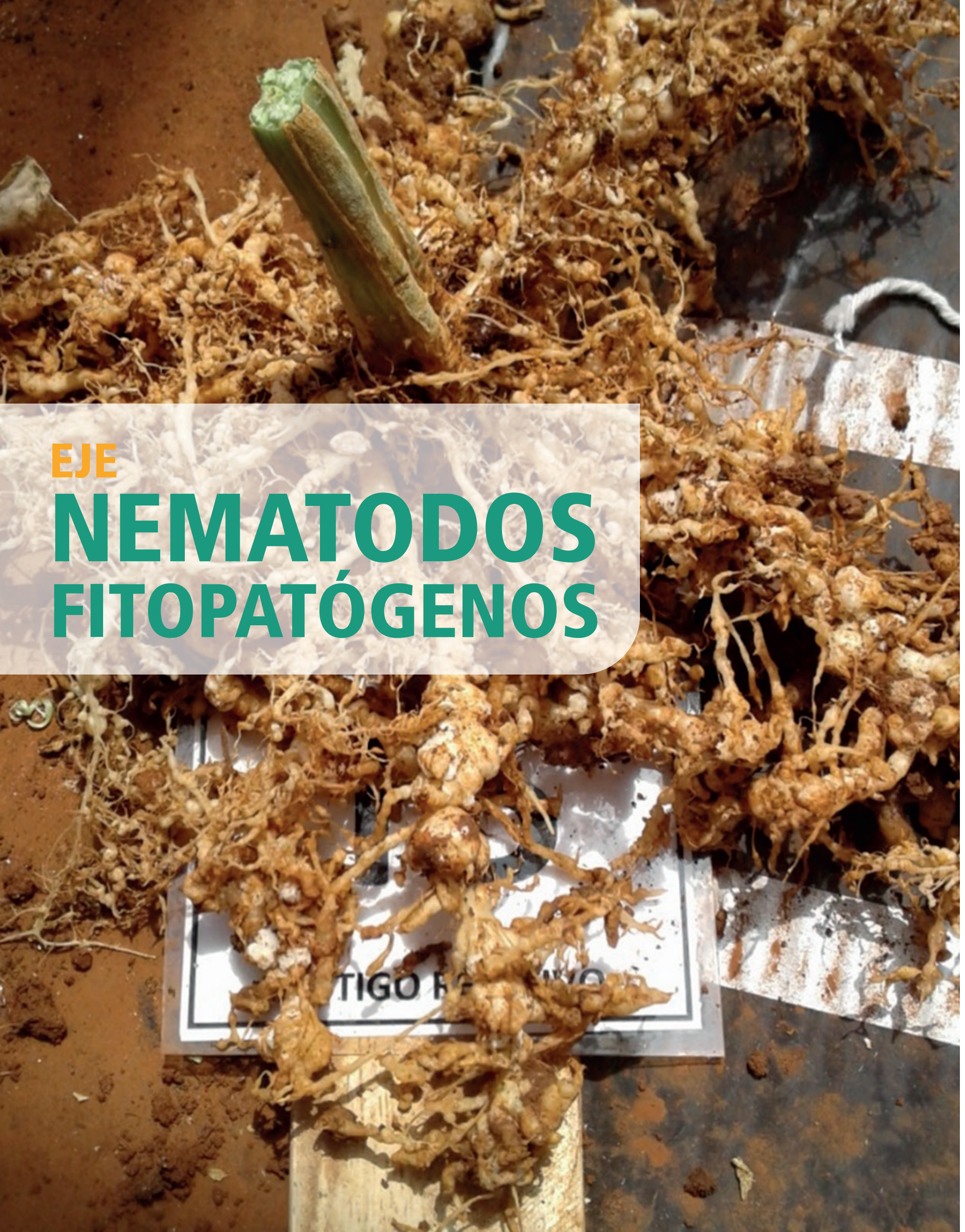

\begin{tabular}{|c|c|c|c|}
\hline 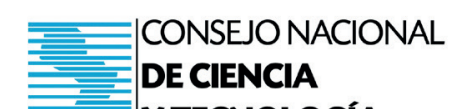 & PRPIENCIA & San Carlos & Feei \\
\hline
\end{tabular}

\section{INCIDENCIA DE NEMATODOS EN DIFERENTES SISTEMAS DE CULTIVOS PROTEGIDOS DE SANDÍA (Citrullus lanatus [Thunb.] Matsum. \& NAKAI)}

Barrios Fleitas, R. M.'; Armadans Rojas, A. J.1; Lopez-Nicora, H. D. ${ }^{2,3}$

'Universidad San Carlos, Departamento de Producción Agrícola, Asunción, Paraguay; ${ }^{2}$ Universidad San Carlos, La Clínica Vegetal de la Universidad San Carlos, Aschiôn, Aaraguay; 'Departament of Plant Pathology, The Ohio sity, Columbus, OH USA.

Uno de los problemas en la producción de sandía es el ataque de plagas, entre ellos, la presencia de nematodos, los cuales son de difícil diagnóstico e identificación. La investigación a campo se realizó en la ciudad de Caacupé y en la zona de Atyrá, a 53 km de la capital, en el departamento de Cordillera, cuyas coordenadas georreferenciadas son $25^{\circ} 16^{\prime} 43^{\prime \prime} S$ y $57^{\circ} 10^{\prime} 14^{\prime \prime} \mathrm{O}$. El objetivo general del trabajo fue identificar los géneros de nematodos en el cultivo de sandía en diferentes sistemas protegidos. El objetivo específico fue cuantificar los nematodos a nivel de género presentes en cada sistema. El diseño utilizado fue descriptivo. Se identificaron los nematodos en tres sistemas protegidos de producción en el cultivo de sandía. Se trabajó con tres sistemas de producción, T1 macrotúnel cubierto con film plástico, T2 macrotúnel cubierto con media sombra negro $50 \%$ y el T3 al aire libre. Se utilizaron tres sistemas con un área de $48 \mathrm{~m}^{2}$ cada una. Los microtúneles con un tamaño de $10 \mathrm{~m}$ de largo, 4,8 $\mathrm{m}$ de ancho y 2,60 m de altura, compuestos por tres hileras con 10 plantas/hilera; es decir, 30 plantas. Para la obtención de los datos se retiran muestras de $500 \mathrm{gr}$ aproximadamente de cada tratamiento. Para cada muestra se realizó la mezcla de 10 submuestras en forma de zigzag dentro de los $48 \mathrm{~m}^{2}$ en cada sistema utilizado para el trabajo. La evaluación se realizó en el mes de noviembre. Como conclusión, en las muestras de suelo, en los tres sistemas se identificaron un gran número de géneros de nematodos, siendo el de mayor presencia el género Scutellonema con 46 nematodos $/ 100 \mathrm{~cm}^{3}$ de suelo. El género Helicotylenchus fue observado en mayor cantidad en los macrotúneles de media sombra y lámina con 40 y 60 nematodos $/ 100 \mathrm{~cm}^{3}$ de suelo, respectivamente, pero no así en el testigo. También se observó la presencia de varios géneros de nematodos denominados de vida libre. En el estudio de raíz, se identificaron mayor cantidad de nematodos en el macrotúnel con media sombra, entre ellos, los más importantes fueron el nematodo de la agalla (Meloidogyne) con 26 nematodos/15,5 g de raíz y Helicotylenchus con 72 nematodos $/ 15,5 \mathrm{~g}$ de raíz. 
CONSEJONACIONAL

USO DE EXTRACTOS NATURALES PARA EL CONTROL DE Meloidogyne incognita EN EL CULTIVO DE LA OKRA (Hibiscus esculentus L.)

Díaz, N.J.F1; Ayvar, S.S.'; Reyna, R.R..; Apáez, B.M.'; Mena, B.A.

'Colegio Superior Agropecuario del Estado de Guerrero (CEP-Csaegro), Cocula, Gro, México; ${ }^{2}$ Universidad Michoacana San Nicolás de Hidalgo. Michoacán, México.

La okra es una hortaliza comestible. Es originaria de África y se distribuye en regiones tropicales y subtropicales, aunque también está presente en altas latitudes de zonas templadas. Esta hortaliza es afectada por Meloidogyne incognita, por lo que el objetivo principal de este trabajo fue comprobar el control ejercido sobre Meloidogyne incognita por extractos comerciales en plantas de okra. El estudio se realizó en el bioespacio del área de fitopatología del Centro de Estudios Profesionales del Colegio Superior Agropecuario del Estado de Guerrero, México. Se utilizó un diseño experimental completamente al azar en el cual se evaluaron 4 tratamientos $(\mathrm{T} 1=$ extracto de ajo, T2 $=$ aceite de soja, T3 $=$ extracto de Quillaja sp. y T4 = testigo) con 4 repeticiones. Se utilizaron como unidad experimental bolsas de polietileno expandido las cuales contenían $5,2 \mathrm{~kg}$ de sustrato compuesto por 60 $\%$ de lama y $40 \%$ de estiércol precomposteado. Las variables de estudio fueron la biomasa fresca y seca, numero de larvas y huevecillos posteriormente a los datos de las variables respuesta fueron sometidos a un análisis de varianza y se realizó la prueba de comparación múltiple de medias utilizando el método de Tukey $(\alpha=0,05)$ con el software SAS ${ }^{\circledR}$. Se determinó que el T2 manifestó diferencias altamente significativas en comparación con el testigo, ya que se registró aumento en las variables respuesta y se observó inhibición de la incidencia de huevecillos por las hembras, por otro lado, el T3 tuvo un efecto similar al testigo, en donde se observó un incremento en la acumulación de biomasa, ni sobre la disminución de la incidencia de Meloidogyne incognita.
CONSEJO NACIONAL

\section{EFECTO DEL NEMATODO AGALLADOR (Meloidogyne spp.) SOBRE VARIEDADES DE SOJA CULTIVADAS EN EL DEPARTAMENTO \\ SAN PEDRO, PARAGUAY}

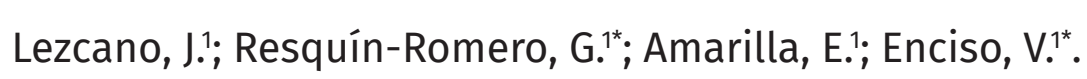

${ }^{1}$ Facultad de Ciencias Agrarias, Universidad Nacional de Asunción, San Lorenzo, Paraguay.

El género Meloidogyne causa pérdidas económicas significativas en la mayoría de las especies cultivadas y la soja no está exenta. Este tipo de nematodos predominan en suelos arenosos bajo las condiciones de temperatura $\left(23\right.$ a $\left.35^{\circ} \mathrm{C}\right)$ que prevalecen en la mayoría de las áreas de cultivos de soja en la zona norte del país. La eliminación del bromuro de metilo y las fuertes restricciones en el uso de otros fumigantes nematicidas plantean la necesidad urgente de detectar variedades de soja resistentes a tolerantes a los nematodos, en particular a las especies sedentarias. El objetivo propuesto fue evaluar el efecto y la incidencia del género de Meloidogyne en soja, cultivadas en el departamento de San Pedro. Ocho variedades de soja fueron cultivadas a campo abierto $(2019 / 2020)$ en un diseño experimental en bloques completos al azar. Las muestras de raíces fueron procesadas en el Laboratorio de Protección Vegetal de la Facultad de Ciencias Agrarias. Se seleccionaron al azar a hembras, para la identificación a nivel de especie según las características del patrón perineal. Se registraron longitud y peso de las raíces de cada variedad, previa desinfestación con $\mathrm{NaOCl}(1 \%)$ y eliminación de tierra adherida a las raíces. Se evaluó la incidencia de los síntomas en las raíces utilizando una escala propuesta por Gutiérrez-Gutiérrez et al. (2011). También se evaluó la severidad del daño de la raíz utilizando una escala de 0 a 3 , donde $0=$ sistema de raíces sano; $1=$ pocas raíces localizadas con agallas; $2=$ hinchazones agrandadas de las raíces muy evidentes en todo el sistema radicular, y $3=$ segmentos de raíces muy agrandados, poca o ninguna formación de raíces laterales, ataques muy intensos en todo el sistema radicular. Las poblaciones de raíces de nematodos se determinaron mediante maceración-centrifugación seguido de flotación centrífuga y se contó con un microscopio estereoscópico. Se identificaron poblaciones mixtas de Meloidogyne incognita y Meloidogyne sp., particularmente. Se detectaron raíces infectadas con los 


\section{CONTROL BIOLÓGICO DE Meloidogyne sp. EN EL CULTIVO DE GLADIOLO (Gladiolus grandiflorus Hort.)}

Díaz, N. J. F. ${ }^{1}$, Ayvar, S. S. ${ }^{*}$, Delgado, N. E. ${ }^{3}$, Gómez, S. J. ${ }^{1}$, Mena, B. A. ${ }^{1}$

'Colegio Superior Agropecuario del Estado de Guerrero, Avenida Vicente Guerrero Núm. 81. Iguala, Guerrero, C.P. 40000. 2Universidad Autónoma, Facultad de Ciencias Agropecuarias y Ambientales, Iguala, Guerrero, México.

El gladiolo es mundialmente apreciado como flor de corte, por los llamativos colores y la belleza de la espiga floral, por lo que México ocupa el tercer lugar en importancia. Por esta razón el objetivo del presente estudio fue evaluar el efecto de agentes de biocontrol sobre Meloidogyne sp. en plantas de gladiolo. Se utilizó un diseño experimental completamente al azar con 6 tratamientos, los cuales fueron los siguientes: T1 $=$ Meloidogyne, T2 $=$ Meloidogyne + Paecilomyces variotii, T3 = Meloidogyne + Trichoderma spp., T4 $=$ Paecilomyces variotii, $\mathrm{T} 5=$ Trichoderma spp. y T6 $=$ Testigo, todos con 4 repeticiones. La unidad experimental constó de una bolsa de polietileno, con sustrato franco arcilloso, el cual se desinfectó al igual que el material vegetal. Se implementó la siembra de los cormos del genotipo Espuma, aplicando riegos ligeros durante el ciclo del experimento. A los 17 días después se aplicaron los tratamientos biológicos a dosis de $1.9 \mathrm{ml}$ y $2 \mathrm{~g}$ por litro, y a los 32 días después se realizó la aplicación a las plantas que serían inoculadas con el nematodo. Se excavó alrededor, se le agregaron 3000 huevecillos, de tal manera que se realizaron dos nuevas aplicaciones de los bionematicidas a los 7 y 21 días después de la primera aplicación. Las variables de estudio fueron número de larvas J2 y huevecillos en raíz. Los datos de las variables de estudio fueron sometidos a un análisis de varianza y a una prueba de comparación múltiple de medias. Los resultados indicaron que existieron variaciones significativas en el número de larvas J2 y huevecillos en raíz. Todos los agentes de biocontrol lograron suprimir la incidencia de larvas y huevecillos. Las plantas inoculadas únicamente con el nematodo registraron incidencia de larvas y huevecillos del patógeno. En conclusión, los agentes biológicos inhiben la población de nematodos en la raíz de gladiolo. 
CONSEJONACIONAL

EFECTO Trichoderma EN EL CULTIVO DE LA OKRA

(Abelmoschus esculentus (L.) Moench)

\section{INOCULADO CON Meloidogyne incognita}

Apáez, B. M ${ }^{1 *}$. Ayvar, S. S ${ }^{2}$. Díaz, N. J. F ². Mena, B. A ². Ensastegue, G. I. A 2 .

${ }^{1}$ Facultad de Ciencias Agropecuarias-Universidad Michoacana San Nicolás de Hidalgo. Prolongación de Mariano ior Agropecuario del Estado de Guerrero. Av. Guerrero 81 Primer piso. Col. Centro. CP. 40000. Iguala, Guerrero. México.

La okra (Abelmoschus esculentus (L.) Moench) es un cultivo que se consume muy a menudo en las zonas donde se produce. Es rica en vitaminas y minerales que la hacen ser un cultivo muy importante. Sin embargo, muchas veces puede ser atacada por diversos patógenos como los nematodos. El presente estudio se llevó acabo con la finalidad de conocer el efecto de Trichoderma en el cultivo de la okra (Abelmoschus esculentus (L.) Moench) inoculado con Meloidogyne incognita. La investigación se llevó acabo en el campo experimental y en el laboratorio de fitopatología del Csaegro, institución ubicada en Cocula, Guerrero, México. Para la siembra se utilizó tierra lama y materia orgánica. Luego de que emergieran las plantas se inoculo el nematodo a cada una de ellas. Se evaluaron los siguientes tratamientos: T. virens, T. bactiva, T. fithan y un testigo. Se utilizó un diseño de bloques al azar con cuatro repeticiones. Los datos se analizaron estadísticamente con el paquete SAS. De acuerdo con los resultados obtenidos, la infección del nematodo y la aplicación de los tratamientos con Trichoderma provocaron diferencias significativas en todas las variables evaluadas. Así, para la variable altura de la planta esta disminuyó en un 45 $\%$ en el tratamiento testigo; es decir, sin aplicación de Trichoderma en relación con el tratamiento de T. bactiva. Por otra parte, el diámetro del tallo se disminuyó en $23 \%$ cuando no se aplica ningún control (testigo) en relación con el tratamiento de T. bactiva. Además, la biomasa total se modificó en $40 \%$ y la longitud de raíz también se vio afectada por la falta de control con una disminución del $55 \%$. El peso de la raíz fue afectado en un $55 \%$ y finalmente el número de huevecillos fue mayor en el tratamiento testigo donde se encontró un $30 \%$ más que en el tratamiento con la aplicación de T. bactiva. El producto T. bactiva y T. fithan es un buen controlador contra el nematodo $M$. incognita.

\begin{tabular}{|c|c|c|c|}
\hline $\begin{array}{l}\text { CONSEJO NACIONAL } \\
\text { DE CIENCIA }\end{array}$ & PR\&CIENCIA & (5) Sanersidad Carlos & Fee; \\
\hline
\end{tabular}

\section{EFECTO DE LA INTERACCIÓN NEMATODO-HONGO \\ EN EL DESARROLLO DE JITOMATE}

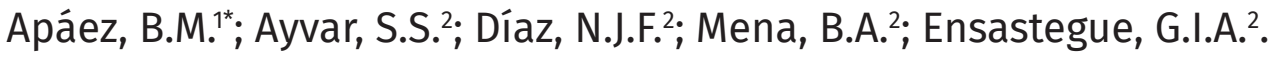

'Facultad de Ciencias Agropecuarias, Universidad Michoacana San Nicolás de Hidalgo, Prolongación de Mariano Jiménez s/n, Colonia el Varillero, CP 60660, Apatzingán, Michoacán, México; ${ }^{2}$ Colegio Superior Agropecuario del Estado de Guerrero, Av. Guerrero 81 primer piso, Col. Centro. CP. 40000. Iguala, Guerrero, México.

El jitomate (Lycopersicum esculentum L.) es afectado por varios patógenos, entre ellos nematodos y hongos. El objetivo fue evaluar el efecto de Meloidogyne sp., Macrophomina phaseolina y Rhiroctonia solani así como la interacción de estos sobre el desarrollo de la planta de jitomate. El material genético utilizado fue río grande bajo condiciones de maya sombra en el Csaegro, institución ubicada en Cocula, Guerrero, México. El sustrato utilizado fue tierra lama y materia orgánica a relación 2:1. La siembra se realizó de forma directa en maceta. Los tratamientos fueron Testigo (T), Meloidogyne (M), Macrophomina phaseolina (Mp), Rhizoctonia solani (Rs), $\mathrm{Mp}+$ Meloidogyne, $\mathrm{Rs}+$ Meloidogyne, $\mathrm{Mp}+\mathrm{Rs}$ y Mp $+\mathrm{Rs}+\mathrm{M}$. Se utilizó un diseño de bloques al azar con cuatro repeticiones. El inóculo del nematodo se obtuvo de una raíz de jitomate, procedente del estado de México. Los hongos fueron proporcionados por el laboratorio de fitopatología de la misma institución. Las variables evaluadas fueron: altura de la planta, diámetro del tallo, número de ramas, número de frutos, peso de frutos, peso de la raíz y biomasa aérea. Los resultados indican que para las variables altura de la planta, diámetro del tallo, número de ramas, número de frutos y peso de frutos se modificó por efecto de tratamientos, mientras que el peso de la raíz y biomasa aérea no se modificaron. Así la altura se disminuyó en un $59 \%$ en el tratamiento $\mathrm{Mp}+\mathrm{Rs}+\mathrm{M}$ que corresponde a la interacción completa en relación con el tratamiento testigo, el diámetro se redujo en $37 \%$, el número de ramas en un $44 \%$, el número de frutos en $20 \%$ y el peso de estos $15 \%$. Los daños causados por la interacción nematodo-hongo son más severos que el ataque por sí solos. 
CONSEJONACIONAL

DE CIENCIA

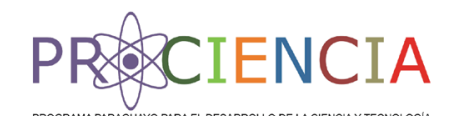

San Carlos

CONTROL BIOLÓGICO DE POBLACIONES DE Meloidogyne sp. EN EL CRECIMIENTO DEL CULTIVO DE JAMAICA (Hibiscus sabdariffa L.)

Apáez, B. M ${ }^{1^{*}}$. Ayvar, S. S ${ }^{2}$. Díaz, N. J. F ${ }^{2}$. Mena, B. A ${ }^{2}$. Sánchez, F. F. J ${ }^{2}$.

${ }^{1}$ Facultad de Ciencias Agropecuarias-Universidad Michoacana San Nicolás de Hidalgo. Prolongación de Mariano Jiménez s/n. Colonia el Varillero. CP 60660. Apatzingán, Michoacán. México. Correo: maricela.apaez@umich.mx. ${ }^{2}$ Colegio Superior Agropecuario del Estado de Guerrero. Av. Guerrero 81 Primer piso. Col. Centro. CP. 40000. Iguala, Guerrero. México.

La Jamaica es un cultivo muy importante en el estado de Guerrero. Sin embargo, es afectado por patógenos y, para el control de estos, es importante usar productos biológicos que no afecten al medio. El objetivo de la investigación fue evaluar el efecto de productos biorracionales en el control de Meloidogyne sp., así como sobre el crecimiento de Jamaica. La investigación se realizó en el Csaegro, ubicado en Cocula, Guerrero, México. Se utilizó Jamaica variedad Tecoanapa. Se colectaron muestras de raíces agalladas de pepino. La siembra se realizó en bolsa para vivero con sustrato estéril. Posteriormente se inocularon 11250 huevecillos por maceta, aplicándolos en la base de la planta. Los tratamientos utilizados fueron: 1. NemaRoot, 2. Spectrum ${ }^{\circledR}$ pae L, 3. Biobacil ${ }^{\circledR}, 4$. NemaRoot + Spectrum $^{\circledR}$ pae

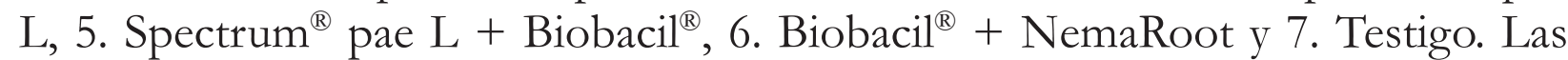
variables evaluadas fueron: altura de la planta, diámetro del tallo, número de hojas, longitud de la raíz, peso seco de a raíz y biomasa total. Se utilizó un diseño de bloques al azar con cuatro repeticiones. Los datos se analizaron estadísticamente con SAS 9.1. De acuerdo con los resultados, la altura de la planta y el diámetro del tallo no mostraron diferencias significativas por efecto de tratamientos, por lo que la altura media fue de $45 \mathrm{~cm}$ y el diámetro de $0,63 \mathrm{~cm}$. Sin embargo, el resto de las variables evaluadas sí se modificaron por efecto de los tratamientos aplicados. Así, el número de hojas se incrementó en un $92 \%$ con la aplicación de Spectrum ${ }^{\circledR}$ pae L en relación con el tratamiento testigo. En cuanto a la longitud de la raíz, esta se redujo en un $68 \%$ en relación con el tratamiento con aplicación de Spectrum ${ }^{\circledR}$ pae L. En cuanto peso seco de a raíz, el tratamiento testigo lo disminuyó en 50 $\%$, mientras que la biomasa disminuyó en un $55 \%$ en relación con el tratamiento con mayor control. La aplicación de tratamientos biológicos disminuye el efecto de Meloidogyne sp. y su efecto sobre la morfología de la planta.
CONSEJONACIONAL

\section{CONTROL BIOLÓGICO CON Bacillus subtilis Y Streptomyces DE Meloidogyne incognita EN RÁBANO (Raphanus sativus)}

Díaz, N. J. F ${ }^{1^{*}}$. Apáez, B. M $^{2}$. Ayvar, S. S ${ }^{1}$. Mena, B. A ${ }^{1}$. Vergara, C. $S^{1}$ ${ }^{1}$ Facultad de Ciencias Agropecuarias-Universidad Michoacana San Nicolás de Hidalgo. Prolongación de Mariano Jiménez s/n. Colonia el Varillero. CP 60660. Apatzingán, Michoacán. México. Correo:

maricela.apaez@umich.mx. 2Colegio Superior Agropecuario del Estado de Guerrero.
Av. Guerrero 81 Primer piso. Col. Centro. CP. 40000. Iguala, Guerrero. México.

Las hortalizas ocupan un lugar importante dentro de la alimentación diaria de la población. Entre ellas se encuentra el rábano, el cual puede presentar diversos problemas fitosanitarios. La investigación se llevó a cabo con el objetivo de evaluar la acción Bacillus subtilis y Streptomyces en el control de Meloidogyne incognita en el cultivo del rábano. El estudio se realizó en el Csaegro, institución ubicada en Cocula, Guerrero, México. La siembra del rábano se llevó a cabo de forma directa y posterior a eso se inoculó el nematodo. Los tratamientos utilizados fueron: testigo (sin aplicación), Meloigogyne, Bacillus subtilis, Streptomyces, Meloidogyne + Bacillus subtilis, Meloidogyne + Streptomyces y Meloidogyne + Bacillus subtilis + Streptomyces. Las variables evaluadas fueron número de hojas, biomasa aérea, longitud de bulbo, diámetro del bulbo, longitud de raíz y número de huevecillos. Se utilizó un diseño de bloques al azar con cuatro repeticiones. Los datos se analizaron estadísticamente con el paquete SAS. Los resultados indican que las variables evaluadas se modificaron por efecto de tratamientos. Así, el número de hojas menor se presentó en el tratamiento donde se inoculó el nematodo, pero no se aplicó ningún producto para el control. Esta disminución fue del $75 \%$ en relación con el tratamiento con mejor control (Bacillus subtilis + Streptomyces), en relación con la biomasa aérea la aplicación de Bacillus subtilis + Streptomyces incrementó en $48 \%$ en relación con el tratamiento donde no se aplicó control. Respecto a la longitud de bulbo, disminuyó en $70 \%$ en relación con el tratamiento que presentó mayor control del nematodo (Bacillus subtilis + Streptomyces). Para el caso del diámetro del bulbo el tratamiento testigo presentó valores menores con disminución del $67 \%$, mientras que el peso del bulbo disminuyó en $62 \%$, la longitud de raíz en 61 \% y el número de huevecillos más alto se presentó en el tratamiento con inoculación del nematodo sin aplicación de control. Bacillus subtilis + Streptomyces disminuyó el número de huevecillos del nematodo. El tratamiento con la combinación de Bacillus subtilis y Streptomyces es una buena alternativa de control de Meloidogyne incognita en el cultivo del rábano. 


\section{NEMATODOS FITOPARÁSITOS ASOCIADOS A SOLANÁCEAS CULTIVADAS}

\section{EN EL DEPARTAMENTO DE CORDILLERA, PARAGUAY}

Caballero-Mairesse, G. G. ${ }^{*}$; Enciso-Maldonado, G. A.; Valiente-Raidán, H. N.2; Pedrozo-Fleitas, L. M. ${ }^{2}$ y Lopez-Nicora, H. D. ${ }^{1,3}$

'La Clínica Vegetal, Universidad San Carlos (USC), Asunción, Paraguay; '2entro de Investigación Hernando Bertoni (CIHB), Instituto Paraguayo de Tecnologia Agraria (IPTA), Caacupé, Paraguay, 3 The Ohio State University, Columbus, OH USA.

El tomate y el pimiento se destacan en el Paraguay en términos productivos y de consumo. Un potencial peligro para su desarrollo son los nematodos fitoparásitos, que pueden ocasionar graves pérdidas. Conocer la abundancia y la diversidad de nematodos fitoparásitos de estas producciones contribuirá a mejorar la toma de medidas ante su ataque. Para identificar nematodos fitoparásitos asociados a solanáceas cultivadas (tomate, tomate cherry y pimiento), 18 muestras de suelo provenientes de diferentes localidades del departamento de Cordillera, Paraguay, fueron analizadas en La Clínica Vegetal de la Universidad San Carlos. Estas muestras compuestas se colectaron extrayéndolas a $30 \mathrm{~cm}$ de profundidad, en zigzag, de forma equidistante y aleatoria. Cada muestra estuvo compuesta de 15 a 20 submuestras. Se realizó la extracción de nematodos a partir de $100 \mathrm{~cm}^{3} \mathrm{de}$ suelo, mediante la metodología adaptada de flotación-centrifugación con solución azucarada. Los nematodos se identificaron y cuantificaron bajo microscopio invertido a una magnificación de $40 \times$. Se determinó la abundancia y frecuencia de los nematodos fitoparásitos. Se identificaron 10 géneros de fitonematodos: Criconemella, Helicotylenchus, Hoplolaimus, Meloidogyne, Pratylenchus, Rotylenchulus, Scutellonema, Trichodorus, Tylenchorbynchus, Xiphinema y nematodos del grupo Tylenchidos, como también aquellos de vida libre como bacteriófagos, fungíferos y predadores. En $100 \mathrm{~cm}^{3}$ de suelo, las mayores abundancias de fitonematodos superaron los 100 individuos, registrando cantidades de 110 a 784 especímenes. Por otra parte, la mayor frecuencia correspondió a Tylenchorbynchus con $89 \%$, seguido de Helicotylenchus, Meloidogyne, Criconemella, Tylenchidos, Rotylenchulus, Hoplolaimus y Pratylenchus con 78, 72, 61, 56, 28, 22 y $17 \%$, respectivamente. Los menores valores fueron de 6 a $11 \%$ para los fitonematodos restantes. Gran parte de los nematodos identificados, como Meloidogyne, Pratylenchus y Rotylenchulus, presentan respaldo científico sobre su capacidad de ocasionar daños en cultivos. Adicionalmente, nuestros resultados resaltan la elevada frecuencia de Tylenchorbynchus, por lo que resulta importante seguir realizando monitoreos a fin de determinar su impacto. 
Quinto webinar: https://youtu.be/hNMU3I0a9Cc

Webinar 5 - internacional: 29/mayo/2021

Los temas y disertantes del quinto webinar fueron:

- "Problemas de nematodos en banana, plátano y café", a cargo del Ing. Agr. Óscar Guzmán Piedrahita, Ph.D., Universidad de Caldas, Colombia.

- "Uso y manejo de defensivos agrícolas", a cargo del Ing. Agr. Miguel Colmán Cámara de Fitosanitarios y Fertilizantes (CAFYF)

Sexto webinar: https://youtu.be/tpoggKzsIsI

Webinar 6: 05/junio/2021

Los temas y disertantes del sexto webinar fueron:

- "Control biológico de nematodos en cultivos extensivos", a cargo del Ing. Agr. Adans Colmán, Ph.D., Universidad Nacional de Asunción (UNA).

- "Control de nematodos en Paraguay", a cargo del Ing. Agr. Vicente Mangano, USC.

\section{Séptimo webinar: https://youtu.be/dumItQyohAw}

Webinar 7: $17 /$ junio/2021

Los temas y disertantes del séptimo webinar fueron:

- "Nematodos asociados en cultivos extensivos", a cargo del Ing. Agr. Fabio

Centurión, Agremiación de Ingenieros Agrónomos de Campo 9 (AIAC 9).

- "Pulverizaciones eficientes", a cargo del Ing. Agr. Ricardo Chamorro, Agremiación de Ingenieros Agrónomos de Campo 9 (AIAC 9).
Octavo webinar: https://youtu.be/gL8y3ZzVVEE

Webinar 8: 26/junio/2021

Los temas y disertantes del octavo webinar fueron:

- "Avances del proyecto PIRT19-2‘Distribución y abundancia de nematodos fitoparásitos de importancia socioeconómica en las principales zonas de producción agrícola del Paraguay"', a cargo del Ing. Agr. Horacio Lopez-Nicora, Ph.D., Universidad San Carlos, Asuncion PY; The Ohio State University, Columbus, OH USA.

- "Importancia del manejo de los suelos para una producción sana de los cultivos", a cargo del Ing. Agr. M.Sc. Martín Cubilla, consultora Nuestro Suelo S. A.

\section{Taller de QGIS}

http://eventos.usc.edu.py/2021/07/08/taller-de-creacion-de-mapas-con-qgis/

- Módulo 1 17/junio/2021: "Vectorización de datos y geo procesos".

- Módulo 2 31/junio/2021: “Análisis espacial y diseño de mapas”.

A cargo de la Ing. Agr. Laura Torres Domínguez, de la consultora Campo Inteligente. 
"La publicación se realizó en el marco del proyecto PIRT19-2 cofinanciado por el Consejo Nacional de Ciencia y Tecnología (CONACYT) con recursos del FEEI"

\section{APOYAN:}

-

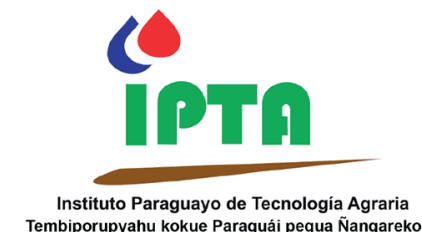

Tembiporupyahu kokue Paraguái pegua Ñangarekoha

-

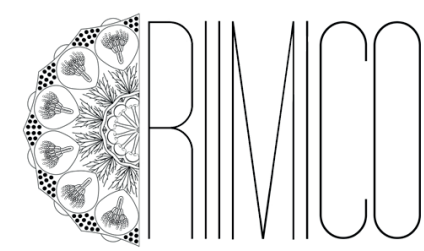

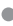

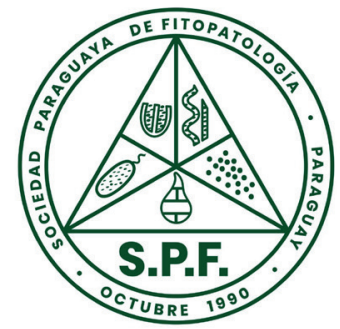

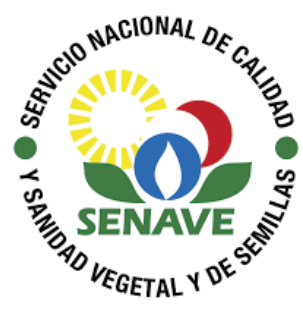

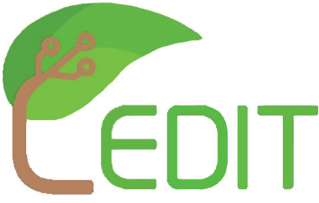

Centro de Desarrollo e Innovación Tecnológica
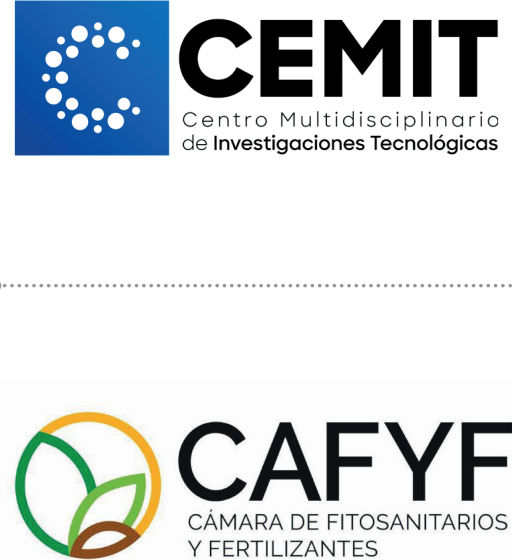

CAFYF

CÁMARA DE FITOSANITARIOS Y FERTILIZANTES

$(((\cdot)))$

NUESTROSSUELO : CAMPOINTELIGENTE

CONSEJONACIONAL DE CIENCIA $\overline{\overline{\text { CONACYT }}}$ Y TECNOLOGÍA
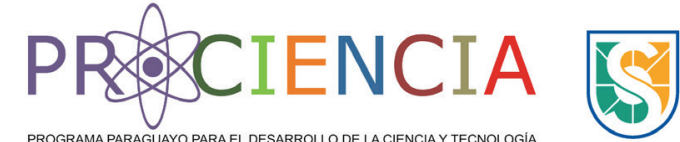

Universidad San Carlos 